\title{
RECONSTRUCTING THE EMPOWERMENT PROCESS: PERSPECTIVES OF BANGLADESHI IMMIGRANT MARRIED WOMEN IN TORONTO, CANADA, IN RELATION TO THEIR LABOUR MARKET INTEGRATION PROCESS
}

By

MARSHIA AKBAR

A thesis submitted to the Faculty of Graduate Studies and Research in partial fulfillment of the requirements for the degree of Master of Arts

Department of Geography and Environmental Studies Carleton University

Ottawa, Ontario

(C) Copyright

September 2009, Marshia Akbar 


$\begin{array}{ll}\begin{array}{l}\text { Library and Archives } \\ \text { Canada }\end{array} & \begin{array}{l}\text { Bibliothèque et } \\ \text { Archives Canada }\end{array} \\ \begin{array}{l}\text { Published Heritage } \\ \text { Branch }\end{array} & \begin{array}{l}\text { Direction du } \\ \text { Patrimoine de l'édition }\end{array} \\ \begin{array}{l}395 \text { Wellington Street } \\ \text { Ottawa ON K1A ON4 } \\ \text { Canada }\end{array} & \begin{array}{l}\text { 395, rue Wellington } \\ \text { Ottawa ON K1A ON4 } \\ \text { Canada }\end{array}\end{array}$

Your file Votre refférence

ISBN: 978-0-494-60292-8

Our file Notre référence

ISBN: $978-0-494-60292-8$

NOTICE:

The author has granted a nonexclusive license allowing Library and Archives Canada to reproduce, publish, archive, preserve, conserve, communicate to the public by telecommunication or on the Internet, loan, distribute and sell theses worldwide, for commercial or noncommercial purposes, in microform, paper, electronic and/or any other formats.

The author retains copyright ownership and moral rights in this thesis. Neither the thesis nor substantial extracts from it may be printed or otherwise reproduced without the author's permission.
AVIS:

L'auteur a accordé une licence non exclusive permettant à la Bibliothèque et Archives Canada de reproduire, publier, archiver, sauvegarder, conserver, transmettre au public par télécommunication ou par l'Internet, prêter, distribuer et vendre des thèses partout dans le monde, à des fins commerciales ou autres, sur support microforme, papier, électronique etlou autres formats.

L'auteur conserve la propriété du droit d'auteur et des droits moraux qui protège cette thèse. $\mathrm{Ni}$ la thèse ni des extraits substantiels de celle-ci ne doivent être imprimés ou autrement reproduits sans son autorisation.
In compliance with the Canadian Privacy Act some supporting forms may have been removed from this thesis.

While these forms may be included in the document page count, their removal does not represent any loss of content from the thesis.
Conformément à la loi canadienne sur la protection de la vie privée, quelques formulaires secondaires ont été enlevés de cette thèse.

Bien que ces formulaires aient inclus dans la pagination, il n'y aura aucun contenu manquant. 


\begin{abstract}
Immigrant women, who are members of a visible minority group, are disadvantaged in the Canadian labour market. Considering the situation of visible minority women in a position of relative powerlessness, the notion of empowering them to gain access to appropriate forms of employment has been highlighted in the current literature. Drawing on theoretical perspectives of women's empowerment, this study investigates the labour market integration of Bangladeshi married women in Toronto. Insights from poststructuralist feminism and feminist qualitative methods have enabled this study to explore how Bangladeshi married women, who are family and dependent class immigrants, are trying to make a place in the Canadian labour market. The inquiries of the study are explored through three types of qualitative research methods consisting of focus group discussions with Bangladeshi married women, participant observation in a Community Based Organization (CBO), and in-depth interviews with three CBO workers. The study's findings reveal that, overall, Bangladeshi married women have difficulties accessing employment in the mainstream labour market, as well as in the selfemployment sector because of a number of socio-cultural and structural barriers including gender and racial discrimination that are prominent in the employment sector. The study also critically analyzes the notion of women's empowerment, and sheds light on how the empowerment process takes shape in the practical context through the influence of women's different positionalities, various socio-cultural factors and macro level policies. The study suggests the necessity for further examination of diversified and differential labour market integration issues of visible minority women in Canada and the process of their empowerment.
\end{abstract}




\section{Acknowledgements}

I would like to express my sincere gratitude to my thesis supervisor, Dr. Fran Klodawsky, for her guidance and encouragement throughout the period of my studies at Carleton. I would also like to express my appreciation to Dr. Louise De La Gorgendiere, member of my supervisory committee, for her advice and patience in responding my queries.

I am especially grateful to all of the women, who shared their stories and made this project possible. The moments I shared with them will be remembered forever. I am also grateful to the workers of community based organizations, who provided me valuable information that enriched my research. Particularly, I would like to give special thanks to Sultana Jahangir, Program Coordinator of South Asian Women's Rights Organization, for her warm attitude and assistance in identifying research participants.

I would like to acknowledge Natalie Pressburger, Graduate Secretary, for her help and prompt responses to all of my queries over the past two years.

I would like thank all of my friends for their compassion and encouragement that they provided me all the way of this journey.

Finally, and most importantly, I am grateful to my parents, my brothers and sisters, for their unconditional love and continued support in my life. Special thanks to Songita Akbar, my sister, whose phone calls and loving words gave me strength and motivation to reach this goal. 


\section{Table of Contents}

$\begin{array}{ll}\text { Abstract } & \text { ii }\end{array}$

Acknowledgements $\quad$ iii

Table of Contents $\quad$ iv

List of Tables $\quad$ viii

List of Maps $\quad$ ix

List of Appendices $\quad$ X

List of Acronyms $\quad$ xi

Chapter One: Introduction and Framework of the Research $\quad 1-21$

1.1 Background and Objectives of the Research 1

1.2 Situating the Research Framework 11

1.3 Chapter Outline of the Research $\quad 18$

Chapter Two: Barriers to Minority Women in the Canadian Labour $22-48$ Market: Literature Review

2.1 Introduction $\quad 22$

2.2 Status of Minority Immigrants in the Canadian Labour Market: An 23 Overview

2.3 Institutional and Socio-cultural Barriers to Minority Women 26

2.4 Policy Constraints to Minority Women in Accessing Employment 38 Opportunities

2.4.1 The Immigration Act $1978 \quad 39$

2.4.2 Canada Health and Social Transfer and Ontario Work Program 41 
2.5 Voluntary Organizations and Social Networks: A Promise for Change?

Chapter Three: Concepts of Women's Empowerment: Theoretical 49-70 Framework of the Study

3.1 Introduction

3.2 Women's Economic Empowerment: the Meanings and the Debates

3.3 Understanding the Process of Empowerment

3.3.1 Agency

3.3.2 Resources

62

3.3.3 Achievements: Overcoming Structural Barriers

3.4 Conclusions

68

Chapter Four: Methodology of the Research

4.1 Introduction

4.2 Qualitative Methodology

4.3 Reflections on the Research Process

4.3.1 Preparing the Research Framework

4.3.2 Positionality

4.3.3 Subjectivity of the Research

4.3.4 Power Relations

4.4 Focus Group Discussions 
4.7 Ethical Issues of the Research 97

4.8 Analysis of the Information 98

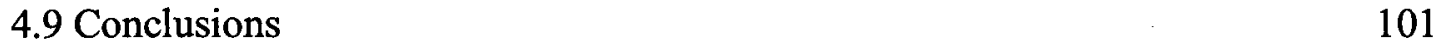

Chapter Five: Overcoming the Labour Market Challenges?: The

Takes of Bangladeshi Married Women

5.1 Introduction

103

5.2 Labour Market Constraints of Bangladeshi Married Women 104

5.2.1 Starting from Zero Again! 105

$\begin{array}{ll}\text { 5.2.3 When Language is a Panic! } & 113\end{array}$

$\begin{array}{ll}\text { 5.2.3 Are We Educated Slaves? } & 116\end{array}$

$\begin{array}{ll}\text { 5.2.4 The Impact of Cultural Norms } & 119\end{array}$

5.2.5 The Impact of Triple Day Burden 123

5.2.6 Home-based Work: An Alternative Solution for Survival 125

$\begin{array}{ll}\text { 5.2.7 The Context of Support and Disagreements } & 127\end{array}$

5.3 Agency of Bangladeshi Married Women $\quad 130$

5.4 Accessing Organizations' Support and Gaining Achievements 135

5.4.1 The Controversies of Seeking and Getting Organizations' Support 138

5.4.2 The Constructs of Women's Empowerment 142

5.4.3 Constraints and Challenges of the CBOs 146

5.5 Conclusions: A Critical Insight $\quad 151$ 
6.1 Introduction $\quad 155$

6.2 A Synopsis of the Study 156

6.3 Limitations of the Study $\quad 166$

$\begin{array}{ll}\text { 6. } 4 \text { Conclusions } & 167\end{array}$

$\begin{array}{lr}\text { Appendix } & 169-177\end{array}$

$\begin{array}{lr}\text { References } & 178-188\end{array}$ 


\section{List of Tables}

Table 4.1: Template of Focus Group Discussions 92

Table 4.2: Themes and Topics of Data Analysis $\quad 100$

Table 5.1: A Brief Introduction of SAFSS, BCS and SAWRO 137 


\section{List of Maps}

$\begin{array}{ll}\text { Map 4.1: City of Toronto } & 78\end{array}$

Map 4.2: Study Area: Danforth and Victoria Park Area 78 


\section{List of Appendices}

Appendix 1: Letter of Information and Consent Form (for the participants of focus group discussions)

Appendix 2: Letter of Information and Consent Form (for the participants of interviews)

Appendix 3: Questionnaire for Face-to-Face Interviews with the Workers

175 of Community Based Organizations 


\section{List of Acronyms}

\begin{tabular}{|c|c|}
\hline BCS & Bangladeshi-Canadian Community Services \\
\hline CAP & Canada Assistance Plan \\
\hline $\mathrm{CBO}$ & Community Based Organization \\
\hline CHST & Canada Health and Social Transfer \\
\hline COSTI & $\begin{array}{l}\text { Centro Organizzativo Scuole Tecniche Italiane } \text { (Italian } \\
\text { Immigrant Aid Society in English) }\end{array}$ \\
\hline $\mathrm{CPF}$ & Canadian Parents for French \\
\hline $\mathrm{EC}$ & European Commission \\
\hline ESL & English as a Second Language \\
\hline IRPA & Immigration and Refugee Protection Act \\
\hline IUSSP & International Union for the Scientific Study of Population \\
\hline LSIC & Longitudinal Survey of Immigrants to Canada \\
\hline NSGVP & National Survey on Giving, Volunteering and Participating \\
\hline OCISO & Ottawa Community Immigrant Services Organization \\
\hline OWP & Ontario Work Program \\
\hline RCEE & Royal Commission on Equality of Employment \\
\hline SAFSS & South Asian Family Support Services \\
\hline SAWRO & South Asian Women's Rights Organization \\
\hline UN & United Nations \\
\hline WAP & Welfare Assistance Program \\
\hline Wl & World Education Service \\
\hline
\end{tabular}




\section{Chapter One: Introduction and Framework of the Research}

\subsection{Background and Objectives of the Research}

I want to begin the context of my research by telling a story of a Bangladeshi immigrant woman, Laila (37 years old), who came to Toronto in 2005, along with her husband, a son and a daughter in order to search for a better life, and a secured future for their children. During my field research, she described her post-immigration socio-economic integration experience as such:

After coming to Toronto, my husband got a job in a security company. He was completely depressed and unsatisfied with that job, as he was a manager of a public bank in Dhaka and, used to hold a higher social position. But, he had to accept that job to look after the family. I used to spend most of the time at home. I wanted to do something but, I had no idea how to look for a job, and where to gather information. I collected a number of job postings from newspapers, and applied for a few jobs. I wanted to do administration related work because I have a Master's degree in Public Administration. But, I did not get any job interview offer ... In July 2006, my husband suddenly lost his job. He was trying hard, but could not find any job. We were in terrible financial crisis. At that time, I was ready to do anything. My husband took me to a number of community-based organizations. They [workers of these organizations] suggested me to take a course in English Language. I started going to ESL [English as a Second Language] classes ... I learned about this organization [South Asian Women's Rights organization] from a woman who also participated in ESL program. After joining in the activities of this organization, I realised that there are many things here for me to do and to learn. I am now taking training in child-care. I will get a certificate from the organization. The best thing is that the training is free. I cannot afford to pay for any training [silence]. But, I am still anxious, because I do not know whether I will get a job or not.

Laila's story illustrates her isolation and separation from mainstream society in Toronto.

Her story indicates how she broke out of the isolation she faced in order to deal with a 
financial crisis. Above all, her story tells about her aspiration to integrate into Canadian society and the labour market by utilizing available and accessible resources. Yet, her story also suggests the uncertainties in finding a job after investing much time and effort. As such, Laila's story illustrates several critical issues that are apparent, generally, in the lives of many Bangladeshi, and other visible minority immigrant women ${ }^{1}$ in Canada. However, the socio-economic integration issues of ethnic minority immigrant women have long been invisible in Canadian policy discourses. Furthermore, women are constructed as passive immigrants, and dependants of male partners in Canadian immigration policies that accept, as well as promote, the ideology of women's subordination and passivity in the male dominated patriarchal society (McLaren and Dyck 2004: 50). Policy makers assume that they (immigrant women) would be taken care of by their husbands/partners, and would manage to integrate in the society automatically (Pinder 2002: 20; Day and Brodsky 1998: 135). This gender based immigration policy promotes men's and women's expected socially appropriate roles, and pushes women towards professional marginalization (Yax-Fraser 2007: 146).

What has made the socio-economic integration issues of visible minority immigrant women noticeable in the policy discourses is the increased rate of poverty, unemployment, underemployment, health and housing crisis among minority immigrant women in recent years in Canada's major cities (Lahey 2005: 2-3). Policy makers, as well as social scientists, felt the necessity to shift their focus to issues of minority immigrant

\footnotetext{
${ }^{1}$ Visible minorities are defined by the Employment Equity Act, as persons, other than Aboriginal peoples, who are non-Caucasian in race or non-white in color (Hou and Picot 2004: 1).
} 
women's socio-cultural and labour market integration in order to eradicate the poverty of minority immigrant families, and increase immigrant women's quality of life. In this regard, feminist scholars note that women's settlement and integration issues need to be considered differently than those of men, because women's experiences of immigration and settlement in Canada differ significantly from those of men (Hunjan 1997: 16). Dobrowolsky and Tastsoglou (2006: 18) summarize the overall challenges of immigrant women as follows:

The differential and unequal social, cultural, political and economic relations of women as compared to men shape and mould im/migrant women's experiences differently and produce different outcomes in the migration and settlement process than those of men. These distinctive dynamics extend from the sexual (and racialized) division of labour at global and national levels, given, for instance: the concentration of women in gendered occupations; the unequal division of labour in the family, where women $\mathrm{im} / \mathrm{migrants}$ continue to do the bulk of the household service and care work; their inferior citizenship claims compared to men based on disparate contributions to the labour market; and their increased 'de-commodification' through their relationship to a male breadwinner. Furthermore, im/migrant women in particular are differentiated from the general population of women, as a result of their 'Otherness' constructed on the basis of language/accent, dress, migrant (legal) status, entry status (independent versus dependent migrants), race/ethnicity, religion, class and so forth and these differences have to be taken into account in the analysis of their citizenship.

From Dobrowolsky and Tastsoglou's (ibid) statement, it is evident that minority immigrant women are the victims of gender and racial discrimination that maintain the devaluation of their labour and the unequal access to the labour market compared to their male counterparts. Visible minority women's alienation from the labour market is identified as one of the root causes of their disempowerment and isolation from various spheres of society. In the Canadian context, it is now a fact that visible minority immigrant women's successful socio-economic integration would not be possible without 
integrating them into the labour market (Lahey 2005: 3). However, gender and racial discrimination against minority immigrant women are highly visible in the Canadian labour market. Not only are minority women underrepresented in the employment sector, but they also are stacked in the low-paid and non-standard employment sector (Townson 2003: 27). The lower rate of labour market participation of visible minority women compared to immigrant men and the mainstream population indicates that, for most minority women, accessing the labour market is a difficult task. Laila's story gives us only a glimpse of the labour market struggles of minority immigrant women. The consequences of the alienation of minority women from employment and income in Canada are not limited to their increasing poverty. The lack of income increases minority women's dependency on male partners and/or social assistance, and exposes them to other forms of vulnerabilities including domestic violence, isolation from the public sphere, and physical and psychological stress (Smith 2007: 74; O' Mahony 2005: 4-6). Economic dependence encumbers immigrant women's empowerment in decision making in different spheres of their lives (Mitra 2007: 30-31). Because of these facts, recently minority women's empowerment and labour market integration issues are in the forefront of debates on immigration and settlement issues in Canada. The notion of empowering minority women implies providing necessary assistance to them to overcome labour market barriers. Feminist researchers contend that, even though the empowerment of minority women has become a common rhetoric in the policy and planning statements, in the practical field, minority women's situation has remained unchanged (Lahey 2005: 4). 
One of the reasons for minority women's lower participation in the labour market is the focus of government and non-government organizations solely on their shortcomings in language and communication, work experience, education and training (Liu 2007: 2-4). As a result, the other forms of labour market barriers, such as gendered and racial discrimination, gendered divisions of labour in the employment sector, employers' discriminatory attitudes towards minority women, and employers' tendency to under evaluate foreign credentials, remain unaddressed (ibid). In this regard, Parpart et al. (2002: 11) note that, "official institutions employ discourses of employment but often failed to translate them into action ... thus, women's empowerment may have entered the discourses but it failed to offer women power over those institutions or power to demand fundamental change". The existence of institutional barriers, therefore, restricts minority women in accessing employment opportunities, even after obtaining the necessary education and training.

The generalized representation of minority women's labour market integration issues in policy discourses is another reason for their labour market struggles in Canada. Feminist scholars argue that this generalized representation not only screens out the issues of the most disadvantaged groups, but also deliberately overlooks the differences in the needs and requirements of a particular group of ethnic minority women (Siemiatycki 2005: 3-4; Bakan and Kobayashi 2000: 2). Generalization fails to identify the cultural and /or religious components of a particular ethnic group that have significant influence in shaping the pattern of women's spatial mobility, access to employment opportunities and other social supports, the perception of their needs and requirements, and their ability to 
overcome labour market barriers. Therefore, feminist scholars are increasingly advocating bringing in the voices of different groups of ethnic minority women into the academic and policy discourses, in order to address the particular labour market issues of minority women in Canada. My research endeavour is an attempt to bring in the voices of Bangladeshi married women, by exploring the context of their empowerment in relation to accessing labour market opportunities in Toronto, Canada. How are Bangladeshi married women making a place for themselves in the Canadian labour market? What kind of problems do they face in accessing labour market opportunities? And, how are they trying to enhance their ability to overcome labour market barriers? These are the questions upon which I have framed my research.

One of the reasons for focusing on Bangladeshi women's labour market integration is their lower rate of labour market participation in Toronto even though they possess relatively high levels of educational qualification compared to the mainstream population (Lindsay 2004: 13-14). Another reason is the lack of literature on the socio-economic integration of Bangladeshi immigrants even though Bangladeshis are one of the fastest growing immigrant populations in the major cities in Canada (ibid: 9). I have selected Toronto as my research area because it is the major immigrant receiving city in Canada, and the main settlement location of the majority of Bangladeshi immigrants. Toronto is, thus, fruitful ground to understand and explore the experiences of Bangladeshi married women within the context of its diverse and multicultural society. I have investigated the labour market experience of Bangladeshi married women in Toronto, whose formal citizenship status is either "dependent class" or "family class". Dependent class women 
are those who accompany their husbands (principal immigrants) during the immigration process, and family class women are those who migrate to Canada through the sponsorship process (i.e., sponsored by their husbands) (Citizenship and Immigration Canada, 2009) $)^{2}$. The main difference between these two categories of Bangladeshi married women is that dependent class women come along with their husbands, and family class women join their sponsors (husbands) later. I am interested in the labour market issues of family and dependent class Bangladeshi married women, because they are not considered as economic agents during immigration process, and are assumed to be taken care of by their husbands/partners after immigrating to Canada (McLaren and Dyck 2004: 42 \& 50). Through my research, I have aimed to explore whether Bangladeshi married women are relying on their husbands' earnings or are searching for employment, and under what circumstances they are searching for employment. These queries are crucial to understand the gaps between macro level settlement and integration policies, and micro level experience that immigrant women go through in their everyday lives.

The main objective of my research is to construct Bangladeshi married women as social actors, who are motivated to overcome institutional barriers and change their labour market situations. Kitson (2003: 7) states that immigrant women are not always the victims of discrimination; the exposure to a new socio-cultural context provides immigrant women with opportunities to renegotiate the barriers in the labour market. The changing socio-cultural context of a new country expands women's understanding of themselves, and how they perceive their disadvantaged social location, as a source of empowerment and agency. In order to portray the efforts of Bangladeshi married women

\footnotetext{
${ }^{2}$ Online source: http://www.cic.gc.ca/english/immigrate/index.asp
} 
to overcome labour market barriers, I have adopted the concepts and approaches of 'women's empowerment'. The concepts of women's empowerment explicitly deal with the journey of women from a position of powerlessness to a position of power, through which they gain the ability to bring changes to their disadvantaged situation (Carr 2003: 13; Busch and Valentine 2000: 83). I have framed the empowerment of Bangladeshi married women in accessing the labour market opportunities in relation to the concepts of structural barriers, agency, resources and achievements, as proposed by Naila Kabeer (2003: 169-175). I have explored structural barriers of Bangladeshi married women through analyzing their labour market integration problems, and described their agency through outlining their motivations to overcome those problems. I have illustrated their access to, and involvement with, Community Based Organizations (CBOs) in order to understand what kind of assistance (resources) they get from these organizations to overcome their labour market problems. Finally, I have discussed whether these women have succeeded in overcoming their labour market barriers (achievements).

In my study, I have focused on Bangladeshi married women's perceptual understanding of empowerment, as well as their actual ability to overcome labour market barriers. For this purpose, I emphasize these women's interests and needs in relation to their various positionalities that inspire them to deal with the labour market constraints, individually and collectively, through their involvement with CBOs. The reason for emphasizing the initiatives of $\mathrm{CBO}$ s is that these organisations are considered a focal point for enhancing social ties and networks and accessing social capital, which is a key factor in accessing employment (Lin 2005: 4). Furthermore, community-based and/or non-government 
voluntary organizations are identified as key players in enabling women's empowerment through initiating bottom-up approaches at the community level, and through providing minority/disadvantaged women a platform to express their specific needs and problems (Cottrell 2008: 136). However, researchers suggest that the roles of CBOs need to be scrutinized because these organizations are also a part of a socio-economic structure in which an organization's own interests (profits, ideologies) and limitations (limited funds, dependency on other institutions for funding) influence the nature of their initiatives and the capacity to assist minority women (Wallace and Frisken 2004: 151; Berger et al. 2005: 14). Therefore, to address the above stated issues, I have critically analyzed the roles of $\mathrm{CBOs}$, and the nature of involvement of Bangladeshi married women with these organizations' activities.

The rationale for analysing Bangladeshi married women's labour market integration in relation to the concept of women's empowerment is to understand how the process of their empowerment takes place at the practical level under particular circumstances. Social scientists have emphasized the necessity of bringing in the practical context of a particular group of people in the analysis of the empowerment process in order to have a deeper understanding of the nature of their empowerment (Perkins and Zimmerman 1995: 570). As Perkins and Zimmerman (ibid) note, "both empowerment processes and outcomes vary in their outward form because no single standard can fully capture its meaning in all contexts and populations". Researchers have identified the socio-cultural characteristics possessed by a particular group of people in a particular place, as key factors in directing the nature and the outcomes of an empowerment process. Perkins and 
Zimmerman (1995: 572) emphasize analyzing the theoretical models of empowerment in relation to examples of practical contexts in which an empowerment process takes place. In this regard, the narratives of personal stories are considered as 'a valuable resource' to link the practical context with theoretical constructs (ibid). Through analyzing the narratives of the labour market integration experience of Bangladeshi married women, $\mathrm{I}$, therefore, linked the practical aspects of their empowerment process to the theoretical constructs of empowerment. I conducted field research in a Bangladeshi neighbourhood in the Danforth and Victoria Park area in Toronto in order to identify how socio-cultural factors in neighbourhood and community expectations influence Bangladeshi married women's perceptions of empowerment, and their capacity to access employment opportunities. It is important to note that culture is a learned attribute; it can be transformed, as well as interpreted, in different ways based on the positionalities of people, and the nature of places, politics and historical time (Abu-Lughod 1991 cited in Hunjan 1997: 6). Therefore, I also put emphasis on the differential perceptions of Bangladeshi married women in relation to their labour market experiences. This attempt not only provides me the ground to explore the unique and particular labour market issues of Bangladeshi married women in Toronto, but it also allows me to critically analyze the theoretical understandings of women's empowerment. Moreover, through analyzing the labour market integration experience of Bangladeshi married women, I have identified the gaps between the generalized assumptions and the practical context of their empowerment, which is a major issue in the labour market integration process of these women in Toronto. 


\subsection{Situating the Research Framework}

My quest to investigate the labour market integration experience and the context of empowerment of Bangladeshi married immigrant women in Toronto is directly involved with issues of 'representation'. Representing the life experiences of other women is a contested term based on the fact that women's life experiences are embedded within the spatial (location), temporal (history), socio-economic and cultural contexts in which they hold distinct positionalities in terms of age, level of education, marital status, religion, race, and ethnicity. Therefore, a multiplicity of experience is unavoidable when women's relative positionalities within particular contexts are acknowledged. In the terrain of multiple positionalities of women, the universality of women's standpoint, as well as the claim of producing absolute truth about their experience, is impracticable. As Scott (1992: 37) states, "experience is at once always already an interpretation and is in need of interpretation. What counts as experience is neither self evident nor straight forward; it is always contested, always therefore political". In order to explore and interpret the contextual labour market experiences of Bangladeshi married immigrant women, I have taken on the concept of poststructuralist feminism. Poststructuralist feminism is an appropriate philosophical standing for my research because it deals with the issues of representing subjective knowledge (life experiences of other people) (Haraway 1991: 195).

The term 'poststructuralism' appeared in the literature of English-speaking countries in the early 1970 s. The validity of the term is based on the rejection of the "formalism of 
structuralist linguistics and its (at least implicit) epistemological subject" (Poster 1989 cited in Johnston et al. 2000: 625). Poststructuralism suggests a social constructionist position, which casts doubt on the possibility of producing universal, value free, and absolute truth. Social constructionism replaces the notion of objectivity of knowledge production with the notion of subjective and interpretive abstraction of knowledge through the selective use of language (Scott 1992: 25). Poststructuralists argue that, "meanings - the ways in which we understand the world - are not natural or universal, but instead constructed through specific power relations and through situated interactions and participation in the social world" (Hickey and Lawson 2005: 100). From a poststructuralist viewpoint, knowledge gained through experience is represented through language that is constituted and structured by those who experience and represent it. The constitution and representation of knowledge are historically mediated through the lens of micro and macro politics of power, domination, and resistance (O'Mahony 2005: 22). Therefore, poststructural thinkers include the context of privilege and marginalization, and a conceptual pluralism in contrast to what has been "conceived as relatively closed (although not static) linguistic, economic and social systems" (Johnston et al. 2000: 625).

Poststructuralist thoughts on women's multiplicity of experience and the politics of representation were not taken into account in the feminist movement until the mid-1980s. In the early period of North American second wave feminism, the assumptions of feminist theorizing were grounded in an analysis of oppressive sex-based divisions of labour under the dominant ideologies of patriarchy that systematically oppress women through social, economic and political institutions (Walby 1991: 20). The aim of 
feminists was to make space for women, in the everyday practices of the university and beyond, and in the knowledge that is produced about this world. As Cotterill (1992: 594) states, "a major commitment of academic feminism has been to create a theory and method which centers on women's perspectives and experiences so that they can understand themselves and their social world". However, the assumption of a universal 'women's standpoint' in feminist theorizing, which is grounded in the common experience of women under a patriarchal system, was insufficient to capture the complexity of women's experience and was, in fact, a barrier to women's solidarity (Kline 1991: 40-41). Therefore, though academic feminists were creating a space for women to ensure that their experiences of oppression would be heard, the inequalities and differences among women in relation to their varied locations within the society remained invisible (Cotterill 1992: 594). The rise of feminism in Western contexts, and the domination by white Western women in academic research, resulted in a tendency to project their own experiences as representative of all women. As white, middle class feminists took their social locations for granted and generalized the nature of oppression to all women, the experiences of women from different positionalities in terms of class, race, religion, ethnicity and socio-cultural contexts were completely overlooked (Pratt 2004: 129). Therefore, the efforts of feminists to promote women's collective interests failed, as they were challenged by black women, women of color, and visible minorities, who asserted that although all women are oppressed, not all women are equally oppressed. $\mathrm{Ng}$ (1991: 27) states that, "as Women, we live in sexist world order. However, we black Women and other Women of Colour in addition live in a racist world order which so far has denied us entry into the mainstream of the Women's Movement". 
The occasional appearances of Black women, women of color, and Third World women in Western feminist academic literature ensured their position as the "Other" women who were inferior and homogeneous subjects because of their "backward" indigenous culture (Mohanty 1991: 5). The failure to acknowledge heterogeneity among women and their relative positionalities within the society in early feminist literature established the fact that women can also become the oppressor by using their class, race, education, privilege and interests, and can create further marginalization of relatively powerless women $(\mathrm{Ng}$ 1991: 31). The call to account for differences among women across race, class, culture and sexual orientation, especially by black feminists and feminists of color, resulted in a growing recognition of poststructuralist problematization, and critical interrogation of the politics of exclusion and othering of women in feminist literature (Elam and Wiegman 1995: 22).

Poststructural feminism, as a concept, emerged in Europe, especially in French literature in the early 1980s. Poststructural feminists emphasized "particularly the role of language in the construction of femininity and ... began to problematize feminism's essentializing or totalizing gestures and its roots in Enlightenment humanism" (Elam and Wiegman 1995: 15).

"Feminist critiques", Butler writes "ought to explore the totalizing claims of a masculinist signifying economy, but also remain self-critical with respect to the totalizing self critical gesture of feminism". From this perspective, poststructuralist problematization of feminism itself is essential to avoid the erasure of heterogeneity and difference upon which the universal subject of humanism is based. (ibid: 22) 
To avoid the essentialist assumptions, Butler (1992: 16) emphasizes the deconstruction of general and fixed categorizations of women's social location, and suggests the possibility of resignification of women's identity in different contexts of social reality. Such an attempt certainly provides adequate room for the inclusion of differences among women. However, a number of poststructural feminists use the term 'strategic essentialism' and suggest that, under certain circumstances, it is necessary to essentialize women's identity and simultaneously deconstruct it (Youdell 2006, Anderson 1993, Bondi 1993). As Anderson (1993, cited in Gulson 2008: 156) suggests, there is a "paradoxical manner in which at certain moments in the negotiation of power relations, marginalized peoples appeal to the racialized identities assigned them; that is, certain groups engage a 'strategic essentialism' through which to articulate their opposition and secure reforms". Pratt (2004: 138) illustrates the notion of enhancing the collective interests of women on the basis of their marginalization. According to Pratt (ibid), "mapping contradictions in space can be an effective way of visualising exclusion and building alliances across excluding groups". The concept of strategic essentialism is relevant to my research endeavour, as it explores the marginalization of Bangladeshi immigrant married women in the Canadian labour market, and analyzes the extent to which their marginalization is associated with their gender and visible minority status. Thus, I have taken gender and the visible minority status of Bangladeshi married women (gendered and racial norms) as common grounds to explore their labour market challenges in Toronto.

The representation of Bangladeshi married women's labour market experience is also associated with the perspectives of postcolonialist and/or Third World feminists. The 
term 'postcolonial' indicates the time period after the end of colonial rule. Postcolonialism analyzes the socio-cultural and political characteristics of societies that were shaped by colonialism. Postcolonialism also illustrates how the voices of colonized women are subjugated through colonial discourses to maintain the supremacy of colonial imperialism (Raghuram and Madge 2006: 271). Bangladeshi women were the victims of colonial subjugation, because of years of colonial history in the Indian Sub-continent. Takhar (1991: 215) points out that "the colonial image of South Asian women as being unable to resist the power exerted by patriarchal relations in the face of Dharma (religion) and Karma (culture) has been transported (over time) to the post colonial British context as a racialized discourse". Agarwal-Narale (2005: 5) suggests that Western views construct South Asian women as passive, suppressed and miserable based on their patriarchal family relations and gender roles, without considering the cultural context in which gender roles are embedded. The core of the postcolonial approach, therefore, is to provide a theoretical perspective for unmasking the colonization process, which is operated through radicalized and gendered power relations, and brings to light the voices of marginalized subalterns in the feminist literature, whose voices have been silent during the process (O'Mahony 2005: 21). O'Mahony (ibid: 25) further states, "the post colonial concepts emphasize understanding and interpreting the cultural contexts and localized meanings of perception, emotions, expectations and assumptions of empowerment of Third World women through which their social realities take shape". The perspective of Postcolonialism is important for my study in terms of understanding the impact of cultural norms on Bangladeshi married women's perceptions of their empowerment in relation to accessing labour market opportunities in Toronto. 
Over the years, a number of feminist positions have emerged from the poststructural feminist standpoint, including postcolonial feminism, Islamist feminism and Third World feminism. All of these concepts generally lay the ground to examine the production of knowledge of gender, race and class relations from different socio-political locations (Gunew 1990: 2). In this regard, Butler (1992 cited in Elam and Wiegman 1995: 22) states, "'poststructuralism' is not strictly speaking, a position, but rather a critical interrogation of the exclusionary operations by which 'positions [including feminist positions] are established". The key message of poststructural feminism is that:

We must consider the ways that structures of racism, sexism and class oppression and their ideological formations are historically implicated within a particular context. In doing so we will confront the complexity of women's experience of oppression and the consequent differences in women's priorities and concerns, and will thus maintain a historically-based and contextual approach to analyzing, strategizing and actively working for women's liberation. (Kline 1991: 40)

In order to analyze and represent the diversified experience of women, poststructuralist feminists focus on bringing the geographical and historical locations and positionalities of both the researcher and the researched into the research process (Haraway 1991: 195). The necessity of transparency in the research process emerged from critiques that poststructuralist problematization can also construct a new orthodoxy and politics of inclusion and exclusion. A "new hierarchical power structure [has emerged] within academic feminism in which the theoretical problematizers often occupy the most prestigious and powerful positions" (Elam and Wiegman 1995: 26). In order to defuse power relations in the research process, poststructuralist feminism emphasizes adopting multiple qualitative methods for collecting information, and creating knowledge through 
transformative, non-exploitive, and critical research practices (Hunjan 1997: 67). Poststructuralist feminist scholars use the term 'reflexivity' as a strategy to present the construction of knowledge as situated through intense reflection and self critique (Hickey and Lawson 2005: 100). As $\mathrm{Ng}(1991: 23)$ states:

We need to re-examine our history, as well as our own beliefs and actions, on a continuous basis, so that we become able to better understand and confront ways in which we oppress others and participate in our own oppression. While this in itself will not liberate us completely from our own sexist, racist and class biases, it is a first step in working toward alternate forms of alliances and practices which will ultimately help us transform the society of which we are a part.

Therefore, reflexivity means the critical disposition of the researcher's positionality, objectives, achievements, and limitations within the research. I have framed my research through drawing upon the methodological approaches of critical research practice suggested by poststructuralist feminist scholars in order to document the labour market experience of Bangladeshi married women from their own positionalities and perspectives. The following section outlines the organization of the research on the basis of the contents of each chapter.

\subsection{Chapter Outline of the Research}

The research is organized into six chapters. The first chapter introduced the research through explaining the objectives and the rationale of exploring the empowerment process of Bangladeshi married women in relation to their labour market integration in Toronto. It then highlighted the concept of poststructuralist feminism, which is the 
philosophical standing of the research, in order to justify an understanding of knowledge creation and interpretation as subjective.

Chapter two is a review of the literature. It discusses the background of the research through providing an overview of the labour market situation of visible minority women in Canada. The central focus of this chapter is to illustrate the socio-economic and political factors that influence minority women's capacity to access employment opportunities. The chapter analyzes the articulation of gendered and racialized norms in the labour market integration process of minority women. The literature review also discusses why and how immigration and socio-economic integration policies have failed to include the specific labour market issues of minority women. The roles of non governmental community-based organizations are also scrutinized in order to analyze its potential to provide minority women an alternative means to establish their needs with regard to overcoming the labour market barriers.

Chapter three provides the theoretical framework for the research. It discusses assumptions and arguments about women's economic independence and their impact on women's overall empowerment process. The discussion is organized through outlining the perspectives of liberal, Marxist and poststructuralist feminists with regard to women's labour market participation, and relevant issues of their empowerment in different spheres of their lives. It then describes the process and elements of empowerment through which deprived groups gain a position of power in order to overcome their marginalized situations. This includes the analysis of agency, resources and achievements, which are 
the basic elements of an empowerment process. This chapter also includes why and how I have drawn on the theoretical perspectives of empowerment to analyze the labour market integration process of Bangladeshi married women.

Chapter four discusses the methodological framework of the research. The rationale of using qualitative methods in the research, and the theoretical concept of critical research practice are analyzed. An overview of my own positionality in relation to the research, subjectivity, and the context of power relations, is illustrated in order to ensure transparency in the research process. This chapter then discusses how empirical data were gathered and interpreted to address the inquiries of the study. It includes the rationale and the process of conducting focus group discussions with Bangladeshi married women, participant observation in a Community Based Organization (CBO), and interviews with CBO workers. The ethical issues of data collection and interpretation are also outlined. The chapter ends with a discussion of the process of data analysis and interpretation.

Chapter five outlines the findings of the study through analyzing the narratives of nineteen Bangladeshi married women, who participated in focus group discussions and three CBO workers, who participated in interviews. The chapter discusses the main themes of the empowerment process, such as structural barriers, agency, resources and achievements in relation to the labour market integration process of Bangladeshi married women. The discussion on structural barriers covers the nature of problems that Bangladeshi married women face while searching for a job in the mainstream labour market, as well as in the self-employment sector. The agency of these women is analyzed 
by outlining the factors that drive them to search for employment, and motivate them to enhance their capacity to overcome labour market barriers. Further discussions focus on the involvement of these women with CBOs, and analyze the effectiveness of the CBOs in strengthening the capacity of these women to access labour market opportunities. The chapter concludes with a critical overview of how the empowerment process takes place in a practical context, and how it differs from the theoretical constructs of women's empowerment. This chapter emphasizes that the broader perspectives of socio-economic, cultural and political factors, which generate the marginal labour market situation of Bangladeshi married women through enforcing gendered and racialized ideologies, need to be scrutinized in order to create the possibilities of structural reform at the practical level.

Chapter six provides an overview of the research, and outlines the key findings. It summarizes the objectives, methods, and findings of the research, and sheds light on the aspects that stimulate further questions regarding the labour market issues of Bangladeshi married women in Toronto, Canada. 
Chapter Two: Barriers to Minority Women in the Canadian Labour Market:

\section{Review of Literature}

Equality does not mean sameness; equality means that we have to treat differences differently ... It should not be necessary for people to make themselves the same as the others in order to qualify for equal respect (Abella 1984 cited in Saloojee 2003: 39-40).

\subsection{Introduction}

National statistics in Canada continue to show that visible minorities, especially minority women, are disadvantaged in the labour market and are experiencing a higher unemployment rate than the average Canadian born population (Galabuzi 2005: 53). The disappointing situation of recent immigrants in the labour market indicates the opposite of the central objective of Canadian immigration policy that accentuates seeking out a skilled population with a strong potential to contribute to the country's economic sector (Lochhead 2003: 2). It is evident that the situation of minority immigrant women in the labour market is worse than that of male immigrants (Townson 2003: 27; Lahey 2005: 1). It is important to note that there is not much literature specifically on Bangladeshi immigrant women's labour market integration issues. However, several studies discuss various socio-economic issues of visible minority immigrant women in Canada. Through reviewing the relevant literature, this chapter aims to provide a general overview of the labour market situation of visible minority women in Canada. For this purpose, this chapter addresses two questions: how are visible minority women positioned within the Canadian labour market? And, which factors are shaping their labour market situations? 
Through addressing these two questions, this chapter illustrates the extent to which minority immigrant women encounter difficulties because of their 'minority' status and gender identity. The first section of this chapter illustrates the general situation of minority immigrant workers within the Canadian labour market. The second section discusses how institutional and socio-cultural barriers are affecting minority women's labour market integration process. The third section analyzes the articulation of gendered and racialized norms in Canadian immigration and social support policies, and their impact on the labour market integration of minority women. The fourth section describes the potential as well as limitations of non-government Community-based Organizations (CBOs) to address labour market issues of minority women, and to ensure their successful socio-economic integration. The chapter provides some insights into the disadvantaged labour market conditions of minority immigrant women.

\subsection{Status of Minority Immigrants in the Canadian Labour Market: An Overview}

Immigration accounted for more than $50 \%$ of the net population growth in Canada, and $70 \%$ of the growth in the labour force over the first half of the 1990s, and it will increase to more than $90 \%$ by 2010 (Galabuzi 2005: 54). The Canadian economy is highly dependent on the immigrant population, considering the natural decline in the Canadian born population and population aging, which can have an adverse impact on the labour market. The transformation of the Canadian economy from an industrial economy to a knowledge-based, technology and service-oriented economy at the beginning of 1980s 
also influenced immigration policy which targets people with high human capital (Liu 2007: 2).

The main assumption of the human capital theory is that "[h]igher levels of skill and knowledge, achieved through education and training, lead to higher productivity which is expressed in higher earnings for those who possess them" (McBride 2000 cited in McLaren and Dyck 2004: 42). But the human capital theory does not reflect the practical situation of recent immigrants in terms of their earning and employment patterns. Even though immigrants to Canada are selected based on a point system (developed in the late 1960s and entrenched in the Immigration Act 1978) that takes into account their age, education, skills and employment experience, national data show that immigrants arriving since 1980 are "disproportionately stuck at the bottom of the economic ladder, in terms of income, employment, access to high paying sector and jobs and employment status ... and disproportionately consigned to low paying part-time, temporary, insecure employment under poor working conditions" (Galabuzi 2005: 53). According to the Longitudinal Survey of Immigrants to Canada (LSIC), more than half of skilled economic class immigrants are working in an occupation other than that for which they were qualified (Chui 2003: 21). It is also evident that education and professional experience do not provide any advantage in the employment market for immigrants who belong to visible minority groups, compared to the Canadian born population (Li 2001 cited in Galabuzi 2005: 56). This situation indicates that the point based system through which immigrants' qualifications are assessed during the immigration process does not have any significance in terms of labour market integration for the minority immigrants in Canada. Whether 
they worked in a high-skilled or a low-skilled occupation, recent immigrants earned less than their Canadian-born counterparts (ibid). The increasing poverty rate among recent immigrants (from $24.6 \%$ in 1980 to $35.8 \%$ in 2000 ) results from their unemployment and underemployment situations (ibid). Increasing poverty rates are evident for newcomers regardless of their age group, education level, language background, and family type (Lochhead 2003: 1), but comparatively more frequently among South Asian immigrants (Linsday 2007:15) . It is evident that South Asians in Canada "are more likely than the overall population to have incomes that fall below Statistics Canada's low-income cutoffs" (ibid). Researchers also identify that the situation of minority immigrants is shaped by the locational characteristics of the place where they settle. Three-quarters of immigrants settle in Canada's three largest cities: Toronto, Montréal and Vancouver, and employment issues of immigrants are more frequent in these cities (Preston and Murnaghan 2005: 67). It is evident that visible minority immigrant women are one of the disadvantaged groups in the Canadian labour market, as they bear disproportionately larger shares of unpaid, poorly paid, part-time and other forms of irregular jobs (Townson 2003: 27). Data show that "in 2001, immigrants who had been in Canada for five years or less had a lower employment rate than the Canadian born population, with a particularly large gap emerging between immigrant and Canadian born women" (Schellenberg and Hou 2003: 50). It is observed that in Toronto, minority women are much more likely than Canadian-born women to be manual workers, and earn less at their jobs than other women in Canada (Citizenship and Immigration Canada 2005: 50 \& 56). Lahey (2005: 1) states that "the gap between women and men's incomes is so large and so intractable that it is accurate to say that women and men literally inhabit two separate economies" in 
Canada. Minority women encounter constraints at different stages in the labour market integration process, including barriers in accessing employment opportunities, and barriers in upgrading their status within the labour market. Research evidence shows that these barriers result from gendered and racialized ideologies that shape the institutional and socio-economic process of minority immigrant women's settlement and integration (Grant 2007: 137). The following section provides an insight into aspects of institutional and socio-cultural constraints that reduce minority women's access to labour market opportunities.

\subsection{Institutional and Socio-cultural Barriers to Minority Women}

Based on the literature on visible minority women's labour market integration issues, it can be understood that a number of factors influence their labour market situation, as well as their access to skill development, and career advancement opportunities. Generally, the lack of recognition of foreign credentials, inadequate language and communication skills, lack of work experience in Canada, and the lack of familiarity with the Canadian job market are identified as the main constraints for obtaining employment for visible minority immigrants (both men and women) (OCISO 2005: 1-2). However, Liu (2007: 2-4) identifies the above-mentioned issues as 'formal' constraints, and suggests that 'informal' constraints, such as sexism and racism, significantly influence Canadian labour market integration mechanisms. Several studies point out that systemic structural barriers, such as entry requirements of employment (Canadian skills and work experiences), employers' lack of knowledge about foreign credentials, and employers' 
negative attitudes towards minority women, adversely affect their participation in the labour market (Hathiani 2007; Liu 2007; Saloojee 2003). Racial discrimination is identified as a major factor in the distribution of employment opportunities among visible minority immigrants regardless of their gender (Liu 2007: 5, Ng 1993 cited in Kitson 2003: 22). Esses et al. (2007, cited in Hathiani 2007: 130) state that "visible minority immigrants are especially likely to experience discrimination in employment and that this discrimination is specifically attributable to their visible minority status". Research evidence indicates a link between the increase of immigrants from non-European countries and the disadvantaged labour market participation of newcomers (Lochhead 2005: 35-36, Schellenberg and Hou 2005: 50). Frances Henry defines the discriminatory situation of racial minorities as the 'differential incorporation' into Canadian society (Hathiani 2007: 132). The differential incorporation theory suggests that some ethnic groups are more easily incorporated into mainstream culture in a multicultural society than others, based on their race and ethnicity (ibid). Differential incorporation of minority groups undercuts the assumption of a level playing field and equality of opportunities, and erodes a person's capability to develop his/her skills and capacities (Hathiani 2007: 132, Menshah and Firang 2007: 23). Budhu (2001, cited in Hathiani 2007: 132) states that "systemic and structural racism - through major societal institutions, from educational, labour market, to justice and service delivery systems, creates barriers, which prevent visible minority communities from fully developing their potential and participating equitably in Canadian society". Liu (2007: 3-4) states that an employer's tendency to assess the attributes of newcomers based on mainstream corporate cultural norms, and their (employers') reliability with regard to internal contacts and referrals in 
the hiring process, automatically exclude recent immigrants from the job market. Immigrant women suffer more than men in building rapport with the employers, because of their limited opportunity to enhance their skills and their limited access to social networks both inside and outside their own communities (Kitson 2003: 23-24). Liu (2007: 8) further elaborates on cultural stereotyping in some job sectors, and emphasizes employers' tendency to foster cultural sameness within the organization, and the negative impact this has on visible minority immigrants' entry into the labour market. Canadian work experience as an entry requirement is a 'cultural parameter', "a retroactive condition placed on newcomers, impossible to fulfil without first being part of the workforce" (The Public Policy Forum 2004 cited in Liu 2007: 10). Topen (2007: 140) suggests that belonging to a particular culture, religion and ethnic group acts as a barrier to employment for minority women even before having visual contact with the employer. Based on a study of African immigrant women, Topen (ibid) illustrates how an African 'accent' acts as an indicator to locate African women within a particular job sector (lowpaid, semi-skilled) in the Canadian labour market. As Creese and Kambere (2003, cited in Topen 2007: 140) state, "an African accent cannot be separated from the skin colour of the African who speaks it". Based on a study of South Asian immigrant women, Agarwal-Narale (2005: 5) states that the social construction of the attributes of South Asian women within the Europe-centered society is almost always associated with their backwardness, inferiority and subordination without considering the cultural context. Immigration, thus, exposes visible minority women to a transitional phase in which they constantly encounter both local and transnational gendered and racial norms. $\mathrm{Ng}$ and Estable (1987 cited in Brigham and Walsh 2007: 156) state that "some foreign-born 
people in Canada are not seen as, nor do they see themselves as, immigrants, while others, based on their 'Third World' country origins, race, language ability and/or accent and their lower positions in the occupational hierarchy, are seen as, and see themselves as, immigrants regardless of their legal status". Through this statement, $\mathrm{Ng}$ and Estable describe the constituted meanings of the term 'immigrant women', and the complexity in minority women's identity formation. Minority women's construction of their identity and social location as inferior to, and distinct from, the mainstream population, therefore, drives them towards social exclusion and isolation from mainstream society, and reduces their capacity to take part effectively in socio-cultural, economic and civic life in Canada (Saloojee 2003: 39). Minority women's self identification is largely influenced by Canadian policy discourses that create a separation between mainstream (white Canadians) and visible minorities through categorizing immigrant women based on their origin (European and non-European) in order to address their settlement and integration issues (Brigham and Walsh 2007: 156).

The English/French proficiency and the accent of minority women play a significant role in forming their social identity as well as locating their place in the labour market (Hunjan 1997: 31). An immigrant's ability to communicate, either in English or French, is also a major asset for civic participation. Findings of the Longitudinal Survey of Immigrants to Canada (LSIC) show that employed immigrants with the highest level of spoken English are more likely to have a high-skilled job compared to immigrants who have a lower level of English proficiency (Statistics Canada 2005: 7). There is a lack of research about ethnic minority women's English/French language proficiency in relation 
to their labour market situations. Several studies illustrate that the language barrier has adverse impacts for women, especially family class immigrants, because they do not go through any language proficiency test during the immigration process (Cottrell 2007: 136, Papademetriou, 2007: 2). Their 'dependants' category and passive roles in the immigration process also influence their isolation from civic activities in Canada. Therefore, it takes a long time for them to gain access to information about available communication and skills development services. Moreover, their participation in statefunded English as a Second Language (ESL) programs become almost impossible if they have children below six years of age (Yax-Fraser 2008: 147). Thus, upgrading their language and communication skills is challenging, if not impossible, for most minority women.

The lack of recognition of international credentials and work experience is another major challenge that minority women face in getting access to employment. Overall, the recognition process of foreign credentials is complex in Canada, because of the involvement of many institutions. The institutional arrangement of assessing foreign credentials includes "five provincial assessment authorities, more than 400 regulatory bodies, and more than 200 accredited post-secondary institutions, industry sector councils and non-government organizations" (Jeanotte 2008: 6). The complexity of the credential assessment system is confusing for newcomers, especially for women, as they do not have enough access to information on how and where they can obtain recognition for their credentials (Ikura 2007: 17). In most cases, women who are in the dependant/family class immigrants do not go through a credential recognition process, as they do not 
perceive themselves, nor are they perceived by their partners, as persons with economic potential. The official credential evaluation service of Ontario (World Evaluation Service) was established in 2000 to provide comparable assessment of foreign credentials to immigrants (Owen 2007: 41). But the evaluation process of WES is not consistent with the recruitment process in the job market, as employers have their own standards of evaluating the skills of job-seekers. Therefore, credential assessment services are not helpful for immigrants in finding employment. Owen (2003: 5) emphasizes employers' limited knowledge of assessing foreign credentials, and their practice of undervaluing non-Canadian work experiences compared to Canadian work experience. As Grant (2007: 137) states "foreign qualifications and work experiences are consistently undervalued resulting in initial wage gaps for recent immigrants particularly immigrants of color". Based on the findings of a recent study that compares the credential recognition process of Canada and Sweden, Donaldson (2007: 55) notes that in both Sweden and Canada "foreign credential recognition process tends to rely on a 'difference-blind' or universalliberalist approach which accesses differences from the domestic norm as deficient and inferior thus invalidating the knowledge of immigrant professional, particularly from third world countries".

For most ethnic minority women, the lack of recognition of their foreign credential means that they have to take further education or training from Canadian institutions in order to gain access to employment. Under such conditions, another option for minority women to upgrade skills and gain Canadian work experience is doing voluntary (non-paid) work in different organizations (Poelzer 1991: 201). According to the National Survey on Giving, 
Volunteering and Participating (NSGVP), women in Canada have higher volunteer rates than men, though women receive less employer support than do men for volunteer activities (MacPhail and Bowles 2007: vii). The findings of NSGVP also indicate that women have more time constraints in participating in voluntary work (ibid). Volunteer work can create a "triple burden" syndrome for those minority women who are responsible for domestic work and also hold paid employment at the same time (Topen 2007: 139). Burdens of housework during the post-immigration period usually prevent minority women from taking further education and skills development training, or doing voluntary work. The pattern of domestic responsibilities is considered as one of the crucial factors in enabling and /or disabling the capacity of women to participate in the labour market. Raghuram and Kofman (2004: 97) states that "differences between the ways in which reproductive activities are organized in the countries of immigration and in the sending countries mean that women, who usually have primary responsibility for arranging reproductive activity, may find that they are unable to work in the new country". Kitson (2003: i) points out that the gendered division of labour and patriarchal ideologies remain intact at the household level of Ghanaian immigrants, whether women participate in labour market/ skills development training or not. Yax-Fraser (2008: 147) illustrates that most of the immigrant women from sub-Saharan Africa perform most of the household responsibilities. Hunjan (1997: 32) states that isolation from family, relatives and social networks increases women's, especially South Asian women's, difficulties in managing household responsibilities after immigration, as they used to get help from family members in performing domestic chores. Therefore, minority women's 
increased household responsibilities reduce the opportunities to look for paid employment, especially when they have infants to look after (Yax-Fraser 2007: 147).

Often domestic responsibilities and systematic barriers in the labour market integration process jointly force minority women to have either a dependent status or participate in low paid part-time employment in a non-standard job sector. Non-standard jobs include "contract work, self-employment without employees, temporary work and part-year work, or multiple jobs with a series of employers" (Townson 2003: 1). Townson's (ibid: 27) study suggests that visible minority women are more likely than other women to be employed in non-standard jobs. A study of female-dominated home care work in Ontario suggests that racial minority and Aboriginal women are mostly employed in less skilled, lower paying and casual jobs (Denton et al. 1998 cited in Townson: 2003: 26). As Zeytinoglu (2000: 223) states: "racial minority workers, particularly those of low economic class, tend to have limited bargaining power and knowledge of their rights and are easily relegated into insecure poorly paid jobs with no career mobility". The concentration of minority women in non-standard job sector is a crucial concern in Canada, as non-standard work does not provide the benefits of employment insurance, public pensions, parental benefits/leave and child-care facilities, because of the short timeframe and discontinuous characteristics of non-standard jobs (Townson 2003: 2). Stephenson and Emery (2003: 2-4) suggest that single mothers and/or lone-parent minority mothers are struggling with economic insecurity as most of them work in parttime non-standard jobs. Among all types of non-standard work, part-time jobs are the most preferred option for women, in general, because they offer flexible shifts that enable 
women to juggle household and paid work (Pinder 2002: 72). There is a growing trend of part-time jobs compared to full-time jobs in Canada, which indicates a transition in the labour market situation overall. Townson (2003: 6) suggests that this transition is a result of the demand for flexibility, and competitiveness of services in a globalizing economic environment. Considering the poorly paid conditions, absence of economic security and disparity of wages among men and women in part-time jobs, Pinder (2002: 72) suggests that "since most part time jobs are occupied by women, there is a gender based stratification in part-time job sector which can result in the further marginalisation of women". Pinder (ibid: 66) also emphasizes gender-based occupational segregation in the Canadian labour market. Teaching, nursing and health related occupations, clerical positions and sales and services are the main sector where nearly $70 \%$ women work and "these jobs are characterized as low skilled, low paid with poor working conditions and little or no opportunities for advancement" (Statistics Canada 1996: 67). Considering the absence of minority women in professional and managerial positions and their concentration in the textile and clothing industries, Pinder (2002: 72) suggests that "while occupational segregation separates women from men in the labour force, it also separates women in terms of race and ethnicity".

Barriers to entering the mainstream labour market sometimes encourage minority women to consider the option of self-employment, which is another form of non-standard job. Rooney et al. (2003: 8) illustrate that self-employment has been increasing among women in Canada particularly, among minority women. Minority women are mainly working as child-care providers, cleaners and small business owners and they earn less 
than their non-minority counterparts (ibid). Even though self-employment provides women the opportunity to work autonomously, and the flexibility to perform domestic responsibilities, women do not have the advantage of labour and social protection services (i.e., disability coverage, pension plan, parental support, employment insurance) through self-employment. Moreover, "most self-employed women have difficulty taking time away from their business for maternity/parental, sickness or family care giving reasons, because of their inability to find a replacement, reduced earnings, loss of clients and loss of visibility" (Rooney et al. 2003: 1). Minority women encounter more constraints in securing capital, and starting and managing a business, and they tend to start with less capital than men and focus on local markets at the community level. The gendered divisions that exist in paid work are also evident in the self-employment sector. Self-employed women are mainly concentrated in home-based retail trade and caregiving services; in contrast, self-employed men are mostly concentrated in business and industries, and work outside of their home (ibid). Therefore women's home-based selfemployment blurs the division between women's paid work and unpaid domestic chores. Day and Brodsky (1998: 31) point out that women's concentration in "caring" occupations, which are socially assigned to women in the unpaid domestic sector, implies that "women's work" is economically worth less than is "men's work" and therefore "women's work" is lower paid than "men's work". In this regard, Leach (1998, cited in Bernstein 2001: 8) states that "women's work in the home (paid and unpaid) and out of it takes on different and more ambiguous meanings than does the work of men, wherever it is performed. All work carried out by women in the home, whether paid or not, tends to be symbolically treated as if it were domestic labour". It is argued that the retention of 
cultural and religious norms and traditions in ethnic neighbourhoods enforce gendered ideologies, and influence women to accept home-based work (Hunjan 1997: 14-15). Therefore, minority women often engage with home-based work because of the absence of other options within ethnic neighbourhoods.

The concentration of minority immigrants in ethnic neighbourhoods, especially in Toronto, and its influence on their social and economic lives has recently caught the attention of researchers. Lochhead (2005: 36) states that employment is one of the reasons for minority immigrants to settle in ethnic neighbourhoods. New immigrants tend to live close to their family members, friends, relatives and community people and depend on them when seeking employment (ibid). According to Hou and Picot (2004: 5), residential segregation results from the 'social distance' between the minority group and mainstream society. Minority groups prefer to live in ethnic neighbourhoods in order to stay either close to their own people or away from the dominant groups. Generally, residing in ethnic neighbourhoods helps immigrants to expand their inter-ethnic bonds, and social networks in Canada, and these are considered to be positive factors in accessing employment, and other opportunities such as housing and health care (Lochhead 2005: 36). On the other hand, researchers argue that residential segregation of minority groups makes them vulnerable to various forms of discrimination, and reduces their opportunity to gain language and work skills required for labour market integration (Hou and Picot 2004: 4-5). Preston and Murnaghan (2005: 69) suggest that "incomes of visible minorities who live in neighbourhoods dominated by visible minority groups are lower than those of visible minorities who live in multi-ethnic neighbourhoods". Through 
a comparative study on the settlement pattern of Indian Bengali and Bangladeshi people who share the same language and geo-political (colonial) background, Ghosh (2003: 4) suggests that Bangladeshi people possess strong community ties, and are more likely to settle in Toronto's ethnic neighbourhoods than are Indian Bengali people, and their (Bangladeshi people's) isolation from other ethnic groups results in limited employment opportunities. Hou and Picot (2004: 13) explain the impact of residing ethnic neighbourhoods as such:

The ethnic neighbourhoods may affect the socio-economic interaction both within a minority group and between the group and the rest of the society. Residential concentration enables the retention of ethnic identity and the maintenance of religious, educational, and welfare institutions that are crucial for the social interaction of the group. On the other hand, residential concentration of minority groups may result in social isolation and reduce minorities' incentives to acquire the host-country language or to gain work experience and educational qualifications.

The prominence of traditional cultural norms and ideologies is another aspect of ethnic neighbourhoods. Hunjan (1997: 14-15) notes that the lives of minority groups in ethnic neighbourhoods in Canada are more or less influenced by socio-cultural norms because they have a tendency to retain their own culture within the neighbourhoods. She further states that the retention of traditional culture in these neighbourhoods is often translated through re-enforcing patriarchal control over women's mobility and life style (ibid). Based on a study on women's employment status in Canada, Lahey (2005:3) notes that, "cultural attitudes affect incomes, types of work that are available, the work atmosphere and the many other factors that impinge on access and sustainability of women's paid work as well as on their incomes". However, there is a lack of study on the impact of 
settlement pattern, and neighbourhood culture on Bangladeshi, as well as other ethnic minority women's labour market integration processes.

From the above discussions, it is evident that minority women in Canada are facing systematic institutional and socio-cultural barriers, not only in entering the labour market but also in obtaining equal status within the labour market in relation to men and/or mainstream populations in both formal and non-standard job sector. Researchers argue that incorporating the voices of minority women at the policy and decision making level is the most crucial part of the socio-economic integration process of these women in Canada. Moreover, Canadian policy discourses are criticized because of their gender blindness, and generalized representation of the needs and requirements of minority immigrant women (Siemiatycki 2005: 3-4; Bakan and Kobayashi 2000: 2).

\subsection{Policy Constraints to Minority Women in Accessing Employment Opportunities}

A number of studies indicate that Canadian employment and social protection policies directly affect women's, especially minority women's, mobility outside the home and force them to accept home based and/or part-time non-standard jobs, which do not provide them economic empowerment (Tastsoglou et al. 2005; Pinder 2002; Day and Brodsky 1998; Doherty et al. 1998). Gendered and racialized norms in policy discourses also create differential situations for men and women and/or among women of different cultural and religious backgrounds, ages, levels of education, and marital status in relation to accessing labour market opportunities. In this regard, Tastsoglou et al. (2005: 
91) state that "Canadian labour market integration policies are insensitive to the distinct needs of men and women in terms of considering the dimensions of female and male identities, interpersonal and social relations, and access to resources during the processes of migration and throughout the period of settlement and integration". Therefore, it is necessary to analyze how government policies impact the socio-economic integration process of minority immigrant women.

\subsubsection{The Immigration Act 1978}

The Immigration Act 1978 categorized immigrants under three groups: economic class, family class and refugees. It is suggested that this categorization is rooted within human capital discourses of immigration policies (McLaren and Dyck 2004: 42). Human capital discourse promotes the "neo-liberal ideology of 'self-sufficient citizen', which is founded upon 'masculinizing' logics and visions of citizenship" (ibid). Under the Immigration Act 1978, economic class immigrants are constructed as masculine economic agents, who will contribute to the economy, and are assessed through the point system on the basis of age, education, occupation, work experience and knowledge of the English or French language (Belleau 2003: 94; McLaren and Dyck 2004: 42). Women, especially spouses, are constructed as either dependants of economic immigrants who are their husbands/partners or family class immigrants, who are sponsored by their husbands. The Immigration and Refugee Protection Act (IRPA) which came into effect in 2002, facilitates women to enter Canada as principal applicants through awarding more points for education than work experience, and considering women's reproductive responsibilities that restrict their work opportunities (Tolley 2003: 6). However, the 
majority of immigrant women belong to the dependant and family class categories and their educational qualifications and work experiences are not counted in the immigration process. Women spouses are not required to meet the selection criteria applicable to economic immigrants. Thus, immigration policy emphasizes the economic integration of points-tested economic class immigrants who are generally male. "As the human capital theory values individuals and their skills only if they are considered to be economically productive, family class immigrant women's lives do not form part of the social and national imagination of the state" (McLaren and Dyck, 2004: 50). Men, as economic class immigrants, have significant advantages in the job market owing to their better qualifications. According to Statistics Canada (2003, cited in Townson 2003: 27), low participation rates of immigrant women in the labour market indicate that the majority of these women came to Canada as dependants (spouses/family class immigrants) of economic immigrants (husbands/male family members) rather than as independent economic class applicants. According to Smith (2007: 73-75), women's entry to Canada as dependants of their husbands enormously affects their private (family), as well as public (socio-economic) life. Smith states (2007: 74):

Sponsorship arrangements can reinforce this message of ownership and entitlement, as the men control the sponsorship process. ... Husbands/partners often dictated what the women could and could not do, including obtaining employment or going to school, visiting friends, making phone calls, and even talking to neighbours. ... If a woman insisted on leaving her husband, she would run the risk of being isolated from her immigrant or ethnic community or even faced the risk of rejection from her immediate family.

The process of sponsoring wives, as family class immigrants, automatically puts power in the hands of husbands, who utilize the power to control women's access to family 
resources often through verbal and physical abuse (Cote et al. 2001: 35-36). The passive roles of women during immigration, and their limited knowledge of Canada's immigration system, enable their husbands/partners to use the sponsoring process against them. Consequently, women can become confused about their legal status in Canada and suffer from mental stress, isolation and social exclusion. Their 'transition penalty' remains longer than that of men, and their limited mobility and access to information and services, and limited engagement in civic activities hinder their abilities to take economic opportunities in the labor market (Topen 2007: 139). Thus, it is necessary to take into account the issues of family and dependant class women's specific socio-economic integration issues in further policy and planning.

\subsubsection{Canada Health and Social Transfer and Ontario Work Program}

In order to identify the impact of state policies on the labour market situation of minority women, it is imperative to discuss the attributes of the Canada Health and Social Transfer (CHST). In 1.996, the Government of Canada revoked the Canada Assistance Plan (CAP), and introduced the Canada Health and Social Transfer (CHST). Under the CAP, the Federal government was compelled to provide assistance to any person (permanent legal immigrants) in need, and automatically had to share 50:50 costs of social assistance and important social services with the provinces (Pinder 2002: 3; Day and Brodsky 1998: 1). Day and Brodsky (1998:1) suggest that the shift from the CAP to the CHST is an outcome of the general trend of reducing the federal government's contribution to social assistance programs. Through enacting the CHST, the federal government introduced 
block funds for social assistance and transferred control to the provinces in terms of regulating the spending in social services.

The CHST directly affected women ... especially minority women, single mothers, elderly women, Aboriginal women and women with disabilities ... because of the elimination of the federal government's funding for crucial social assistance including counselling and referral services, child care, child welfare programs, community development services, legal aid, and services for persons with disabilities. (Day and Brodsky 1998: 11)

The most adverse impact of the CHST is the inadequacy of affordable child-care facilities for women that either restricts women's participation in the labour market or doubles their work burden. According to the Royal Commission on Equality of Employment (RCEE), "child care is the ramp that provides equal access to the work force for mothers" (Abella 1984 cited in Doherty et al. 1998: ix). Access to affordable and reliable child-care is, thus, a crucial factor for immigrant mothers in terms of reducing the pressure of their domestic responsibilities and entering and remaining in the job market.

In the absence of federal funding, child-care is expensive and scarce, as it has to be provided by voluntary community-based groups or the private sector under the fragmented support of federal and provincial/territorial programs (Doherty et al. 1998: 9). After the enactment of the CHST, the Ministry of Community and Social Services announced Work Fare or the Ontario Works Program (OWP), which replaced the Welfare Assistance Program (WAP) for employable persons (Pinder 2002: 4). Under the OWP, all employable persons, including mothers of infants and single mothers, are required to have employment in order to get social welfare assistance. In this situation, 
child-care facilities become more crucial than ever for immigrant mothers. Because of the scarcity of regulated and affordable child-care facilities and the compulsory workfare program, immigrant mothers do not have any choice but to accept part time and/or home based work (ibid). According to Orloff (2001, cited in Pinder 2002: 84), "the lack of child care and mandatory work fare [Work Fare program] is the ultimate act of institutionalized gender discrimination". Moreover, under the OWP women are not considered eligible to receive social assistance if they share expenses with husbands/partners. Thus, in the social welfare program it is 'taken for granted' that women and children have access to male income (Pinder 2002: 20). Day and Brodsky (1998: 135) argue that the social support policies of Canada are framed by gendered norms which "assume that women's economic inequality is natural, that women will be looked after inside the family, and that the poverty of women who are not connected to men can be ignored".

From the labour market situation of minority women in Canada, it is clear that they need assistance and social protection from both public and private (voluntary) sector in order to access labour market opportunities, and attain a sense of belonging. The European Union described the importance of social protection as: "social protection provides not only safety nets for those in poverty; it also contributes to ensuring social cohesion by protecting people against a range of social risks. It can facilitate adaptability in the labour market and can thus contribute to improved economic performance" (EC 1999 cited in Rooney et al. 2003: 1). Kershaw (1997: 2) emphasizes the role of the state in distributing the opportunities and resources, through considering unequal positionalities of different groups of people within the socio-economic structure, and suggests that efficient state 
policies can indeed pave the way for women to discover and develop their capabilities. It is evident from discussions on two major policies of the government that the state's role in providing social assistance and employment opportunities to women, especially minority women, who are disadvantaged in the labour market, is minimal in Canada. The absence of state provided social protection along with other forms of gender and racial discrimination exposes minority women to social and economic insecurity and uncertainty. Gender insensitive immigration and social support policies in Canada not only restrict minority women's entry into the labour market, but also hinder their potential to work as economic agents.

\subsection{Voluntary Organizations and Social Networks: A Promise for Change?}

The failure of government policies to capture the specific problems and needs of minority women lays the ground for non-government voluntary organizations to play a prominent role in promoting their (minority women's) rights and empowerment. CBOs are considered as an alternative body to initiate bottom-up approaches at the community level to help understand and represent specific labour market challenges of minority women of different ethnic backgrounds. Cottrell (2007: 136) suggests that community-based voluntary organizations have the capacity to incorporate the voices of minority women and represent their specific problems and requirements. The voluntary sector, thus, can provide minority women with a platform to express their specific needs, increase their sense of belonging, boost self-esteem and enhance feelings of empowerment. Another characteristic of voluntary organizations is that they enhance social integration through 
fostering minority immigrants' civic engagement and community interactions (Berger et al. 2005: 1). Involvement in community life, civic participation and social engagement through different voluntary organizations, is beneficial in terms of combating poverty and taking advantage of labour market opportunities (Lochhead 2005: 36). As Anucha et al. (2006: 6) state, "social capital including civic participation is shown to connect individuals to potential economic partners and to provide high quality information (e.g., job leads, strategic information) and recommendations". Strengthening social networks and/or voluntary connections between individuals and communities is an essential component for achieving social cohesion at both the group and individual level (Tossutti 2003: 32).

There are a number of CBOs in Canada that are now actively working to ensure the successful settlement and socio-economic integration of minority immigrant communities. Many of these voluntary organizations focus on the labour market integration issues of minority women, and have initiated mentoring programs, workplace acculturation training and networking opportunities for minority women to improve their labour market situations. However, there is a gap in the flow of information among different stakeholders in Canada, which is crucial in employment equity and diversity initiatives (Lochhead 2005: 37). Lochhead (ibid) suggests that CBOs should develop partnerships between communities, business, labour, educational institutions and governments in order to enhance knowledge of diversified labour market problems through sharing and exchanging information. It is also necessary for $\mathrm{CBO}$ to initiate cross-cultural training 
and awareness programs for employers to assist them in assessing foreign credentials and reaching potential immigrants.

In spite of the willingness of non government CBOs to support minority women's successful socio-economic integration, they sometimes fail to implement their programs because of several institutional constraints (Wallace and Frisken 2004: 151; Berger et al. 2005: 14). One of the main constraints is the contradictory strategies of CBOs and municipal agencies to address issues of minority immigrants. Municipal agencies usually understand their mandate as serving the entire population of an area; on the other hand, CBOs give priority to the needs and requirements of one or more specific groups (Wallace and Frisken 2004: 151). The dependency of CBOs on the municipal government reduces the opportunity to form equal partnerships with municipal government. Moreover, municipal government and other funding agencies have a tendency to control the activities and initiatives of CBOs. It is important for municipal government and voluntary organizations to work together for their mutual interests but that is not happening in Canada (ibid). Several studies also identify a significant lack of integration and communication between different voluntary organizations (Berger et al. 2005: 14). Thus, the roles of CBOs in strengthening minority women's empowerment in terms of accessing not only employment opportunities but also other social supports are ambiguous. 


\subsection{Conclusions}

In this chapter, I have discussed the overall labour market situation of visible minority women in Canada. It is evident that minority women are the victims of various sociocultural and structural barriers that restrict their integration into the labour market. Gendered and racialized ideologies of Canadian society are the root cause of their alienation from the employment sector. Often the ideologies of women's roles and restrictions in their mobility that are embedded in the minority women's culture compound the labour market barriers for various ethnic groups. However, the major policy discourses ignore these socio-cultural issues, and direct the blame to minority women's inefficiency in communication and work skills. Immigration and social support policies about immigrant women's problems and requirements are inefficient in addressing the specific issues of different ethnic minority women. As a result, minority women are increasingly suffering from poverty, unemployment and a health crisis. Under such circumstances, CBOs are considered as key players in Canada in promoting grassroot movements of minority women to establish their rights and enhance their capacity to overcome labour market constraints. But, the missions of CBOs are also subject to bias and limitations that hinder their capacity to empower minority women in practical terms. The context of minority women's empowerment in terms of accessing employment opportunities, therefore, is a vital issue because the gaps between theories and practice of empowerment are often glossed over by the assumptions of both

government and non-government sector. In the next chapter, I discuss the theoretical 
concepts of women's empowerment, and how I apply the concepts of empowerment in order to analyze Bangladeshi married women's labour market integration process. 


\section{Chapter Three: Concepts of Women's Empowerment: Theoretical Framework of}

the Study

Empowerment is more than participation. It must include the processes that lead people to perceive themselves as able and entitled to make decisions (Rowlands 1997 cited in Parpart et al. 2002: 11).

\subsection{Introduction}

The concept of women's empowerment is rooted in the context of gender inequalities that exist in various realms, including economic, social, familial, ideological, demographic and political. Feminist scholars suggest that, in order to level gender inequalities in various realms of society, it is crucial for women to increase their own power by augmenting their self reliance and inner strength (Hossain and Tisdel 2005: 439). In a broader context, the empowerment of women encompasses not only overcoming gender inequalities, but also overcoming all forms of inequality in society. "Empowered action means coming out of the alienation, marginality and sense of irrelevance that are the lot of those who have no influence over what influences them" (Sadan 1997: 17). Women's empowerment in relation to their participation in the economic sector is considered a fundamental factor of their overall empowerment within a patriarchal society (Mitra 2007:

51). Considering Bangladeshi married women's relative powerlessness and disadvantaged situation in the Canadian labour market, I have emphasized how Bangladeshi married women in Toronto seek to gain access to labour market opportunities. This allows me to illustrate Bangladeshi married women's empowerment 
process, through taking into account the socio-cultural aspects of their labour market experience. This chapter aims to introduce the basic theoretical framework for my research on the labour market integration process of Bangladeshi married women. The chapter is organized into two sections. In the first section, I discuss the debates surrounding women's economic independence and its impact on their overall empowerment process, using the perspectives of liberal, Marxist and poststructuralist feminists in relation to the importance, and impact of women's labour market participation. In the second section, I outline how the process of empowerment can be understood and analyzed. I also discuss how I have drawn on the theoretical perspectives of empowerment to analyze the labour market integration process of Bangladeshi married women.

\subsection{Women's Economic Empowerment: the Meanings and the Debates}

The most straightforward meaning of the term 'empowerment' derives from a position of powerlessness. As Carr (2003: 13) states, "the point of departure in the empowerment process is a position of human misery, whether it is termed powerlessness, oppression, or deprivation". Therefore, an empowerment approach is based on the assumption that, "the capacity of people [i.e., in this case women] to improve their lives is determined by their ability to control their environment, namely, having power" (Hasenfeld, 1987 cited in Busch and Valentine 2000: 83). According to Kabeer (2003: 170), empowerment is the process through which "those who have been denied the ability to make choices acquire such an ability". Zimmerman (1995: 583) defines empowerment as "a series of 
experiences in which individuals learn to see a closer correspondence between their goals and a sense of how to achieve them, gain greater access to and control over resources". In 1997, a paper presented at the Lund seminar on women's empowerment and demographic processes stated that:

[Women's] empowerment is about transformation of the power relations; that it includes both control over material resources, and a change in self-perception and confidence in one's self; that it can be viewed as an outcome and a process; and that women's empowerment involves the transformation of power relations at four different levels: the household/family, the community, the markets and the state. (IUSSP, 1997 cited in Hossain and Tisdel 2005: 439)

The above definitions suggest that women's empowerment is a multi-dimensional concept, which is manifested in different areas of women's lives. There has been a growing debate about the assumption that women's engagement in economic activity can be translated into economic empowerment at different levels in society. Women's economic activity is mainly measured by their involvement in formal and/or informal employment that brings cash income (Nachtwey 2001: 2). The importance of women's participation in paid work is influenced by the discourses that separate women's 'work' from 'economic activity'. Boserup (1970: 16-17) is the first scholar to suggest that many women in the Third World countries (global South) do most of the agricultural work and, therefore, their economic contributions need to be recognized. But women's economic productivity in agricultural and other informal sector has been neglected in various societies, and also in policy making processes. According to the UN definition, “"work' involves 'the production of economic goods and services which should include all production and processing of primary products, whether for the market, or for barter, or for own consumption" (Dutta 2005: 15). This definition of economically productive tasks 
includes most of the domestic chores and agricultural labour of women. However, the traditional definition of economic activities emphasizes the activities carried out for 'pay or profit' (Raju 1993: 2). This notion eliminates women from the economic domain and introduces conflicts between women's reproductive and productive roles.

Liberal feminists are the pioneers who argue that women do not get appropriate recognition for their home-based economic activities, as those tasks are considered to be an extension of women's household chores (Mohanty 1991). Therefore, it is crucial for women to have visibility in the formal economy, through labour market participation. The need for women to integrate into the economic sector is emphasized initially in the theory of modernization. An assumption of modernization theory is that, in male dominated traditional societies, women have modest status that limits their potential to develop self-esteem and gain autonomy. The modernization process creates a favourable environment for women to advance their status within the society by obtaining education and employment opportunities. Safa (1996, cited in Nachtwey 2001: 24) states, "by expanding educational and professional opportunities, modernization would create avenues for women to gain the skills and training necessary to improve their socioeconomic status". But, liberal feminists have criticized the assumptions of modernization theory, and suggest that the modernization process cannot ensure the improvement of women's status, as women have unequal access to resources such as education, employment, credit, and skills development programs (Nachtwey 2002: 25). The notion of modernization is focused on the economic integration of women in Global South and emphasizes their economic independence in terms of fulfilling basic needs, such as food, 
child care and health care. Liberal feminists argue that women's participation in the labour market needs to be analyzed not only in terms of their ability to fulfil basic needs, but also in terms of their capacity to assert strategic needs, through which they may be able to enhance their potential and obtain control over their lives (Mitra 2007: 31-32). The concepts of liberal feminists, therefore, indicate a direct relation between women's labour market participation and the possibility of empowerment.

Liberal feminists suggest that women's involvement in paid work improves the material standard of women's lives and, thus, decreases their dependence on male partners. Women's labour market participation also increases the possibilities of challenging traditional gender roles within and outside the household. Sen (1999 cited in Mitra 2007: 31) states that women's work outside the home is crucial for increasing their agency in other areas, such as the family, health care, reproductive control and social and political life. Blumberg (1991 cited in Mitra 2007: 51) states, "the greater a woman's absolute and relative control of economic resources - most commonly income - the greater is her efficacy and empowerment in a variety of areas including self esteem".

Several studies suggest that women's economic power enables them to negotiate a more equitable division of household labour. This notion implies that women's economic contribution to the family's welfare brings respect for women within the household, which, in turn, gives them the opportunity to assert their own interests and negotiate with regard to domestic responsibilities (Nachtwey 2001: 6). Sassen (1996: 27) suggests that women's opportunity to make decisions at the household level increases their self worth 
and confidence, which leads to women's greater participation in the public sphere. Equality in the domestic sphere stimulates women to take part in political debates and enhances their awareness regarding "common issues and policies that concern their status as workers and as women" (Nachtwey 2001: 6).

Safa (1996 cited in Nachtwey 2001: 62), however, argues that women's wage labour has less potential to contribute to the political arena and work place because they are still considered to be complementary wage earners. Belarbi (1991 cited in Nachtwey 2001: 68) states that at the household level, women's economic contributions and interests in decision-making are considered to be a challenge to male authority. Sen (1999 cited in Mitra 2007: 30) notes that the interpretation of women's employment is conditioned by the cultural context within which factors such as class, religion, ideology, belief and family structure, significantly affect women's employment experience. Marxists and poststructuralist feminists have made a significant contribution in analyzing the sociocultural contexts of women's work, and its broader implications in different areas of their lives, as discussed below.

Marxist feminists emphasize the gendered patterns of labour recruitment and the exploitation of female labour in the economic sector. Marxist feminism argues that modernization and capitalism induce gender hierarchies in the labour market in order to maximize capital accumulation (Pyle and Ward 2003: 462). The process of capitalism utilizes gendered and cultural norms to maintain women as a flexible labour force, and confines them to low-paid and low-skilled positions. For example, in developing 
countries, low-paid female labour is the key factor to maximize profit at minimum production costs, both for domestic and transnational companies (Kabeer and Mahmud 1992: 145). Absar (2002: 4) suggests that women are assigned to specific types of jobs (low-skilled and labour intensive) in the industrial sector, based on assumptions of their appropriateness, not on their previous experience. Marchand and Runyan (2000: 17) note that the feminization of low wage labour rationalizes 'the 'flexibilization' and 'casualization' of labour to keep labour costs down and productivity up in the name of the free trade, global competitiveness and economic efficiency". Mills (2003: 43) states that women's concentration at the lowest level of both pay and authority reveals "the hegemonic capacity of patriarchal norms to define women's labour as not only "cheap" but socially and economically worthless (and therefore less worthy of equitable pay and other treatment) that makes a gendered labour force so crucial to the accumulation strategies of global capital".

Poststructural feminists emphasize the importance of considering class, race, ethnicity and historical differences among women in analyzing their subordination in the labour market (Chowdhry 1994: 166) Poststructural feminism suggests that all women are not positioned at the bottom of the wage scale, as more vulnerable groups (such as rural migrants, minority immigrants) are chosen for cheap labour. Therefore, exploitation of women is segmented by class, ethnicity, race and other socio-economic factors (Mills 2003: 44). The nature of gendered and racial attitudes towards minority women in the Canadian labour market is an example of discrimination against vulnerable groups. Poststructural feminism also suggests that, along with women's relative positionalities in 
society, it is necessary to conceptualize the socio-economic and cultural contexts in which the gendered pattern of labour recruitment takes place (Sinclair 1991: 2). In this regard, the rationale for women's labour market participation is a key measure in understanding the socio-cultural contexts of labour market mechanisms. Nassar (1999 cited in Nachtwey 2001: 72) notes that most of the women in Egypt consider paid work "solely as a means of family subsistence and that very few see work as a contributing factor to their own independence". Kibria (1998: 5) suggests that insolvency and the absence of a male breadwinner are the main characteristics of wage-seeking women in Bangladesh. Thus, women's employment is often linked with male unemployment and desertion (through divorce, or death). This situation is widespread in the lives of immigrant women in Canada. It is evident that, in most cases, migrant women seek work not for improving their financial condition or social status, but rather for the survival of their family. Financial struggles of their family also influence them to accept any type of work, and spend their own earnings to cover household shortages (Salway et al. 2005: 345). This situation reduces the significance of the status of a woman as an important income-earner in the society. As Salway et al. (2005: 316) state, "the socio-cultural construction of women's waged work as secondary, inferior and justifiable only in times of economic need, is supported by structural and ideological forces operating at the level of the household, the labour market, and the wider community".

Women's identities as wage earners also introduce various forms of struggles vis-à-vis their families and social life. Safa (1996 cited in Nachtwey 2001: 40) notes that women's access to income has resulted in "some men shrinking their responsibilities to the family 
and taking advantage of their wives' incomes". As stated earlier women's double and often triple burden syndrome is another issue of their labour market participation. Bhattacharyya (1985: 206) notes that women are disadvantaged in the existing market structure because they have to carry out domestic work and child-care responsibilities, and in most cases the burden of housework prevents women from attaining education and skills upgrading training, which can provide them better bargaining power in the labour market. Thus, "culturally and socially dominant values that define women primarily in terms of their domestic and reproductive roles may dampen the empowering consequences of women's employment experiences" (Nachtwey 2001: 69).

From the above discussions, it is evident that there are numerous debates among social scientists on the interrelationship between women's socio-economic empowerment and their access to employment and income. Yet, social scientists agree on one point, that women's economic empowerment is essential to overcome poverty and economic dependency on men. Recently, researchers have emphasized strengthening women's ability to overcome labour market constraints. The main theme of this analysis is that women are not victims but social actors, who also challenge or renegotiate the authority of others. Mills (2003: 48) suggests that gender inequalities in the labour market are not only sources of exploitation, but also can open new possibilities and new understanding for women themselves, and create a new arena for contestation and struggle. In this regard, women's mobilization through grassroots organizations is emphasized in a number of studies. Neples and Desai (2002 cited in Mitra 2007: 30) note that women's community activism has provided "the space for women to assert their own agency to 
counteract the uneven development associated with global, political and economic restructuring". Mohanty (1995 cited in Mitra 2007: 30) illustrates that, in many countries, women have successfully established their rights in both the domestic and public spheres, through grassroots movements.

My own standpoint, in relation to my research, is influenced by the concept of poststructuralist feminism. I put emphasis on understanding Bangladeshi married women's labour market integration on the basis of socio-economic and cultural contexts in which the gendered and racialized pattern of discrimination takes place. I aim to understand Bangladeshi married women's own expectations and perceptions that they attach to their labour market participation. As Sinclair (1991: 2) states, "comparative analysis of the conditions under which women work and the ways in which their work is defined is necessary both for explaining inequality and for shedding light on the ways in which women's inferior positioning in the workforce is reinforced or can be challenged". However, it is essential to understand what factors influence the process of empowerment in relation to women's labour market participation.

\subsection{Understanding the Process of Empowerment}

Understanding the process of empowerment is the main goal of my research. How can Bangladeshi married women's empowerment be analyzed? Based on what parameters can their empowerment in accessing employment in Toronto be understood? These questions have led me to scrutinize the theoretical concepts of empowerment. The basic 
foundation of an empowerment process is that it is not a linear process, but rather a continuous and reflexive process of gaining power and control (Carr 2003: 11). Staples (1990: 31-32) notes that, "empowerment is a dynamic, dialectical and ongoing process ... [that] strengthens the ongoing capacity for successful action under changing circumstances". Kieffer (1984 cited in Carr 2003: 13) describes empowerment as a "cyclical 'praxis' of action and reflection that permits one to identify the cycle of problems, deconstruct problems, social action and further reflection". Gutirrez (1990 cited in Carr 2003: 10) suggests that "empowerment is a process of increasing personal, interpersonal and political power so that individuals, families and communities can take action to improve their circumstances". Carr (2003: 13-17) notes that women go through a number of stages to gain empowerment, such as identifying the area of deprivation, developing awareness, building interpersonal and collective consensus, understanding the political dimension of the personal problems and taking actions for structural reform. Thus, Carr emphasizes the importance of individual and collective dimensions of empowerment in order to enforce organizational/structural reforms. Carr (2003: 18) suggests that empowerment at an individual level can be achieved through collective actions/movements because a collective consensus creates pressure on the existing institutional systems. A "group offers the opportunity to find power in unison that is more effective than most solo performances and thereby acts as a forceful vehicle in relation with larger systems and communities" (Carr 2003: 19). Carr (2003: 15) also notes that women can identify the political perspectives of their personal problems through sharing oppressive experiences. The link between the individual and the collective removes the separation between the personal and the public sphere which is, "essentially a social 
means of isolating women and separating them from communities which could validate their views about life and society" (Sadan 1997: 138).

Kabeer (2003: 170) suggests that one should look at four interrelated aspects to understand the interplay between individual and collective dimensions of empowerment. These three factors are: agency, resources, structural barriers and achievements. Kabeer (2003: 174) states that women should have access to resources (human capital, social capital and networks) and have capacity and aspiration (agency) to utilize those resources both individually and collectively to reform (achievements) the structural barriers. Reforming and/or overcoming the structural barriers that constrain women's equal rights in various sectors of society, is thus, the ultimate form of empowerment. Women's agency and access to resources are the preconditions for enabling an empowerment process that in turn, facilitates women to overcome the structural barriers. To understand the context of empowerment in relation to the labour market integration process of Bangladeshi married women in Toronto, I analyze their labour market barriers, their agency, access to resources, and nature of achievements. In this regard, it is important to discuss in more depth the concepts of agency, resources and achievements, and how I have addressed these concepts in my research.

\subsubsection{Agency}

People are considered to have 'agency' when they act "as potential agents of their own history", or experience a sense of "cognitive liberation" (Dugan and Reger 2006: 469). Agency includes both "observable actions (decision making, protest, bargaining and 
negotiation), as well as the meaning, motivation and purpose that individuals bring to their actions" (Kabeer 2003: 171). Therefore, the agency of women is necessary in order to create the possibilities of reforming the institutional structure that creates and promotes gender inequalities. This notion implies the involvement of women in various activities to overcome their sense of powerlessness (Busch and Valentine 2000: 83). Agency initially emerges from women's realization of their deprivation and their awareness of an interest in changing the deprived situation. In this regard, women's own perception and interpretation of their problems play a significant role to motivate them in overcoming barriers and taking action (Hossain and Tisdel 2005: 440). Women's positionality within the social structure is considered a vital factor in their agency formation. Therefore, women's sense of powerlessness needs to be looked at in relation to their multiple positionalities that shape their attitudes and desires for overcoming deprived situations. Analyzing the agency of Bangladeshi married women is, thus, crucial to understand their perceptions regarding their labour market integration problems, their awareness in overcoming the problems, and the nature of initiatives that they take to express their concern and awareness. In analyzing Bangladeshi married women's perceptions and agency, I consider their level of education, age, previous work experience in Bangladesh and/or in Canada, family structure (i.e., presence of infant child, husband's employment status) and attainment of Canadian education/training as key indicators of their positionality in the social structure. Therefore, I identify how different positionalities of Bangladeshi married women produce different sets of concerns and actions to deal with their labour market problems. My main argument is that women's agency is not a homogeneous and universal attribute, but, rather, it is a constitutive attribute that 
develops through the interplay of different sets of factors (i.e., the positionality of women, cultural and religious norms) and, thus, women's priorities, concerns about their deprivation, and their actions vary. The agency of women also takes shape through the influence of existing socio-economic structures and institutional systems that can both enable and restrict the mobilization of their agency.

\subsubsection{Resources}

Kabeer (2003: 172) defines 'resources' as the medium of power that mobilizes the agent to take an active role in structural reform. Resources are "distributed through the various institutions and relationships in a society" (ibid). Kabeer emphasizes the roles of social capital (social networks and grassroot organizations) in strengthening and mobilizing an individual's agency. Lin (2005: 4) defines social capital as "resources embedded in one's social networks, resources that can be accessed or mobilized through ties in the networks". Coleman (1990 cited in O'Brien and O' Fathaigh 2004: 3), one of the pioneers of social capital theory, suggests that social capital forms though relations between individuals, and enables individuals to achieve those goals that cannot be achieved independently. Putnam (1995: 66) emphasizes the pluralistic aspect of social capital, and suggests that social networks and civic engagement enable people to tackle problems that affect the socio-economic life of a particular group of people, such as poverty, unemployment and crime. Putnam (ibid) also suggests that social capital provides the ground for people to cooperate for mutual benefit through involvement with voluntary organizations. Both Coleman's and Putnam's ideas are reflected in concepts related to women's empowerment. As Parpart et al. (2002: 4) state that women's 
empowerment must be understood as both individual conscientization, as well as the ability to work collectively in order to bring about change. In relation to empowerment, the outcome of resource mobilization leads to the development of organizational networks to initiate active roles (Perkins and Zimmermann 1995: 570). Building organizational networks involves the interaction between individual conscientization (power within) and collective action. Mainly grassroot and community-based voluntary organizations act as a catalyst for establishing networks and relationships among people and promoting collective needs (Rankin 2002: 4). In my research, I have focused on Bangladeshi married women's involvement with CBOs, their individual and collective consensus regarding labour market constraints, and their actions through the organizations to overcome labour market barriers. In this regard, I have also examined how Bangladeshi married women's perceptions and cultural ideologies influence their initiatives and the nature of their participation in organizations.

Another area of investigation relates to the roles of community-based organizations in enhancing social ties and networks, which is a key factor in accessing employment (Lin 2005: 4). As Ooka and Wellman (2003: 2) state,

Social networks are an important and often successful means of searching for jobs. They provide network capital, a form of social capital that links people interpersonally to job opportunities. Accordingly, social contacts within and outside of ethnic communities in job searches can produce, reproduce, or overcome inequality along racial/ethnic lines.

Ooka and Wellman (ibid), thus, emphasize the importance of both inter and intra-ethnic social networks. Social scientists describe inter and intra-ethnic networks as bridging and bonding networks respectively (Putnam 2000 cited in Anucha et al. 2006: 3). A bonding 
network means "a 'bonding" function between 'like' individuals (intra-ethnic), whilst a bridging network means a 'bridging' function in which individuals develop relationships and networks with individuals different from themselves (inter-ethnic)" (Berger et al. 2005: 2). Bonding networks tend to strengthen group homogeneity and identity, whilst bridging social networks expand the knowledge and adaptability of individuals. Research evidence suggests that bridging networks expand the scope of different job opportunities for new immigrants, and, on the other hand, "in group" and/or bonding networks often restrict new immigrants to low paying job sector in Canada (Anucha et al. 2006: 3). Anucha et al. (ibid) emphasize that bonding networks may assist immigrants to access to certain jobs, but "it may lead to structurally restricted categories of work that create inequality between groups". Dobrowolsky and Tastsoglou (2008: 83) suggest that access to both bonding and bridging social networks is crucial for minority women in order to overcome labour market constraints and cross-cultural differences. Therefore, it is important to scrutinize the roles of CBOs in enhancing both intra and inter-ethnic bonds. I also place emphasis on the gendered dimensions of social networks. Feminist researchers suggest that gender differences in accessing social networks stem from the "dissimilar social structural locations" of men and women that give different opportunities for men and women to develop and utilize social ties (Anucha et al. 2006: 10). "Social networks cannot be free from inequalities that arise from structural power differences in society that contribute to the many disadvantages women experience in different spheres of their life course because "power relations are rooted in the system of social networks" (Foucault 1982 cited in Anucha et al. 2006: 1). Dobrowolsky and Tastsoglou (2008: 80) suggest that women's social networks emerge on the basis of their 
care-giving, food-related and faith-based activities; thus reflecting their culturally assigned care giving roles. Hence, it is important to investigate whether the networks of Bangladeshi married women are based on their gendered roles. In this regard, I discuss the initiatives that these women have taken through the assistance of voluntary organizations (CBOs) to gain access to employment and income. I also analyze the potential of their initiatives to gain a stable income source.

\subsubsection{Achievements: Overcoming Structural Barriers}

The final outcome of an empowerment process is 'achievements'. "In relation to empowerment, achievements have to be looked at in terms of both the agency exercised and their consequences" (Kabeer 2003: 173). Stromquist (2002: 29) suggests that achievements in an empowerment process are associated with 'conflicts', which emerge at two levels: "externally, with the surrounding institutions that maintain the established order in society and internally, by the positionality of women's need". Parpart et al. (2002: 4) describe that, an empowerment process is both enabled and constrained by the existing institutional structure of power. Contemporary feminists explain the nature of women's powerlessness "as a manifestation of institutional and structural sexism and the resulting alienation from oneself" (Carr 2003: 14). To be empowered, it is necessary for women to challenge existing power relations and institutional structures that support gender discrimination (Baliwala 1994 cited in Mitra 2007: 50). Molyneux (2001: 152) suggests that reforming the institutional structures is largely dependent on women's interests and motivations. Molyneux introduces the term 'practical' and 'strategic' gender interests to analyze the motivation of women's active roles in social movements. According to 
Molyneux's (2001: 152-153) view, 'practical' gender interests involve "the satisfaction of needs arising from women's placement within the sexual division of labour" and 'strategic' interests "claim to transform social relations in order to secure a more lasting repositioning of women within the gender order and within society at large". Ray and Korteweg (1999: 2) explain Molyneux's concept as:

Practical gender interests arise from women's position in the sexual division of labor and tend to involve struggles not for liberation but for the ability to fulfill their roles as wives and mothers. On the other hand, strategic gender interests, seek to change the rules under which women live, and can be arrived at only after practical interests have been taken into account.

According to Molyneux's concept, Third World women's grassroot movements (for food, water supply and wage increases) are considered practical, whereas middle class women's movements (for land ownership rights and equal employment opportunity) are considered strategic (Ostergaard 1992: 172). Some scholars suggest that the ability of women to make strategic choices is the most effective measure that leads them towards empowerment (Kabeer 1999 cited in Mitra 2007: 49). However, Molyneux's notion is criticized based on the fact that, a sharp distinction between 'strategic' and 'practical' gender interests is unrealistic. It is argued that practical (poor women's interests) and strategic (middle class women's interests) interests "are not always self-evident and do not 'emerge automatically' from a structural position but rather are created in the process of struggle" (Ray and Korteweg 1999: 3). Yet, the concept of practical and strategic gender interests implies the necessity of taking into account the diversities in women's needs and interests while exploring their efforts at empowerment. Through bringing in the positionalities of Bangladeshi married women, I focus on the diversities of their 
perceptions, concerns and interests in relation to their labour market integration. As stated earlier, in relation to empowerment, achievements mean overcoming constraints through challenging and/or reforming the existing structure that creates power blocks, and powerlessness for a particular group of people. Thus, in order to analyze Bangladeshi married women's empowerment (achievements), I examine the extent to which they succeed in overcoming their labour market constraints. In doing so, I emphasize the outcomes of organizational initiatives and collective actions, in terms of reforming the gendered and racialized pattern of labour recruitment.

One significant insight of my study is that it discusses general perspectives on the concept of empowerment in relation to a particular context, through raising the specific labour market issues of Bangladeshi married women. The study, thus, identifies how Bangladeshi married women's positions within the society and their cultural and religious background and perceptions, shape the meaning and nature of their empowerment. Exploring particular circumstances is an effective means, not only to document the experience of a group of people, but also to contribute to the development of theory. Conducting specific case studies is useful to better understand the broader social processes that structure the experience of a particular group of people (Rose 2001: 9). Study of a particular group's experience, therefore, "can be used to develop a theoretical model, and then to see if this model applies to cases that have some structural similarity but are different in details" (ibid). Thus, exploring the context of Bangladeshi married women's labour market experiences has the potential to expand the theoretical understanding of women's agency and structural constraints, their access to resources, 
and the nature of their achievements in relation to socio-economic integration in Canada. By doing so, the study also provides a basis to explore and compare the labour market experiences of different groups of immigrant women in Canada.

Another significant element of the study is that it focuses on analyzing the labour market situations of Bangladeshi married women and relevant issues on the basis of their own points of views which is highly emphasized in the contemporary literature. It is suggested that the multiple facets of an empowerment process can better be understood through women's own interpretations of their experiences across class, race and ethnicity. According to Parr (cited in Busch and Valentine 2000: 83), the term 'empowerment' should be portrayed as the "ability to speak one's own truths in one's own voice and participate in the decisions that affect one's life". As Hossain and Tisdel (2005: 440) state, "women themselves are the best judges of their own well-being or status in the society. Therefore, a proper assessment of the empowerment of women, requires an understanding of how women, themselves view their positions vis-à-vis men, at the individual stage through the greater societal level". Through my research, I present the voices of Bangladeshi married women in Toronto, whose voices have not been included, so far, in the academic literature.

\subsection{Conclusions}

This chapter discusses the theoretical concepts of women's empowerment, and explains why and how I have applied these concepts in analyzing the labour market integration of 
Bangladeshi married women in Toronto. The term empowerment means the ability of an individual or a group to overcome deprivation and inequalities. In this study, the term mainly implies overcoming gender inequalities, as well as other forms of inequality, that exist in different spheres of society. Women's participation in the economic sector is given huge importance in the empowerment literature. Liberal feminists, especially, identify women's access to employment as the most vital factor in overcoming gender inequalities. However, Marxist feminists argue that gendered ideologies are also manifested in the economic sector. As a result, women are considered as complementary sources of labour and are mostly concentrated in low-paid, non-standard job sector. Poststructural feminists suggest that, in order to understand women's disadvantaged situation in the labour market, one must look at class, race, ethnicity and historical contexts along with gender differences. Contemporary researchers emphasize the importance of strengthening women's ability to overcome labour market barriers, as well as other forms of inequalities. Women's self-improvement and collective movements through organizational associations are identified as a powerful medium of gaining empowerment. However, the process of empowerment needs to be understood and analyzed considering the practical context in which women's own views, expectations, sources of assistance and cultural constructs shape the nature and course of the empowerment process. Analyzing the empowerment process through the practical experience of people also opens new channels to examine and expand the theoretical perspectives of empowerment. I frame the analysis of Bangladeshi married women's empowerment in accessing employment in Toronto through incorporating the sociocultural context of their labour market experience. For this purpose, I explore the 
perceptions of Bangladeshi married women, and illustrate their labour market integration experience through their narratives. The next chapter discusses the methodologies that I have adopted to collect and interpret the necessary data for my research. 


\section{Chapter Four: Methodology of the Research}

Knowledge construction involves editing in and editing out, holding an abeyance, choosing and reflecting, connecting and disconnecting, all part of the process of theorizing (Raghuram and Madge 2006: 278).

\subsection{Introduction}

In the first chapter, I mentioned that the study methodology had been framed in connection with poststructuralist feminist concepts that advocate incorporating the voices of the participants in order to explore their experiences through qualitative research methods. In this chapter, I elaborate on the methodological framework of the study, and issues relevant to the research process. The aim of this chapter is to provide an idea of how the research data were gathered and interpreted to address the inquiries (objectives) of the study. For this purpose, I organize the discussion of this chapter into five sections. In the first section, I illustrate the rationale for using qualitative research methods in my study. In the second section, I discuss the theoretical concepts of maintaining the validity of qualitative data through a critical research practice. In this regard, I describe my own positionality in relation to the research participants, subjectivity, and power associated with the research, by reflecting on my field research experience. In the third section, I outline the methods of collecting data in detail. In this section, I describe the rationale and the process of conducting focus group discussions with Bangladeshi married women, participant observation in a $\mathrm{CBO}$, and interviews with $\mathrm{CBO}$ workers. In the fourth section, I illustrate the ethical issues of data collection and the measures that I adopted to 
minimize risks to the participants. In the fifth section, I explain the process of data analysis and interpretation.

\subsection{Qualitative Methodology}

Historically, feminist scholars have tended to use multiple and innovative qualitative methods, such as ethnographic studies, interviews, and focus group discussions to collect empirical data, as these methods do not ignore the complexities of life, but explore these complexities through engagement (Dwyer and Limb 1991 cited in Dutta 2006: 53). Qualitative methods are appropriate for my study as these methods, especially open ended questions and discussions, provide the room to capture a participant's feelings and experiences. I have adopted qualitative methods (focus groups, interviews and participant observation) because of their ability to "explore individuals' experiences and how these experiences are influenced by their position in the social structure" (Mullen 2005: 47). Hunjan (1997: 67) states: "by using qualitative methods to discover a person's experience and how s/he understands this experience taking into account contextual factors (culture, position and time) a researcher may gain a more holistic understanding of the phenomenon of interest". Qualitative methods help to explore two important questions that are relevant to my study, namely, "what is the shape of societal structures and by what processes are they constructed, maintained, legitimized and resisted?" and, "what are individuals' experiences of place and events?" (Winchester 2000: 4-5). These questions are relevant to understand the labour market integration experience of Bangladeshi married immigrant women within the context of Canadian society. Rose 
(2001: 9) suggests that qualitative research not only documents the experiences of a group of people, but also by exploring the answers to what, why and how, particular case studies contribute to theory development. Conducting specific case studies, therefore, is useful to better understand the broader social processes that structure the experiences of a particular group of people.

A fundamental issue in representing the labour market integration experience of Bangladeshi married women is preservation of validity and rigour in the data collection and interpretation process. The term 'validity' "refers to the plausibility of relationship between data and concepts" (Rose 2001: 33). This notion implies that there has to be transparency in the data collection and interpretation process, and "quality control throughout the stages of knowledge production" (Kvale 1996 cited in Rose 2001: 33). Poststructuralist feminism encourages one to become conscious of the processes of knowledge accumulation that influence how one knows, what she/he knows, so that one can justify his/her choices, and make the process of knowledge accumulation visible to others (Raghuram and Madge 2006: 279). This concept implies conducting transformative and non-exploitive qualitative research through clarifying the researcher's position, acknowledging the subjectivity of knowledge creation and the power relations between the researcher and the researched, and situating the research in a particular geographical and historical context (Rose 1997: 308-309).

Feminist scholars use the term 'reflexivity' as a strategy to make the process of research transparent through intense reflection and self critique. Hunjan (1997: 67) explains the 
rationale for reflexivity in the research process by stating that, "as researchers we cannot impose our definition of reality on those we want to learn more about, as this would go against the very goal of wanting to know more about another's experience of reality". The notion of reflexivity implies careful consideration of the researcher's role in dealing with conceptual, practical, political and ethical aspects in order to maintain validity and rigour in the process of research. Therefore, it is pertinent to describe the process and methods of my research as constituted, as well as subject to judgement.

\subsection{Reflections on the Research Process}

\subsubsection{Preparing the Research Framework}

My interest in issues of women's empowerment is relevant to my own experience of being part of a middle class family within the socio-cultural context of Bangladesh. Being a daughter of educated parents, I enjoyed the privilege of gaining higher education. After getting a Master's degree in geography and urban planning, I started working as faculty member in a public university in Bangladesh. As a faculty member, I enjoyed a prestigious position, which was perceived to be reserved for men in the male-dominated socio-cultural context of Bangladesh. In my professional arena, I was the only female, and on many occasions, I felt my powerlessness in decision-making at my work place. Besides my own personal experiences, issues of women's empowerment were highlighted when I observed that many of my female friends quit their advanced studies or full-time jobs, and in some cases, accepted part-time jobs after their marriage. Sacrificing education and/or job after marriage is a common trend for Bangladeshi 
women in order to satisfy the demands of a patriarchal society, where women are positioned as caregivers and home makers. Personally, I believe that women's access to employment and income is crucial to ensure their financial independence, and their ability to make decisions at various stages of their lives.

When I came to Carleton University to attend the Masters of Arts program, initially, I was interested in conducting research on aspects of women's empowerment in relation to the experiences of female garment workers in Bangladesh. The concentration of women in low-paid jobs in the export oriented garment industries of Bangladesh would have been a useful ground to explore the labour market experiences of female garment workers. However, because of the unstable political situation of Bangladesh, I had to drop that idea at the end of my first year of studies, and had to revise my proposal. At that time, I was working as a research assistant for a project on the employment and housing problems of newcomers in Canada. While conducting a literature review for the project, a few articles on the employment issues of South Asian immigrant women caught my attention. The issues of immigration, race and ethnicity, and the struggles of immigrant women to find a job increased my interest in exploring the labour market experiences, and relevant empowerment issues for Bangladeshi immigrant women. Moreover, my own identity as a woman of a Third World country, my location within a visible minority group in Canadian context, and my own experiences while searching for a job in the summer semester, all contributed to helping explore the situation of Bangladeshi immigrant women who, I assumed, have facing serious problems in getting access to employment. 
However, my research endeavour did not emerge from my own assumptions only. Before preparing the structure of the research, I went to Toronto where the largest Bangladeshi community in Canada is located. The purpose of visiting Toronto was to meet and talk with Bangladeshi community representatives about my research interest, as well as to learn more about the interests of the members of that community. I also contacted a few CBOs that deal with the issues of labour market integration of Bangladeshi women, and had a chance to talk with some Bangladeshi people working there. Both CBO workers and community people, especially women, encouraged me to carry on a research project based on Bangladeshi married immigrant women's labour market integration issues in Toronto, because they have a number of problems in accessing employment. This research endeavour, therefore, is the outcome of both my and the Bangladeshi community people's combined interests.

After coming back from Toronto, I reviewed the relevant literature and theories, concepts and methodological approaches, and associated ethical issues in order to prepare the structure of the research. After getting Carleton University Ethics Clearance that reviewed the ethical aspects of human participant research, I went to Toronto again and conducted field research for two months, from $15^{\text {th }}$ September to $15^{\text {th }}$ November, 2008. In the first couple of weeks, I participated in cultural and social events to get familiar with Bangladeshi community. During that time, I also communicated with the key individuals, such as cultural events organizers, social workers, and CBO workers. They provided me with an idea of the overall situation of Bangladeshi people in Toronto, in terms of 
employment, income, household relations, and introduced me to a number of Bangladeshi women to talk about my research interests.

After gaining some knowledge of the Bangladeshi community in Toronto, I limited my study to the Danforth and Victoria Park area of Toronto (Map-1). One of the reasons for selecting this area is that it includes the largest Bangladeshi neighbourhood in Toronto. It is called 'Bangla' town by the local people. Therefore, understanding the situation of the Bangladeshi community, networking with people, and recruiting research participants, were much easier and less time-consuming. Another reason for this location is that there are three CBOs located close to the area: Bangladeshi-Canadian Community Services (BCS), South Asian Women's Rights Organization (SAWRO) and South Asian Family Support Services (SAFSS). These CBOs provide services to Bangladeshi women in order to develop their work skills. The presence of these CBOs near the study area helped me to further explore their activities and interactions with Bangladeshi married women. 


\section{Map 4.1: City of Toronto}

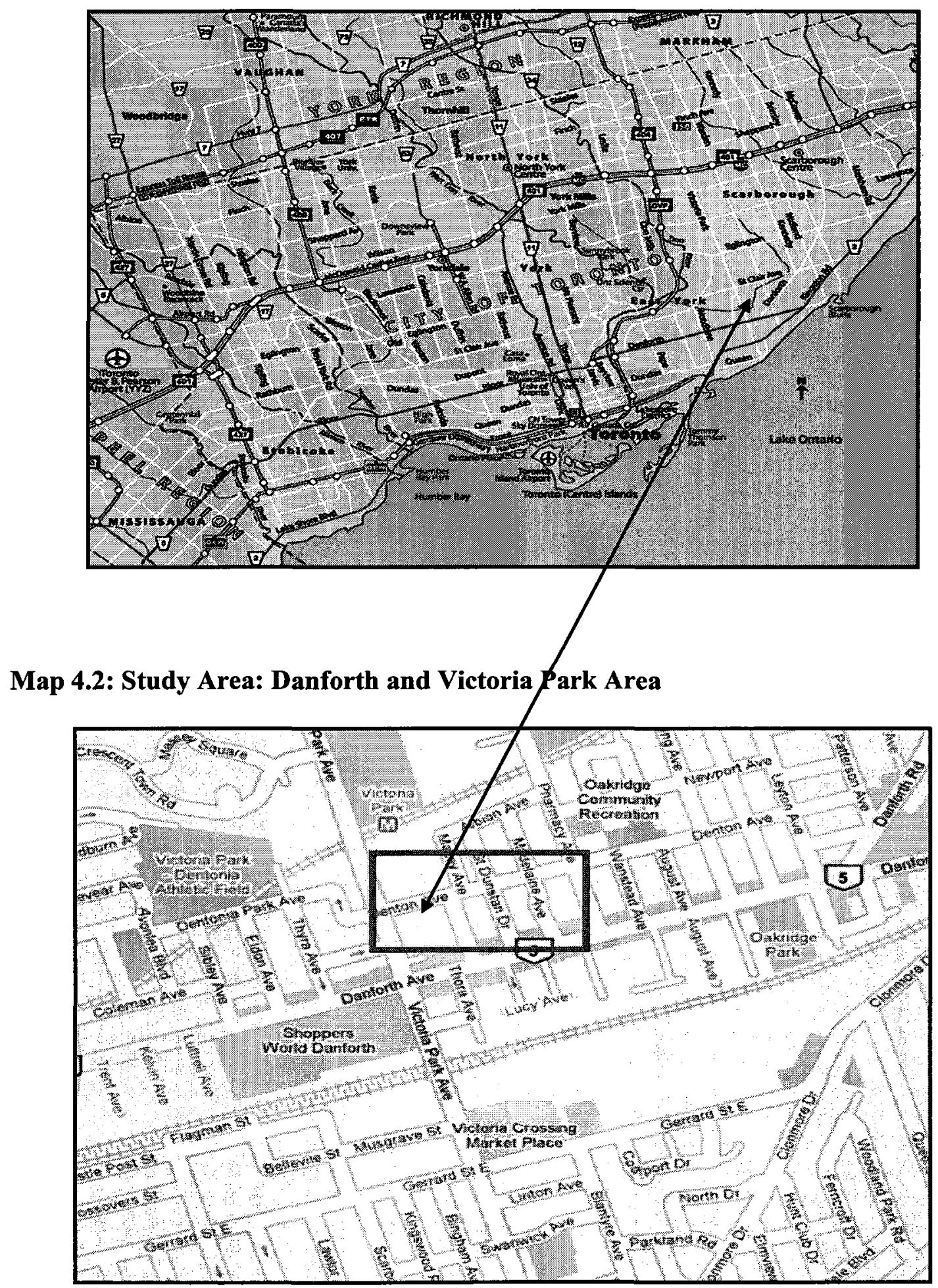

Source: http://www.google.ca 
On the basis of the objectives of the research, I divided the collection of information into two parts: a literature review and the collection of empirical data. In order to understand the issues of labour market integration, and the empowerment of minority women in Canada, I reviewed the literature.on the theoretical concepts of women's empowerment, and the situation of visible minority women in the Canadian labour market. I also reviewed the Immigration and Employment policies of the Federal Government, various policy papers of the Status of Women Canada, the Ontario Provincial Government, and relevant documents of the City of Toronto. Empirical data were collected to investigate the labour market integration experience of Bangladeshi married women, and to understand the initiatives of $\mathrm{CBO}$ workers who were assisting these women to integrate in the labour market. I adopted three types of qualitative methods including focus group discussions with Bangladeshi married women, interviews with $\mathrm{CBO}$ workers and participant observation with a CBO, South Asian Women's Rights Organization (SAWRO) in order to collect empirical data. The process of collecting and interpreting the empirical data was shaped through the mutual interests and interrelationships between me and the research participants. In this regard, I would like to shed light on my positionality in relation to the research participants, the contexts of subjectivity, and the power that was associated with the research process.

\subsubsection{Positionality}

The positionalities of both the researcher and the participants are critical variables in the research process (Hunjan 1997: 68). "Positionality refers to the shaping of perspectives by identifiers such as class, occupation, gender, "race", sexual orientation, etc. (or several 
of these in interaction with each other) as well as location in time and space" (Rose 2001: 23). Haraway (1991: 188-89) suggests that acknowledging a researcher's positionality is the key concept of grounding knowledge, from where the relationship between the researcher and the researched can be visible and open to debate. Madge (1993: 296) states that while situating knowledge, it is critical to acknowledge "the role of the multiple 'self', showing how a researcher's positionality (in terms of nationality, age, gender, social and economic status, sexuality) may influence the 'data' collected and thus the information that becomes coded as "knowledge"'.

My positionality in relation to the research participants developed through mutually constitutive social relations between the research participants and myself. During my field survey, I received a warm welcome, and was offered help and assistance from the Bangladeshi community people in Toronto. This warm welcome from the community, I believe, has resulted from our unique nationality, religious, and ethnic background within the context of multicultural Canadian society. Therefore, my identity as a Bangladeshi woman established me as an 'insider' of the community and encouraged participants to share their labour market struggles and problems with me. However, the relational understanding of positionality also placed me as a scholar in relation to the married women, who participated in the focus group discussions. On various occasions, many of those married women described me as a fortunate person, because I was getting an education from a Canadian university. They assumed that this degree would help me to find a job here in Canada. After knowing that I was unmarried, a few married women told me that I was lucky that I did not need to think about domestic responsibilities and, thus, 
could invest more time in gaining an education and a good job. Yet, most of the married women also expressed sympathy that I could not find a suitable husband. Being unmarried and not having children and family automatically indicates the lack of my ability to understand and interpret the experiences of the participants, who are wives and mothers. My age, level of education and marital status created a distance between me and the married women and, considering these factors, I was considered as an 'outsider' by the participants.

From my own experience, I realised that a researcher's identity as an 'insider' and/or an 'outsider' is a dynamic and fluid phenomenon, which can change depending on the context of the research. In order to understand the feelings and perspectives of these women, I tried to discover and share those experiences that are common for us, such as language problems in Canada, job searching experience, interest in movies, cultural events and traditional foods. By using this tactic, I was able to establish a candid relationship with a few of these married women, who invited me to their houses, and shared private and personal aspects of their lives. During the field research, my identity as a Bangladeshi woman stimulated my own interest, responsibility and commitment to do proper justice with the information, which I collected during my research.

\subsubsection{Subjectivity of the Research}

In qualitative research, it is expected that the researchers may be able to demonstrate the "symbols, feelings and experiences attached to, understood and reported by the

participants, by allowing the participants to define their own experiences and 
perspectives" (Hunjan, 1997: 66). On the other hand, in the terrain of multiple identities of both the researcher and the participants, representing the opinions of others is a highly contested and debatable issue. Mohammad (2001: 108) states, "the research 'findings' can be seen to be produced out of a set of interactions and there will be differences in what even different researchers of the same color, gender and /or class may find or give significance to". Subjectivity of the research is thus, an unavoidable feature, when knowledge is created by a researcher, who possesses distinct social realities and particular extents and boundaries of visions, created for catching the attention and judgement of particular audience (Abu-Lughod 1993: 15). As Ley and Mountz (2001: 235) state: "we are all caught up in a web of contexts - class, age, gender, nationality, intellectual tradition and others - that shape our capacity to tell the story of others".

One of the remarkable themes of poststructural feminism is the rejection of the "role of researcher as an objective, neutral, passive observer, whose emotion and credentials remain detached from his/her actions" (Dutta 1995: 62). Such rejection also demands the acknowledgement of constituted aspects of research that result from the emotional and personal involvement of the researcher with the research subject. In this regard, it is necessary to mention that I frame the research on the basis of the concepts, methods, views, ideas and ethics that I have learned during my academic training at Carleton University. The findings of the research are presented in formal academic language for a particular audience, and most of the Bangladeshi married women, who participated in the research, are not included in that category. In addition, because of the theoretical, conceptual and linguistic differences, the indigenous meanings of various terms such as 
'empowerment', ‘identity', 'women's rights and equalities', as well as, expressions of beliefs, emotions, gesture, and disappointments, were difficult to interpret, as such expressions are unique in a specific language. Thus, the unavoidable variations between theoretical and perceptual concepts of specific terms had a profound impact on the interpretation of information.

The meaning of the term 'empowerment' in Bengali language, for example, is close to women's involvement in local or national politics rather than the socio-cultural process of gaining power to make decisions, and overcome the disadvantaged situation of their lives. Therefore, I had to explain to participants that I wanted to know how they were trying to overcome labour market constraints in Canada in order to understand the process of empowerment. During discussions, I realised that the participants had different reasons to look for a job considering their age, education, family structure, and other socioeconomic characteristics. For example, regardless of age, relatively less educated Bangladeshi married women are looking for a job to contribute to their family's needs, and therefore, are ready to do any type of job. On the other hand, more educated Bangladeshi married women are concerned not only about income but also about their professional advancement. It was quite challenging for me to feel, understand and represent the different opinions of the participants. However, I tried my best to capture and represent the diversified perspectives of the participants in the research. The findings of the research are, therefore, the interpretive understanding of the meanings of experiences that are mutually created and constituted by me and the research participants. 


\subsubsection{Power Relations}

Acknowledging a power differential between the researcher and the researched is another aspect of critical research practice. The unequal distribution and exercise of power is associated with differences in social realities, and the resulting distance between the researcher and the researched. The deconstruction of meanings is, therefore, not neutral but a reflection of the relations of power and privilege. As Abu-Lughod (1993: 5) states: "constructions of self and others are rarely innocent of power". The transparency and subjectivity of a particular research process, thus, cannot be accomplished without acknowledging the context of power and politics. Kobayashi (1994: 76) suggests that the inequalities in the context of research result from the material/analytical power of the researchers that gives them the opportunity to influence the research outcome through directing the opinions of the participants, exploiting the participants, and manipulating the research findings. The impact of power relations even extends after the completion of research, as the researchers reap the benefits of a particular piece of research in terms of gaining degrees, publishing articles, increasing job opportunities, and gaining a place in academic arena (Cotterill 1992: 604-605). During my field research, my identity as an educated woman and a researcher placed me in a position of power with regard to the Bangladeshi married women. These women perceived me as a mediator, who might take their voices to the relevant authorities. Many women asked me if I could help them get a job. Even though I told them that they should not expect any such benefits from their participation, and that the information they provided is only for research purposes, a few women submitted their resume to me so that I could help them find a job. This situation placed them, as well as me, in a vulnerable situation. By describing my own problems in 
getting a job in Canada, I tried to establish myself as one of 'them', which was the best approach from my side to level the power differences. I also tried to encourage them by providing a few examples of successful women who were able to overcome the constraints in the job market.

As a researcher, I enjoyed a certain extent of power in terms of directing the flow of focus group discussions with Bangladeshi married women. However, aspects of positionality and power relations were quite different during the interview sessions with the $\mathrm{CBO}$ workers, where the session was formal. Even though the workers were very friendly with regard to answering questions, they did not provide appropriate answers to a number of questions. They told me that as an employee of a CBO, they did not have the freedom to share certain information with me, such as the source of financial support for the $\mathrm{CBO}$, the description of donors and the involvement of the $\mathrm{CBO}$ with political parties. Information on CBOs' financial sources was important for my study, in order to understand the capacity of the CBOs to assist Bangladeshi married women in their labour market integration process. However, I did not feel comfortable to insist on an answer to these questions. Thus, it is important to note that the context of research does not always offer power to the researcher, as aspects of domination and vulnerabilities can be shifted, depending on the characteristics and interests of both the researcher and the participants. Cotterill (1992: 602) suggests that power should not be viewed as only the attributes of domination and control, as it is also present in the ability to resist, and resistance can be exercised by the participants in the form of non-cooperation, such as by withdrawing themselves from the research, by not answering the questions, or by not providing 
accurate information, which can generate vulnerabilities for the researcher. Cotterill (1992: 603) further suggests that the process of research itself is a part of politics and power relations, within which the subjectivities of knowledge creation are embedded.

Through providing insight about my own positionality in relation to the research, and acknowledging the contexts of subjectivity and power relations, I have made an effort to highlight various elements of the data collection process. Harding (1992, cited in Dutta 2005: 56) suggests that, though the attempt of producing transformative and critical knowledge ensures the revelation of positions, interests and motivations of knowledge makers, "adoption of such methods may not be a guarantee to reinventing ourselves as others but it provides a clarification of the position from which the speech and action emanate and conveys an honest effort on the part of the researcher to admit his/her responsibility in the scheme of the research". Throughout the research process, I was aware that I might bring certain biases, because of my own assumptions, resulting from my own experiences, expectations and 'world views' that I have already mentioned. Through providing the quotations from participants' opinions in the analysis of data, I put emphasis on representing the views of the participants, rather than imposing mine. In the subsequent sections, I discuss the rationale and the process for conducting focus group discussions, interviews and participant observation to provide more in-depth ideas about the methods and techniques of data collection and interpretation. 


\subsection{Focus Group Discussions}

A focus group can be defined as a group interview, generally consisting of five to ten participants, and a moderator, who directs the flow of discussion. In a focus group, data on a particular topic are collected from the conversation and exchange of ideas among the participants (Colucci 2007: 1423). Barbour and Kitzinger (1999: 5) illustrate that focus groups explore "how points of views are constructed and expressed" through documenting the flow of conversation, argument and debate amongst participants. Through focus group discussions, "each woman cannot only tell her own story, but she can also question and challenge the other participants in an effort to gain understanding" (Montell 1999: 51). As such, focus groups allow for the sharing of individual experiences in a group setting through which collective rationalization of beliefs and opinions emerges that shapes an individual's behaviour (Rose 2001: 17).

I conducted four focus group discussions with four different groups of Bangladeshi married immigrant women, because group discussions provided me with the opportunity to explore the collective experiences of the participants in relation to their search for employment in Toronto. Focus group discussions allowed me to understand the pattern of interaction among participants, the similarities and differences of their perceptions and opinions, as well as the dominance and silence of their voices. As Hoggart et al. (2002: 215) note, "groups enable researchers to explore how views are supported in the face of disagreement, with interaction of participants potentially leading to insight that would have not been secured from one to one interviews". Thus, group discussions also helped 
me to get an impression of Bangladeshi married women's group solidarity and social capital potential, which is an important aspect of collective consensus for overcoming the labour market constraints.

There are two crucial factors in the focus group method, such as determining group dynamics and the size of focus groups (sample size). Group dynamics are important because compatibility among participants increases the level of comfort, and provides the ground for sharing opinions. Hoggart et al. (2002: 215) emphasize a shared social background among participants, which may bring them together, and increase their confidence in sharing information. Thus, homogeneity in group composition is crucial, as people in the same situation are more likely to feel confident that they will understand each other's views and experiences.

Qualitative researchers generally follow 'purposive' sampling based on the objective of the study to ensure group compatibility (Rose 2001: 8). In my study, I followed 'purposive' sampling to select participants for the focus groups through considering two criteria. The first criterion was the status of each woman during the immigration process. Bangladeshi married women who came to Canada either as dependants of economic immigrants (husbands), or as family class immigrants sponsored by their husbands, were selected for focus groups discussions. I followed the definition of 'spouse' provided by The Immigration Regulations (1978) of Canada, which state that, "a spouse, with respect to any person, means the party of the opposite sex to whom that person is joined in marriage" (Belleau 2003: 94). The rationale for focusing on the labour market integration 
of dependent, and/or family class Bangladeshi married immigrant women, as stated earlier, was that these women were considered as dependants, rather than economically productive citizens, during the immigration process and, thus, automatically were excluded from the mainstream of the labour market integration process. Another reason for selecting these women was to understand how the domestic responsibilities of women as wives and/or mothers influenced their labour market participation. The second criterion of participant selection was their duration in Canada. Bangladeshi married women who have been living in Toronto, Canada, for more than one year were selected based on the assumption that these women are familiar with the employment issues. Factors such as age, level of education, religion and socio-economic status were not considered in selecting focus group participants in order to capture the perceptions, expectations, and needs of Bangladeshi married women in relation to their various positionalities.

Recruiting participants for focus group discussions, who matched the above stated criteria, was a challenging task for me. During the first two weeks of my field work, I tried to develop linkages with potential participants and $\mathrm{CBO}$ workers in order to get support for participant recruitment. During the period of my field research, South Asian Women's Rights Organization (SAWRO) had a project on Bangladeshi women's skills development. SAWRO mainly provides training in English conversation, sewing and child-care. Bangladeshi women used to meet every Saturday in the Teesdale Place Community Center to participate in these programs. A few Bangladeshi educated women (i.e., doctors, teachers, masters' degree holders) are also involved with SAWRO's 
training programs; they teach English language and sewing to other women. The executive director of SAWRO provided me an opportunity to introduce myself, and explain my research interest at the beginning of the training programs. After hearing my introductory speech regarding my background, and objectives of the research project, a number of married women, including those who were teaching English language and sewing, showed interest in participating in the research. I selected 19 women who were both interested in participation and matched my criteria. The age range of the participants was from 26 to 56 years. I formed four groups randomly among recruited participants. Three focus groups consisted of five women, and one focus group consisted of four women.

As indicated above, the determination of a sample size is another vital aspect in focus group research, and this is influenced by the aim of the study and the quality of data required. Rose (2001: 8) suggests that the size of the sample is generally "determined by the need to tap into a sufficient number of situations and experiences related to the phenomenon being studied until little or no new information or significant variations are discovered by adding more people into the sample (this is called reaching the point of saturation)". However, I decided to limit the sample size to only 19 women in order to complete the field work within one month, given time pressures to complete the research. In selecting the participants, I emphasized including Bangladeshi married women of different ages and levels of education to capture the diversity in their labour market experiences. 
After forming four groups, I asked the executive director of SAWRO to permit me to conduct focus group discussions at the community center, after the regular training sessions on Saturdays. After receiving permission from her, I conducted two focus group discussions at the community center. The other two focus group discussions were conducted in the houses of two participants. The duration of each focus group discussion was about three hours. In the focus group discussions, I followed a moderately structured template to lead discussions, which began with two opening questions leading to five key questions and a few supplementary questions on the central topic, and followed up by two closing questions (see Table-4.1). Morgan (1998: 52) uses the term 'funnel design' to describe this type of less structured template, and suggests that such a template allows the researcher to learn about participants' opinions on topics of interest to the researcher. The leading/key questions of focus groups discussions addressed the labour market integration problems of Bangladeshi married women, their initiatives to gain employment through further education and skill development training, their involvement with $\mathrm{CBO}$, their assessment of the roles of $\mathrm{CBOs}$, and the nature of their collective initiatives through CBOs to overcome labour market constraints. As a moderator, my aim was to facilitate the discussions, rather than directing them. Focus group discussions were recorded by a voice recorder. It is important to note that the focus group discussions were conducted in Bengali language. Later on, I transcribed the discussions into English. 
Table 4.1: Template of Focus Group Discussions

\begin{tabular}{|c|c|c|}
\hline Type of Questions & Questions Asked & Topic Addressed \\
\hline Opening & $\begin{array}{l}\text { Would you please introduce yourself to us? (i.e. name, } \\
\text { age, occupation, hobby) }\end{array}$ & $\begin{array}{l}\text { Encouraging interaction among participants } \\
\text { and forming a friendly environment }\end{array}$ \\
\hline $\begin{array}{l}\text { Opening/introduction } \\
\text { of the topic }\end{array}$ & $\begin{array}{l}\text { Do you think having a paid job is important for you? Tell } \\
\text { us why you are looking for a job? }\end{array}$ & Perceptions of women's needs and interests \\
\hline $\begin{array}{l}\text { Key and } \\
\text { supplementary } \\
\text { question }\end{array}$ & $\begin{array}{l}\text { Would you tell us your experience in searching for a job } \\
\text { in Canada? } \\
\text { What types of problems do you face while searching for a } \\
\text { job? }\end{array}$ & Problems in searching for a job in Canada \\
\hline $\begin{array}{l}\text { Key and } \\
\text { supplementary } \\
\text { question }\end{array}$ & $\begin{array}{l}\text { If you have taken any further education/skill development } \\
\text { training after coming here, tell us what type of training } \\
\text { you would have taken and why? } \\
\text { Is education/skill training program helping you to find a } \\
\text { job here? }\end{array}$ & $\begin{array}{l}\text { Women's initiatives to find a job and the } \\
\text { outcomes of those initiatives }\end{array}$ \\
\hline $\begin{array}{l}\text { Key and } \\
\text { supplementary } \\
\text { question }\end{array}$ & $\begin{array}{l}\text { If you are a member of any community-based } \\
\text { organization, tell us why have you decided to become } \\
\text { involved with the organizations? } \\
\text { What type of help are the organizations providing for } \\
\text { women to gain access in the labour market? }\end{array}$ & $\begin{array}{l}\text { Access to community-based organizations/ } \\
\text { social networks } \\
\text { The roles of the organizations }\end{array}$ \\
\hline $\begin{array}{l}\text { Key and } \\
\text { supplementary } \\
\text { question }\end{array}$ & $\begin{array}{l}\text { Are you satisfied with the initiatives of community-based } \\
\text { organizations? } \\
\text { If not, what factors should those organizations consider } \\
\text { for integrating Bangladeshi married women in the labour } \\
\text { market? }\end{array}$ & $\begin{array}{l}\text { Assessment by women on the roles of } \\
\text { community-based organizations }\end{array}$ \\
\hline $\begin{array}{l}\text { Key and } \\
\text { supplementary } \\
\text { question }\end{array}$ & $\begin{array}{l}\text { Have you ever taken any initiatives collectively to } \\
\text { overcome labor market problems? } \\
\text { What initiatives have you taken? }\end{array}$ & $\begin{array}{l}\text { Group interactions and initiatives towards } \\
\text { overcoming employment problems }\end{array}$ \\
\hline $\begin{array}{l}\text { Summary/moving } \\
\text { towards ending }\end{array}$ & What have we discussed so far? & A summary of the overall discussion \\
\hline Ending & Is there anything that you want to add and share with us? & $\begin{array}{l}\text { Encouraging women to add their } \\
\text { unexpressed ideas }\end{array}$ \\
\hline
\end{tabular}


Focus group discussions took place in a friendly setting. The familiarity of the participants with each other increased the group compatibility, and encouraged them to share their feelings, problems, and experiences in finding a job. However, the course of the discussions with the participants varied depending on the dynamics of the groups. I found that comparatively older and/or less educated women were more expressive than the younger and/or more educated women. But, comparatively, younger and educated women were more dominating in establishing their opinions, because they had more information and experience in terms of job searching and social networking. Therefore, during discussions, older and less educated participants expressed their agreement on various issues (i.e., interview experiences, the stressful job searching process, and experiences at the work place) without practically experiencing those issues. Rose (2001: 18) points out that the domination of certain opinions can influence others, who have no ideas or have different ideas on certain issues, to remain silent. Rose (ibid) states that "the very dynamics of group interaction can create an artificial impression of consensus and conformity if some members feel unable to offer nuances or to express their dissent". During the analysis and interpretation of the data, my aim was to document not only the opinions but also silences and/or agreements that were articulated during the focus group discussions

\subsection{Participant Observation}

Participant observation permits understanding behaviour that goes beyond observing while being a participant (Hoggart et al 2002). It provides a naturalistic environment within which to observe people's regular exhibited behaviours. Morgan (1988: 17) 
suggests that participant observation is appropriate for studies of "roles and organizations". I selected the South Asian Women's Rights Organization (SAWRO), a community-based organization, for participant observation for two purposes. Firstly, the organization is running training programs for developing skills of Bangladeshi women. Thus, participant observation permitted me to observe the nature of Bangladeshi women's involvement with SAWRO, and their interaction with the workers of SAWRO. Secondly, I recruited participants for focus groups from training programs of SAWRO. Therefore, participant observation helped me to become familiar with the participants and establish a closer relationship with them. The participants also got the chance to know more about me through exchanging conversations. I was involved with the programs and activities of SAWRO for a month (October 2008), and took part in a number of events, such as cultural programs, a membership selection event, presentation on the progress of training programs, and a certificate distribution ceremony of volunteers. I also participated in English conversation classes and provided voluntary teaching for Bangladeshi women. My involvement with SAWRO helped me to understand the plans and initiatives of the organization, the process of implementation of the initiatives, and the nature of participation of Bangladeshi married women in the initiatives of the organization.

\subsection{Interviews with CBO Workers}

Interviews are the most common data collection method in qualitative research to learn about individuals' experiences and opinions. Interviews with open ended questionnaires allow researchers to know a person's views through close interaction with them (Hunjan 
1997: 67). In order to explore the motives and initiatives of CBOs, working within Danforth and Victoria Park area, I conducted interviews with three CBO workers. I communicated with three CBOs when I went to Toronto for the first time to know about the labour market problems of Bangladeshi women: the Bangladesh Canadian Community Services (BCS), the South Asian Family Support Center (SAFSS), and the South Asian Women's Rights Organization (SAWRO). After coming back from Toronto, I sent a letter of information to these CBOs, stating my interest in interviewing their workers to know more about the CBOs' programs and initiatives. My aim was to conduct an interview with at least one worker of each selected CBO. During my field research in Toronto, I communicated by telephone with three CBO workers who dealt with Bangladeshi women's socio-economic integration issues, and made appointments with them. Later on, I met with them in their office and described the objectives of my research. All three CBO workers happily agreed to take part in the interviews. The location and time of interviews was decided through consultation with $\mathrm{CBO}$ workers. Like focus group discussions, interviews were recorded with a voice recorder. The duration of these interviews was 45 minutes to 60 minutes. I developed an open-ended questionnaire to lead the interview sessions, and to provide room for the participants to include their opinions (see Appendix-3). I divided the questionnaire into four sections to collect information on specific topics relevant to the objectives of the study. The first section included questions on participants' background, such as, age, level of education and occupation. This section was mainly developed to start the conversation and to create a friendly environment. The second section included questions regarding participants' experiences in working for Bangladeshi women, and their opinions on Bangladeshi 
women's skills and labour market potential. The third section included questions on the roles of the CBOs to empower Bangladeshi women. The fourth section focused on each organization's existing programs, achievements, funding sources and future plans regarding the socio-economic integration of Bangladeshi women in Toronto.

My experience of interviewing CBO workers varied with each participant. The locations of interviews significantly influenced the flow of conversation. For example, the interview with the member of BCS took place at a food court of a shopping center. Because of the gathering of people, and noises in the food court, the flow of conversation was negatively impacted. Thus, discussion on the relevant topics was not explored in depth, and the interview ended quickly. On the other hand, the interview with the member of SAFSS took place in a quiet office setting after office hours. The interview setting encouraged both me and the interviewee to explore relevant topics in depth. After the formal interview session, the interviewee shared her own experience of getting a job and becoming successful in her profession after coming to Canada. The interview with the member of SAWRO took place in a relaxed and cosy setting in her house. As I recruited participants for focus groups through the help of SAWRO and conducted participant observation in SAWRO, a close relation developed between me and the member of SAWRO. Thus, my interview session with her was more intimate and informal. The interviewee had knowledge about my research beforehand, and provided valuable and helpful information. It is important to note that all of the three CBO members were older than me, and possessed a reputable position in terms of making decisions for their organizations. On several occasions, I felt that they challenged my 
authority in judging and/or analyzing the roles of CBOs. In such situations, I explained to them that the research was for an academic purpose, and that I was interested in exploring the effectiveness of CBOs in dealing with labour market issues of Bangladeshi married women. As stated earlier, I did not get answers to several questions from CBO workers, especially on funding sources, political ideologies, and the possibility of collaborative initiatives with other CBOs. However, by talking with them, I explored the perspectives of the CBO workers, and identified the gaps between the expectations of Bangladeshi married women and the types of assistance available for them through such types of CBOs.

\subsection{Ethical Issues of the Research}

Research involving human participants most likely raises several ethical issues for the participants, such as reminding them of unpleasant memories and struggles in everyday life (Kobayashi 2002: 58). There were certain psychological risks for Bangladeshi married women during the focus group discussions, such as reminding them of their struggles in relation to their search for employment, the experiences of direct and indirect racism, and abuses in the work place or at home. There were certain risks for the CBO workers also in revealing their opinions about the activities of the organizations, with which they were involved. The ethical issues of the research were reviewed by Carleton University ethics committee and the research was conducted after getting ethics clearance. In order to minimize the risks of the participants, the research framework developed through considering three aspects, including informed consent, confidentiality and the 
rights of the participants. Through the informed consent form, the participants were informed about the risks and benefits of their participation in the research, and about their rights as participants (Appendix- $1 \& 2$ ). The participants were given the right to withdraw from research at any time during the focus group discussions and interviews. The participants were also given the right to decide whether or not the information they provided would be destroyed, if they chose to withdraw from the research. The participants of focus groups were not guaranteed confidentiality and anonymity, as they shared information with other women. But, the participants of both focus group discussions and interviews were assured that their names and identities would not be disclosed in the thesis or any written publications, and the recordings of their opinions would be destroyed after the completion of the research. Because the consent form was in the English language, I described its contents in Bengali before starting group discussions and interviews, in order to provide clear ideas about the purpose of the consent form. Throughout the field research, I was aware of not generating any kind of risk for the participants through my research.

\subsection{Analysis of the Information}

The main objective of the study was to analyze the labour market integration process of Bangladeshi immigrant married women in relation to the theoretical perspectives of women's empowerment. For this purpose, I organised the analysis of data, collected through focus group discussions, interviews and participant observation, into three broad sections. The first section discusses Bangladeshi married women's labour market 
integration problems, and awareness and agency in relation to overcoming those problems. The second section illustrates the measures taken by Bangladeshi married women through their involvement with CBOs to overcome labour market barriers, and the nature of their achievements through those measures. The third section outlines critical insights into the empowerment process of Bangladeshi married women in relation to their overall labour market integration situation.

A chart of the themes of data analysis and their relevance to theoretical perspectives on women's empowerment is shown in Table-4.2. In order to represent the findings of the study, I use direct quotes from the participants' opinions and illustrate similarities and differences in the opinions of the participants on the same topics by using concise and distinctly relevant quotes (Blunt 2003: 77). I also document comparative discussions on Bangladeshi married women's and $\mathrm{CBO}$ workers' opinions on the same issues. I analyze the findings of the study with regards to relevant literature on issues of women's employment and empowerment. 
Table 4.2: Themes and Topics of Data Analysis

\begin{tabular}{|c|c|c|c|c|}
\hline $\begin{array}{l}\text { Themes of } \\
\text { Women's } \\
\text { Empowerment }\end{array}$ & $\begin{array}{l}\text { Theoretical } \\
\text { Perspectives }\end{array}$ & $\begin{array}{l}\text { Topics Addressed } \\
\text { in the Analysis }\end{array}$ & \multicolumn{2}{|c|}{ Broad Categorization of Analysis } \\
\hline $\begin{array}{l}\text { Structural } \\
\text { Barriers }\end{array}$ & $\begin{array}{l}\text { Manifestation of } \\
\text { institutional sexism } \\
\text { and racism }\end{array}$ & $\begin{array}{c}\text { The nature of } \\
\text { problems that } \\
\text { Bangladeshi married } \\
\text { women face while } \\
\text { searching for a job } \\
\text { in Toronto }\end{array}$ & \multirow[t]{2}{*}{$\begin{array}{l}\text { Identification of } \\
\text { the area of } \\
\text { deprivation and } \\
\text { formation of } \\
\text { agency }\end{array}$} & \multirow{4}{*}{$\begin{array}{c}\text { Variations in } \\
\text { needs and } \\
\text { interests based } \\
\text { on } \\
\text { Positionalities of } \\
\text { women (i.e., age, } \\
\text { level of } \\
\text { education, family } \\
\text { structure, } \\
\text { employment } \\
\text { experience) }\end{array}$} \\
\hline $\begin{array}{l}\text { Women's } \\
\text { Agency }\end{array}$ & $\begin{array}{l}\text { Observable actions, } \\
\text { and meanings and } \\
\text { purposes of those } \\
\text { actions }\end{array}$ & $\begin{array}{c}\text { Motivation of } \\
\text { Bangladeshi married } \\
\text { women to } \\
\text { overcome labour } \\
\text { market barriers }\end{array}$ & & \\
\hline Resources & $\begin{array}{l}\text { Access to institutions } \\
\text { and networks }\end{array}$ & $\begin{array}{l}\text { Access to CBOs' } \\
\text { programs and } \\
\text { initiatives; Nature of } \\
\text { CBOs' programs } \\
\text { and initiatives }\end{array}$ & \multirow[t]{2}{*}{$\begin{array}{l}\text { Measures to } \\
\text { overcome labour } \\
\text { market barriers }\end{array}$} & \\
\hline $\begin{array}{l}\text { Achievements } \\
\text { (Consequences of } \\
\text { the exercise of } \\
\text { agency) }\end{array}$ & $\begin{array}{l}\text { Structural reforms to } \\
\text { gain power and } \\
\text { overcome constraints }\end{array}$ & $\begin{array}{l}\text { The changes in the } \\
\text { labour market } \\
\text { situation of } \\
\text { Bangladeshi married } \\
\text { women }\end{array}$ & & \\
\hline Critical Insights & $\begin{array}{l}\text { Questioning the } \\
\text { constructs of } \\
\text { empowerment to better } \\
\text { understand the } \\
\text { practical aspects of } \\
\text { women's situation }\end{array}$ & $\begin{array}{l}\text { Whether } \\
\text { Bangladeshi women } \\
\text { are accessing } \\
\text { employment } \\
\text { opportunities or } \\
\text { adapting with the } \\
\text { opportunities } \\
\text { available for them? }\end{array}$ & \multicolumn{2}{|c|}{$\begin{array}{l}\text { Drawing conclusions on the } \\
\text { empowerment process of } \\
\text { Bangladeshi married women in } \\
\text { Toronto in relation to their labour } \\
\text { market integration, based on the } \\
\text { collected information }\end{array}$} \\
\hline
\end{tabular}




\subsection{Conclusions}

This chapter discusses the process of research and the methods of data collection and interpretation. The research is structured by qualitative methodologies that provide room to incorporate a person's experience of events, and to analyze/develop theory based on practical phenomena. These perspectives imply that there has to be transparency in the collection and interpretation of people's perceptions, as well as in interests and assumptions of the researchers, in order to maintain the validity of knowledge production. Therefore, I have outlined my positionality in relation to the research, subjectivity and power relations that are associated with the research, to make the process as constituted and transparent as possible. I personally believe that women's access to employment is one of the key factors in establishing their equal position and promoting their rights in various spheres in society. However, my aim was to explore Bangladeshi married women's personal views on their labour market integration process in Toronto. In order to collect information directly from Bangladeshi married women, I conducted focus group discussions with four groups of Bangladeshi married women who came to Canada as family and/or dependant class immigrants. I also interviewed three $\mathrm{CBO}$ workers to investigate the CBOs' programs and initiatives to assist those women in their job searching process. I conducted participant observation in SAWRO to learn firsthand about the activities of the organization, and the nature of Bangladeshi married women's participation in the organization. During my field research, I put emphasis on participants' consent, confidentiality of their opinions, and their rights in participating/withdrawing from the research to deal with ethical concerns. I analyzed the 
collected information in relation to theoretical perspectives on women's empowerment by providing direct quotes from participants' opinions, as well as by reflecting upon my own views. The findings of the study are discussed in the next chapter. 


\section{Chapter Five: Overcoming the Labour Market Challenges?: The Tales of Bangladeshi Married Women}

\subsection{Introduction}

The four main themes of the empowerment process: structural barriers, agency, resources and achievements, are discussed in this chapter in relation to the labour market integration experience of Bangladeshi married women, who came to Toronto as either family or dependent class immigrants. These family and/or dependent class women, who are not considered as income earners in the formal immigration process, and are assumed to be taken care of by their male partners, are desperately looking for a job in the Canadian labour market. However, it is evident that, both 'dependant' status (and its gendered implications), and visible minority status (and its racialized implications) act as negative factors in women's labour market integration process in numerous ways. This chapter intends to discuss whether these women are able to transform their status from a position of powerlessness to a position of power to overcome labour market barriers. For this purpose, this chapter addresses three questions: i) what kind of problems are these women facing in order to access employment opportunities in the Toronto? ii) why are they motivated to look for a job and overcome labour market barriers? and iii) what have they achieved by accessing employment opportunities? In order to address these questions, this chapter discusses the narratives of nineteen Bangladeshi married women and three $\mathrm{CBO}$ workers who participated in this research ${ }^{3}$.

\footnotetext{
${ }^{3}$ Participants of the research are identified by pseudonyms.
} 
The discussion of this chapter is broadly divided into four sections. The first section discusses the nature of problems that Bangladeshi married women face while searching for a job, both in the mainstream labour market, as well as in the self-employment sector. The second section illustrates the factors that play significant roles in the formation of their agency and encourage them to look for solutions to overcome their labour market barriers. The third section analyzes Bangladeshi married women's involvement with $\mathrm{CBOs}$ and the effectiveness of the supports that they get from these organizations to overcome their labour market barriers. The fourth section critically analyzes how the empowerment process takes place in a practical context through summarizing Bangladeshi married women's agency, access to the supports of CBOs (resources), and the nature of their achievements with regard to overcoming the labour market constraints. The objective of this chapter is to shed light on the different socio-economical, cultural and political factors that influence the labour market integration process of Bangladeshi married women.

\subsection{Labour Market Constraints of Bangladeshi Married Women}

Bangladeshi married women encounter a number of constraints to access employment opportunities in Toronto. Most of the time, they fail to find a job because of their lack of skills and education that are required to get a job. Often, they struggle in the labour market despite having education and required skills, because of racial and gendered ideologies including undervaluation of foreign credentials, non-recognition of their foreign work experience, and discriminatory attitudes of the employers. In addition to 
these factors, women's domestic and reproductive responsibilities, and cultural norms influence Bangladeshi married women's access to the labour market and preference for a job in various ways. Among the Bangladeshi married women who shared their labour market integration experience during focus group discussions, a few have succeeded in getting a job in the mainstream labour market, a few are involved in self-employment, and the rest are still struggling to find an income source. However, their labour market integration experience in Toronto is somewhat frustrating and disappointing. All of them described their job searching experience with pain and agony during focus group discussions. The following discussions will shed light on how non-recognition of foreign credentials and work experience, women's lack of language proficiency, discrimination in the work place, domestic responsibilities and cultural ideologies influence Bangladeshi married women's labour market experience in Toronto.

\subsubsection{Starting from Zero Again!}

The lack of the recognition of foreign credentials and work experience is the most disappointing aspect of the job search process for Bangladeshi married women, especially for those who are comparatively well-educated, and have extensive work experience. Undervaluation of their education and work experience means that they have to start from the beginning in Canada. The labour market integration experiences of Resma, Dorin and Rosy indicate how highly educated Bangladeshi married women are struggling to gain entry into the Canadian labour market. 
Resma (26 years old) has a Master's degree in business administration and worked as a research assistant in an international organization in Dhaka. After getting married (to a Canadian citizen), she came to Toronto to start a family. Before coming here, she had no idea about the job market situation in Toronto. She was shocked when she realized that her education and work experience had no value in the Canadian labour market.

Resma: I was much excited before coming to Toronto. I was not worried about getting a job. I have good results and work experience ... I started sending applications for jobs. What can I tell you? I think I sent at least 20 applications. Only once, I was called for an interview. But, I did not get the job [disappointment] ... Even the grocery store near my neighbourhood did not recruit me! Finally, I got a job in a grocery store in down town. I never thought of working in a grocery store after taking a Master's degree!

Dorin (39 years old), who has a Master's degree in computer science, explained her frustration as follows:

Dorin: I worked as a computer programmer in an international organization for 11 years in Dhaka. After coming here, I did not get any job offer. I have no idea why they [employers] do not count my education and work experience. I wanted to do another Master's degree from here. I applied for [a] student loan but did not get it ... Then, I joined an electronics company. I used to pack microchips of computer. It is a monotonous and stressful work. I worked for one and half year in that company then, I quitted the job. I could not bear the mental stress. Now, I am jobless again!

Rosy is a 50 year old doctor who has a $\mathrm{PhD}$ degree in public health. Her husband, who is also a doctor, could not find a job after coming to Toronto. Therefore, she had no choice, but to accept a low-skilled job initially, in order to take care of her sick daughter.

Rosy: My daughter was sick and I needed money but, there was no opportunity to work as a doctor here. Nobody even called me for an interview. I could not find any job. Then I started working in a shoe factory. I lost that job after a few months. I do not know why I lost that job. Then, I took a job in a biscuit factory. Thank god, the manager did not fire 
me from that job [laughter]. I worked there for five months. After that, I took a diploma in public health from Toronto University. Now, I am doing consultancy with a government organization. You can't imagine how much I struggled to find a job!

After hearing Rosy's experience, Laila (37 years old) described the circumstances under which she gave up looking for a job in her own field of study. Laila has a Master's degree in public administration. She failed to get a job in her own field of study, so she started taking training in child-care. Yet, she is not hopeful to find a job even after this training.

Laila: After sending a few applications, I gave up. Without connections, no one can get a job here. I do not see any hope for myself. If I can not find a job after this [child-care] training, I do not know what will I do? I do not understand why our men and women, who are highly educated, are not getting a job in their own field. Even my husband could not find a job in his field ... It is important now to get a job in any sector and earn money. I do not think about my professional career any more.

Other women in the focus group discussions added their own experiences:

Mariam: Oh! I can not think about working right now. I have a small child. I am just learning English now.

Sahana: That is why I am trying to do home-based work. I am aged now; I will not be able to do stressful jobs in factories.

Zamila: See, if a highly educated doctor struggled so much to find a job, what will happen to us?

Rosy: We should not think this way. Just think it is the beginning. We need to start from the beginning ... First, we have to do small things, and, then, we should try for bigger opportunities. It is a new country; here we can not expect to gain everything easily. First, we have to make ourselves efficient.

Sahana and Zamila suggested that women should start from the beginning to find employment. 
Sahana and Zamila, who are comparatively less educated, and older women (both are 56), are not even trying to look for a job in the mainstream labour market. Rather, they prefer to do home-based work within the community. Even though Sahana worked as a teacher for 15 years in a secondary school in Dhaka, she is not looking for a job in the teaching field, because her previous teaching experience is not recognized in Canada.

It is evident that most Bangladeshi married women did not go through any formal credential recognition process. Often the failure of their husbands to find a job in their professional field discourages them to go through the credential recognition process. Most women, who never worked before in Bangladesh, do not think it is important for them to go through the process. The complexity of the process of recognizing foreign credentials and work experience in Canada also discourages them to go through the system. The credential recognition process is lengthy and the system varies from one institution to another. As stated earlier, there are hundreds of regulatory bodies and educational institutions, which are involved in the recognition process of foreign credentials in Canada (Jeanotte 2008: 6). There is no standard process that exists in Toronto to recognize foreign credentials and work experience, which is acceptable to the credential recognizing institutions, as well as by the employers. Thus, there is no guarantee whether one will be able to obtain and/or utilize the recognition of education and work experience in the job market. 
Farida (41 years old) has a post graduate degree in medicine and, has 8 years of work experience in her medical field. She described her views on the Canadian credential recognition system as such:

Farida: I feel embarrassed when people call me a doctor in the neighbourhood. I am not a doctor anymore. I cannot practice [my] medical profession because I do not have a licence to work here. The process of licensing is lengthy and it involves much time and cost. There is a written exam, then an interview. Passing or failing depends on their [examiners'] will. If they like you, you will get it, if not, you won't. I have gone through the exam and in the end, they [examiners] told me to take a course in medicine from here, which is very expensive. What is the point of going through this licensing process? Just waste of money!

Dorin added: Yes, exactly, you are right, that is why I did not try to get credential recognition from here. [The] same thing happened in my husband's case [who has a Master's degree in computer science]. In the end, they told him to take further education from here ... My plan is to take a Master's degree from here. I know this is the only way to get a job in my field.

There is a common concern among Bangladeshi married women about getting a Canadian degree and/or work experience, because these criteria are mandatory for all types of jobs. Liu (2007: 10) describes the requirement of 'Canadian experience' at the entry level as a 'cultural parameter' and a tool of discrimination against minority immigrants (Liu 2007: 10). The requirement of Canadian work experience not only restricts Bangladeshi married women's job searching process but also confines their career advancement in the job sector.

Rosy: Of course, without Canadian experience you will never get a job. I took a degree from here, still I did not get a permanent job, because the employers want Canadian experience. They did not count my 12 years of experience in this [public health] field, so, they offered me a temporary contract based job. 
Rosy is dealing with uncertainty of her job every moment. There is no guarantee that she can continue her job after the expiration of her current contract. Also, she does not get any benefit including pension, medical allowance, and unemployment insurance from her current job.

Rosy: Even though I have a job now, every night I search for jobs in websites to make sure that after the expiration of the current contract, I have another job offer. Job searching is like a never ending task for me.

Labour market struggles often create confusion among Bangladeshi married women. As a result, they jump from one option to another option without knowing whether their efforts will pay off in the job market. Anita (36 years old) has no idea what option is the best for her. Anita was an English teacher in a public college in Dhaka. After knowing that she must get certification from Canada to work as a teacher, which will take 4-5 years, she became confused, and started searching for alternative options through which she could start earning money more quickly.

Anita: It is not possible for me to take such a long training to get permission to teach here ... I applied for a language teacher position in government and non-governmental organizations. I did not get any job, because I do not have any work experience here. Now, I am taking training in data entry and analysis. I have heard that there are lots of opportunities in data entry sector ... I just need a job right now. Later on, I will think about getting further education.

Anita went through the Bangladesh Commission of Public Service examination to get a job in a public college. Yet, her education and work experience could not provide her even a survival job position in Toronto. Research findings indicate that employers' lack of knowledge about foreign credentials and work experience is one of the reasons for minority immigrants' higher unemployment rate (Liu 2007: 2-4). It is disappointing that 
there are no initiatives on behalf of both government and non-governmental organizations to help to establish an information database on the characteristics of foreign credentials and work experience, so that the employers could have an idea about the qualities of minority immigrants.

It is evident that most educated Bangladeshi married women did not expect that they would face struggles to gain a job in the Canadian labour market. Recognition of educational qualifications and work experiences of their husbands through the point system during the immigration process, gave these women the impression that their husbands, as well as they would get a job in their professional field after coming to Canada. However, non-recognition of foreign credentials in the Canadian labour market restricts these women to gain a job and creates financial problems in their lives. During focus group discussions these women raised many questions about the significance of the point system in the immigration process.

Dorin: We [she and her husband] did not know that the recognition of educational qualifications and work experience in the point system is not applied to the labour market context. So we had false expectations that we would get a job in our field, as our degrees are recognized during the immigration process. After coming here we realized that none of us will get a job without Canadian degrees. But, it is not possible for both of us to start studying at the same time. We need an income source first to survive here.

Anita also mentioned the same issues. Both she and her husband's work experiences are not counted here, which is quite unexpected for them.

Anita: Our agent said we [she and her husband] have very good chance in gaining a job in Canada. Canada needs doctors and teachers. More than one year passed, none of us got any job. We do not want to do odd-jobs. We will not be able accept odd-jobs mentally. If 
I knew about the labour market situation I would not come here. My husband is a doctor and I am a teacher, we were doing well there [in Bangladesh].

The requirement of Canadian experience is mandatory not only for formal jobs but also for non-standard jobs, which are low-skilled, low-paid and discontinuous in character (i.e., garment sector, cleaning service, customer care, and data entry). As a result, getting a job in the non-standard sector is also difficult for Bangladeshi married women. According to Hena (36 years old), many Bangladeshi women do not accept odd-jobs initially; instead, they look for a stable (good) job, which is a mistake. As a result, they remain unemployed for long time. Hena graduated in sociology, but after coming here, she started working in a garment factory, as she did not wait to get a job in her field of study.

Hena: I knew about the labour market crisis beforehand. My sister, who has been living in Toronto for 8 years, told me to accept a job offer immediately no matter what type of job it is, because, if I remain unemployed for a long period, then I will not get any job at all. It is wise to take the opportunity of getting Canadian experience in any field.

A number of Bangladeshi married women, regardless of their educational background, are willing to accept any kind of job, because of their financial crisis. However, many women are not getting the opportunity to work, even in low-paid and low-skilled job sector. The conversations among Babita (29), Shabi (34), Tuli (38), and Sima (38) indicate how difficult it is for them to get a survival job (i.e., low-skilled job) in Toronto.

Babita: I do not expect much. I am willing to do any type of work but, I have not found any work yet. Even employers of grocery shops want Canadian experience. How will I have Canadian experience if no one here gives me a job? 
Shabi: We are not getting even an odd-job! Employers say we do not have language and communication skills. I have observed that many workers in grocery shops and other stores are not good in English. Actually everything depends on their [employers'] will.

Tuli: The main thing is Master's degree holders are doing these jobs. If educated people occupy these odd-jobs, then no place remains for less educated people.

Sima: Oh! Even our men are not getting a job here. How can we have the expectation? Having or not having education has nothing to do with the job market here. Our education is not recognized here and that means we all are in same situation!

One thing is clear from the opinions of Bangladeshi married women that regardless of their different levels of education and work experiences, they have to think about starting from the beginning all over again in terms of getting any type of job after immigrating to Canada. "Starting from zero" is how Rosy described her job searching experience. In the next section, I will shed light on the language and communication problem of Bangladeshi married women, which is another major constraint for them to access employment opportunities.

\subsubsection{When Language is a Panic!}

The language barrier is the most common problem among Bangladeshi married women, not only in terms of getting a job, but also in terms of taking further education and training. The language barrier also restricts their capacity to interact with the mainstream population and other ethnic groups. For comparatively well educated women, like Resma, Rosy, Dorin and Anita, the main concern is fluency and the accent of their spoken English. However, for less educated and comparatively older Bangladeshi married women, who are not used to speaking English, any kind of communication in English is a 
challenging task. One of the reasons of their struggles in communication is that they did not obtain any formal training in English language before coming to Canada. As dependant and family class immigrants, they were not required to have a language test. Moreover, there was not much opportunity to practice English language in everyday life in Bangladesh.

The following conversations illustrate how Bangladeshi married women perceive their language and communication problems in relation to accessing employment opportunities in Toronto.

Resma: I do not need to take any language course from here. My English is fine. I do not have a Canadian accent and I will never have that, because I did not grow up here. I know, because of my accent, I am not getting a good job in my field.

Anita: Even though I have a Master's degree in English, I did not get a job as an instructor in English language in any institution. What can I say about our English? Knowing and not knowing is the same! ... Many Europeans have terrible English. I don't think they are suffering as much as we are.

Shilpi: I graduated many years ago. I have forgotten what I have learned. It is not that I don't know English. I know English but because I do not have any practice, I cannot speak fluently. It is like I have in my mind what to say but can not express those thoughts in English.

Hena: English is our main problem. Some jobs require proficiency in both English and French. It is impossible to learn two languages!

Sapna: I am learning simple conversations. I hope that is enough to start a home-based child-care business. 
It is evident that Bangladeshi married women are struggling with language and communication problems in different ways. Resma and Anita's opinions indicate that even though they do not have problems with English, their language proficiency is not recognised by the (Canadian) employers. In that case, they do not have further hope to get a desired job. On the other hand, Hena, Shilpi and Sapna, who do not know English that well, are struggling with learning it in order to get a job or to start a home-based work. Most Bangladeshi married women, who are struggling with language, are confused about whether or not they should go to English as a Second Language (ESL) classes or community based organizations' training programs to learn English. A few Bangladeshi married women said that the ESL training program is not helpful, because the instructors are mostly Canadians, and it is hard for them to understand their accent and language lessons.

Shilpi: I went to ESL class for a couple of time[s]. But, I did not get anything what she [instructor] said. It is hard to understand their [Canadians'] accent. If we do not know what they are saying, how can we learn? I do not know English. So, I could not ask her any question. We need a teacher who can speak Bengali too. Then, we will be able to tell him/her about our problems.

Sapna: Yeah! It is important to learn English in relation to Bengali. Then, we will be able to learn it better. Here (in the community based organization) we discuss our lessons both in English and Bengali. All of us already improved our language.

Resma on the other hand, has different views.

Resma: It is necessary to learn English from an English speaking person in order to learn properly. Learning English from a Bangladeshi teacher is not helpful in terms of getting a job.

Thus, Bangladeshi married women have different views on attending ESL training. Perceptions of their language problems largely depend on their level of education and 
proficiency in English. Those who have comparatively lower proficiency in English do not feel comfortable attending ESL training. Rather they prefer to attend the community organizations' training where they do not feel embarrassed because of their language problems. Even though language problems vary among Bangladeshi married women, in general, all of them are dealing with issues of language proficiency to some extent. The language issue of Bangladeshi married women is compounded by the fact that often employers in Toronto look for bi-lingual persons (as Hena mentioned). Bi-lingual persons are considered as an asset un the job market in Canada (CPF 2008: 17-19). However, the lack of language proficiency both in English and French, reduces Bangladeshi married women's chance to get a job in these sectors.

\subsubsection{Are We Educated Slaves?}

Bangladeshi married women, who have managed to get a job in Toronto, are dealing with different types of problems at their work places. One of the concerns of these women is the status (full-time or part-time) of their jobs. Resma told that her employer organizes her work schedule in a way that she gets less than 40 hours per week. Thus, her job status is not counted as full-time, and she does not get the benefits of a full-time job. Presently, providing less than 40 hours to the employees is a common trend, particularly in the nonstandard job sector. Employers try to cut labour costs by providing less than 40 hours to employees so that, they (employees) cannot claim the benefits of a full-time job. In these cases, the employers prefer to recruit recent immigrants, especially minority women, so that they can take advantage of minority women's vulnerability and can maintain low labour costs. 
Resma: Several times, I requested the manager of grocery store to give me either 20 hours or 40 hours per week. But, he did not agree with that. If he gives me 20 hours per week, he will need to recruit another part-time worker. Neither does he want to recruit another person, nor does he want to recruit me as a full-time worker. Therefore, he gives me $28 / 29$ hours per week. If I had a full-time status, I could save some money for my study.

Resma's plan is to do a diploma course in accounting. After hearing Resma's experience, Hena described her experience in getting working hours in the garment factory.

Hena: The same thing happened to me! When I was recruited my employer said it is a full-time job. But, when he gave my schedule, I got only 30 hours! I asked the employer about it and he told me that he will give me 40 hours after two/three months. Nine months have been passed, but, still, I am getting only 30 hours per week!

Dorin explained that her employer used to change her work schedule every two weeks, thus, she had tough time to manage the other responsibilities (i.e., doing grocery and domestic work, helping her son in his studies).

Dorin: My work schedule affected my family life a lot. I did not have a fixed time to work. Sometimes, I used to get schedules in the morning, and sometimes in the evening. Especially he [employer] used to give me schedules on weekends ... But, I could not complain about that. During the interview, they [the interviewers] told me that they need someone who will be able to work on weekends as well. I agreed because I was unemployed for two years!! I wanted to utilize this chance.

Both Resma and Hena mentioned that their employers not only show discriminatory attitudes towards them in terms of providing working hours, but also show rude behaviour if they make any mistake.

Resma: I need to be extra alert at the grocery store. If I make a single mistake, my employer says that he will fire me.

Hena: Yeah, employers know we desperately need a job. So they always take advantage of our weakness. 
While talking about discrimination against minority women at the work place Rosy mentioned:

Rosy: None of us is out of it. Racial discrimination is everywhere. The main point is there is no way to prove that ... We are educated slaves here! If we say something they [the employers] will fire us from the job.

Getting fired from a job is not desired by Bangladeshi married women in any way especially when getting a job in the first place is so tough for them. Therefore, most of them try to get along with their employers and accept whatever time schedules and working hours are provided. Looking for another job is not a pleasant experience for these women. For most Bangladeshi married women, job searching is a lengthy process. One of the reasons for their slow job searching process is their limited access or, in some cases, no access at all to necessary information, that can help them in finding a job. It is observed that Bangladeshi married women's lack of knowledge of potential job sectors and job vacancies, their lack of skills in preparing cover letter and resume, and lack of knowledge of the interview process, reduce their chance to apply for a job, and become successful in the interview process. There are a number of organizations (such as, Skills for Change, Neighbourhood Links, and COSTI) in Toronto, which provide free internet services for immigrants to search for jobs. They also provide guidelines for the interview process, and offer assistance to prepare a resume and cover letter. However, most Bangladeshi married women do not have information about services offered by these organizations. Most Bangladeshi married women have very limited mobility outside the neighbourhood, which is why they expect to get all information regarding the services of different organizations through their neighbourhood community center. It is evident that cultural and religious ideologies have significant influence in Bangladeshi married 
women's limited mobility, access to information and job choices. This is the topic of the following section.

\subsubsection{The Impact of Cultural Norms}

The prominence of traditional cultural norms and ideologies within the neighbourhood is an important aspect that influences the labour market access of Bangladeshi married women. Based on a study of labour market participation of Bangladeshi women, Mahmud (1997: 238) suggests that 'purdah' is a prominent cultural and religious code, which shapes not only Bangladeshi women's employment pattern but also their lives in every sphere of society. "Purdah literally means curtain or veil and in the narrowest sense involves the seclusion of women within the four walls of their homes and the veiling of women when they move outside their homes" (Chen 1990 cited in Mahmud 1997: 235). Thus, "in a broader sense, purdah involves the exclusion of women from the public 'male' sphere of economic, social and political life" (ibid). Mahmud (1997: 238) further states that the practice of 'purdah' influences "the distance a woman would be willing to travel to work, the distance a husband would permit his wife to travel, a woman's willingness to work for a stranger, and the receptivity of potential employers". Ghosh (2003: 3) illustrates that Bangladeshis are more likely to live in ethnic neighbourhoods in Toronto, and express and retain their culture through the two most essential elements of their identity, such as Bangla (language) and Islam (religion). As a religious and cultural parameter, the 'purdah' system is, therefore, very prominent in the Bangladeshi community. The following conversations indicate how, in various ways, the 'purdah' 
system and dominant cultural ideologies influence Bangladeshi married women's perceptions of their lifestyle.

Mariam: I do not feel comfortable in going out alone because I am not used to interact with people. Sometimes it is embarrassing to go out with veil. People always look at me when I am on the street! They do not understand our culture.

Zamila: Yeah, all of them, men and women, observe me too.

Sahana: Wearing veil is fine with me, but for younger women it is tough ... If they [young women] go out in Western outfits, people say many things [in negative sense] about their dress up and get up.

Rosy: This is a cold country, so there is no way to wear our traditional dresses here. It is ridiculous! When we wear shirt and pant they [especially men] say we are losing our culture ... I don't care. If one wants to live here, one should get accustomed to the culture here.

Mariam: But, we should maintain our religion and culture too. It is necessary to wear the veil when we go out. Why should we give up our tradition?

Sahana: If we do not wear the veil, community people will say bad things about us.

Zamila: Yeah!

Rosy: Well, I try to maintain [purdah] as much as possible. But, it is not always possible.

From the above discussions, it is evident that there are contradictory views among the Bangladeshi married women in terms of maintaining 'purdah'. However, most of these women are concerned about how other people will react if they do not follow the 'purdah' system. Negative sentiments among community people about their use of Western outfits, to some extent, also discourage these women from going out to interact with the mainstream society. Cultural and religious norms, therefore, limit Bangladeshi married women's mobility outside the community, and thus, their access to information. 
It is also evident that the norms of 'purdah' have significant influence on Bangladeshi married women's choices of jobs, and preferences of working hours. A number of Bangladeshi married women prefer to work morning shifts, and want to do those jobs, where they do not have to mingle with men. As a result, they want to do home-based work, or look for a job in the female dominated sector (i.e., sewing, child-care, home-care and data entry related jobs). However, cultural ideologies, especially, 'purdah' do not affect the labour market integration of all Bangladeshi married women in the same way. The following conversations of Bangladeshi married women indicate how cultural ideologies influence their sentiments regarding job preference in various ways.

Suzata: Many women here work in the evening shifts. I cannot work till night. My husband will never allow me. My husband says home-based work is much better and I agree with him. In this way, [through home-based work] I can earn money and also take care of family.

Mamata: Me too, I need to take care of my two sons.

Lima: I do not want to work with men. I am not comfortable with that ... The best thing in home-based work is that we do not have to interact with other people. Interacting with Canadians is tough. I do not know their culture and language [English] well.

Dorin: I do not think working with men is a big deal. My husband does not have any objection about it ... I prefer evening shifts. I am not a morning person [laughter]. The good thing of working in the evening shifts is that you can do all household work before leaving home for your job.

Farida: Yeah, it [working with men] is also a normal thing for me. During my undergrad study, we [both men and women] used to do lab classes in closed doors for hours. I see them [men] as my colleagues. But, I know a doctor's life is different from other women. 
Mamata: If I worked before in Bangladesh, then I could adjust to it [interaction with males]. Now, I am not comfortable working with men. I think we need work opportunities inside the neighbourhood.

Hena, who is working evening shifts, said,

I do not like to work till late night, especially on the weekends. I feel scared on the street at night. Moreover, my husband does not like it either. People in the neighbourhood also say many things. I told my employer about my problems, but he did not give me morning shifts yet! No women in the neighbourhood stay out till night.

From the above discussions of Bangladeshi married women, it can be understood that their labour market integration, in many ways, is influenced by their own perceptions of their capacity, their husband's acceptance and expectations, and community culture and ideologies. För comparatively educated Bangladeshi married women (for example, Farida, Resma, Dorin), who have previous work experience in Bangladesh, the norms of 'purdah' are not a prominent factor in their job preference and job searching process in Toronto. But, for those who never worked in Bangladesh, overcoming religious and cultural barriers in a new country is a difficult task. The dominant cultural ideologies in the neighbourhood, particularly 'purdah', therefore reduce many Bangladeshi married women's ability to interact with people, to search for information on labour market integration services, and to take available employment opportunities. Moreover, the norms of 'purdah' contradict with the core concept of women's empowerment that emphasizes women's economic independence, autonomy and self-reliance. 


\subsubsection{The Impact of Triple Day Burden}

The cultural beliefs and expectations regarding women's productive and reproductive responsibilities directly influence Bangladeshi married women's education, their skill development process, and the nature of their participation in the labour market. Bangladeshi married women are considered to be solely responsible for taking care of domestic and reproductive responsibilities in the household under a patriarchal social system. Generally, their participation in the economic sector is welcomed, mostly in times of family's financial crisis (Salway et al. 2005). Therefore, they are considered as secondary income earners in the household. Such an assumption decreases the chance of Bangladeshi married women taking further education, training, and skill development programs, after which they can look for a better job in Canada. Moreover, their household responsibilities have increased after immigration, because of the absence of maids, and other family members, who used to help them to perform household activities in Bangladesh.

Sima: If I go to work, who will look after the family? There is no one to help me here. I do not expect help from my husband in domestic works because he is not used to doing these things ... It is hard for me to invest time to learn new things to get a job.

Bobita: Doing a full-time job is not possible for me because I have three kids to look after. My husband also works. It would be great, if I can do something by staying home.

Tuli: One good thing is that there are lots of modern appliances here, so cooking and cleaning is much easier. The main problem is looking after the children. I don't want my children to stay alone at home. They will get spoiled if I let them stay alone.

Sabi: Yeah, a mother needs to look after many things ... I am interested in a part-time job. If I do a part-time job, I will be able to earn some money and manage my domestic work. 
It can be understood from the above conversations that Bangladeshi married women do not expect help from their husbands with household work. Rather, they prefer part-time and/or home-based work so that they can carry on their household responsibilities. Those, who have a job, face more difficulties juggling both productive and reproductive responsibilities.

Hena: After coming from work at night, I have to cook for morning. I try to prepare something for my son so that he can take lunch to school. Buying a meal from outside is expensive ... I wake up early in the morning to prepare breakfast for my husband and son. I cannot ignore my domestic responsibilities, no matter how exhausted I am.

Resma: I try to do major things [domestic works] once in a week. We are only two people [husband and wife] in the family, so I can manage. But sometimes, I feel tired after coming from work and still I have to cook because my husband does not know how to cook!

Bangladeshi married women, who have infants and grown up children, struggle the most in terms of searching for a job and taking necessary training. Most of them cannot look for paid work because of the absence of affordable and available child-care services within and near the neighbourhood. Some of them bring their children to other Bangladeshi women, who provide child-care services informally within the neighbourhood. However, keeping their child in an informal child-care facility is not preferred by many of them. It is observed that a number of Bangladeshi married women bring their children with them when they participate in SAWRO's training programs.

Lima: I always take my daughter wherever I go. I can not afford child-care because it is expensive ... Many women provide home-based child-care service in the neighbourhood. But, I do not like to keep my daughter in another person's house, because it is not safe. We need a child-care center in the neighbourhood. 
Dorin: Yeah, I know, I had this difficulty in Bangladesh. I used to keep my son in my parent's house. Now my son is 17 , so I do not have to look after him. If, I had a small child, I could never think about studying or working full-time!

Mamata, who has two grown up sons, said:

You can find a solution for toddlers but, there is nothing for those who are between 6 and 13. It is a huge problem. There are no facilities for these kids to participate in any activities after school hours. So, they stay at home after coming from school ... I have to think about my sons, before involving myself in anything.

Anita whose mother lives in Toronto said:

My mother takes care of my son and daughter. I am lucky that I do not have to think about day care ... I have heard that there is a long waiting list in public child-care services. Often it takes more than one year to get child-care services here!

Domestic and reproductive responsibilities, in many ways, influence Bangladeshi married women's labour market integration experience and preference of jobs. Often domestic, reproductive and productive activities impose a daily triple burden on women. In order to cope with a daily triple burden, a number of Bangladeshi married women end up doing home-based work which has limited potential with regard to income and expansion of their business.

\subsubsection{Home-based Work: An Alternative Solution for Survival}

It is observed that home-based work is a popular option among Bangladeshi married women as an alternative source of income because of a number of factors, such as their domestic and reproductive responsibilities, lack of communication and work skills, and their restricted mobility due to the 'purdah' system. Many Bangladeshi married women are already involved with home-based catering, sewing and child-care services. It is 
necessary to get legal certification especially in order to provide child-care and catering services. But, most Bangladeshi married women, who are involved with these services, do not have any formal certification. As a result, they are providing these services in exchange for minimal wage within the community. Moreover, they are always worried about unwanted incidents.

Sapna: I am looking after four children now. I am getting only $\$ 3$ per hour. Imagine how low my income is. The families who keep their children do not have the ability to pay more than this. I do not have any formal training on child-care. Therefore, I can not demand more money. Moreover, I am always worried about uncertain incidents. If anything happens to any child, then I am in trouble!

Suzata expressed worries about her catering service. She started her catering service immediately after coming to Toronto. Usually she supplies foods/meals during social gatherings, and cultural programs within the neighbourhood. The maintenance of the quality of food is an issue in her work. Because of the lack of preservation and storage facilities, she cannot supply food regularly. So her income is low and discontinuous.

Suzata: I am not getting enough money through this work. I cannot expand the business because I have a small fridge in my house. Thus, I do not have storage facility, which is very important in food business. Sometimes people complain about the quality and smell of the food. I am worried all the time. Lots of women in this community are supplying food these days ... If people do not like my food, they will not order anymore. I will lose my income.

Bangladeshi married women, who are engaged in home-based work informally, need formal training and certification, and the opportunity to expand their businesses outside the neighbourhood. But, the opportunity to take training in home-based work, including child care, sewing, and catering for free of cost is limited. Recently, a few CBOs (such as Micro Skills and SAWRO) initiated free training programs in home-based work for 
these organizations will be able to start a home-based business, and maintain a stable income source overtime is still a question. I will shed light on the debates surrounding home-based work later in this chapter. In the following section, I will discuss how the opinions of Bangladeshi married women are shared, as well as contested during focus group discussions to understand the points of their agreements and disagreements regarding their labour market issues.

\subsubsection{The Context of Support and Disagreement}

As mentioned earlier, the significance of a focus group is that it allows the participants to share their individual perspectives through which collective rationalization of beliefs and opinions emerge (Rose 2001: 17). During focus group discussions, opinions are constructed by both the similar and different views of the participants, and are mediated through the dominance and silence of their voices (Barbour and Kitzinger 1995: 5). During group discussions, Bangladeshi married women not only shared their common problems to access employment but also learned from each other about various issues with regard to accessing employment opportunities. Those who did not face problems with their credential and work experience recognition, and/or did not experience discrimination at work place, learned about these issues from other women. Many women, who had no experience of doing home-based work, expanded their knowledge about the prospects and problems of such work. In spite of having different types of labour market integration issues based on their different positionalities (i.e. age, levels of education, work experiences and expectations), these women showed compassion and encouragement to each other based on the fact that all of them were struggling to some 
extent to integrate into the labour market. Their problems in finding a job in Toronto encouraged them to share not only their labour market integration experiences but also problems in their private lives (for example, financial problems, issues of domestic lives and family relations).

However, these women expressed different views on a number of issues, which raised debates among them. One example of one such debate is related to their participation in ESL courses. Comparatively better educated women preferred to participate in one ESL course to learn the English language properly, through interacting with Canadian English speaking instructors. On the other hand, comparatively less well educated women do not prefer the ESL courses, because they do not feel comfortable with the English speaking instructors. Instead, they like to attend English language training where they can learn from a Bangladeshi instructor. As stated earlier, those who do not prefer ESL courses indicated their problems in understanding the lessons, explaining their questions to the instructors, and establishing relations with them (instructors). As the lack of proficiency in English language is one of the major constraints of these women to gain a job, it is a crucial issue for them to decide which ESL instructor option is the best for them. However, during discussions these women were persistent with their own preferences, and provided a logical argument to support their own ideas. The disagreements among women on the effectiveness of attending ESL courses not only indicate the differences in their capacity to learn the English language but also the differential needs of these women with regard to getting assistance to learn English. 
Another aspect of argument among Bangladeshi married women related to their differential views on religious and cultural norms of 'purdah', which restrict their mobility and interactions with males. As discussed earlier, these ideologies have a broader impact on Bangladeshi married women's choices of jobs, and abilities to take various opportunities to upgrade their skills. The tendencies of comparatively less well educated women (such as, Suzata, Mariam, Mamata, Lima), who have no work experience from Bangladesh, are to confine their job search within the female dominated sector. These women have more conservative views in terms of using western outfits and mingling with men. On the other hand, more educated women (such as Rosy, Farida, Dorin) are influenced by the logic that women should follow the mainstream culture to take labour market opportunities, and utilize their abilities. It is observed that the logics of those who supported the necessity of adjusting with the mainstream culture, were much stronger and they dominated the conversation. A few women did not provide any opinion about the impact of cultural and religious ideologies on their job searching process. The silence of these women points to their discretion in terms of maintaining a neutral position about issues of cultural and religious norms. The differences in their opinions, therefore, signify their differential interests and needs. It is observed that regardless of their differential views on the above stated aspects, all of these women are highly motivated to upgrade their skills to integrate into the labour market. Under what circumstances are these women motivated to access employment opportunities? How has agency developed among them to overcome labour market barriers? The issues are discussed in the next section. 


\subsection{Agency of Bangladeshi Married Women}

The formation of agency is an essential aspect in an empowerment process to generate the possibilities of reforming institutional structures that create various forms of inequalities (Kabeer 2003: 170). As my interest is to understand Bangladeshi married women's empowerment in accessing the labour market in Toronto, I emphasized understanding whether they are motivated to overcome their labour market constraints, and why they are concerned about gaining a job. Both in the mainstream labour market and self-employment sector, Bangladeshi married women are dealing with different types of constraints in terms of gaining a job and a stable source of income. Those who have already gained a job are mostly concentrated in the low-paid, low-skilled or temporary contract-based jobs. However, regardless of their age, level of education and employment experiences, most of them are trying to enhance their capacity to access employment opportunities. Their agency with regard to taking on the challenge of the labour market stems from a number of factors: their economic struggles in managing family expenditure, interests in advancing a professional career, and exposure to new (Western) ideologies regarding women's autonomy and economic self-sufficiency. All of these factors inspire them, not only to discover employment opportunities, but also to become aware of their rights and capabilities.

Financial crisis in the family is a major issue, which drives Bangladeshi married women to look for an income source. It is evident that before coming to Canada, most Bangladeshi married women assumed that they would look for a job after their husbands 
get a job and got settled (economically). Those who never worked before in Bangladesh did not have any expectation of involving themselves with paid work. However, the unemployment and underemployment status of their husbands, and the consequent economic crisis of their family, compel them to look for an income source. The following conversations of Tuli, Babita and Sabi, who had no work experience in Bangladesh, indicate how their husbands' unemployment and financial problems are motivating them to take on the role of a primary income earner in the family.

Tuli: I never thought of working in Canada because I have no work experience ... I never had to think about family expenditure, because my husband was responsible for earning money, and take care of family's financial matters. But, here, things have changed. My husband has not found a good job yet. He does not want to do an odd-job here. He wants to start an MBA program. Until he completes his study and find a good job, I have to take the responsibilities of my family. My husband needs my support.

Sima: Yeah, men are already frustrated. They need our support ... We [her family] are on welfare assistance now. It is hard to manage a family by welfare assistance because prices of everything have increased ... Government has reduced the amount of welfare assistance. People say it was much higher before. We [husband, wife and a son] get around $\$ 1100$ per month. I need at least $\$ 1600$ per month to manage my family. How can I get this extra $\$ 500$ ? My husband is not earning. Even an ordinary job can save me from financial crisis.

Sabi: I am dealing with more problems. Before coming here, my husband borrowed some money from his relatives. He promised that he would return their money soon after coming to Canada. Now, my husband is job-less. We can barely manage our needs. He [husband] feels embarrassed to talk about financial problems with his relatives ... Both of us are trying to find a job so that we can return their [relatives'] money.

Shilpi, who never worked before and spent most of her life managing her extended family in Bangladesh, explained the reason of her job search as such:

Shilpi: I am exhausted with many problems. My husband worked in a factory for two months. After that he became mentally sick. He is now a psychiatric patient. He realised 
that he has no hope here, and could not bear the shock. He was a government officer in Bangladesh ... Now he is under medical treatment. We can barely manage by welfare money ... My husband's sickness is affecting my son's and daughter's lives. They do not go out or enjoy anything here. I need to do something to earn and save my family. I am communicating with different organizations to look for help but no solution came out yet!

The unemployment and/or underemployment status of Bangladeshi men, who came to Canada as principal applicants and went through the point system during the immigration process, indicates the intensity of the overall labour market crisis among Bangladeshi immigrants in Toronto. Under such situations, most Bangladeshi married women are trying to contribute to the family income through any type of work. However, many Bangladeshi married women, who have long-time work experience in Bangladesh in their professional field, are motivated to enhance their capacity to obtain employment not only to tackle the family's financial crisis but also to advance their own careers. For Anita, Resma and Rosy, obtaining a professional identity is a crucial factor in their job searching process.

Anita: As a teacher, I was honoured and respected by everyone in Bangladesh. Now, I feel miserable because I do not have any professional entitlement. Who I was before means nothing here. I wish I could become a teacher again!

Resma: But, starting a career here is time consuming. It is hard to keep patient and motivated ... I am mentally ready to start studying all over again. I know it will take long time but, there is no other option. Otherwise, I will never be able to build up a career here.

Rosy explained her professional career as an organ of her life without which her life is incomplete.

Rosy: My profession is like an organ of my body. Since I started studying in a medical school in Bangladesh, I always imagined myself as a doctor. This is the most important identity for me ... I want to advance my career more. I am looking forward to having a 
permanent job in the public health sector. I have planned to sit for an exam for a government job.

Comparatively educated and professional Bangladeshi married women's expectations in relation to employment, therefore, differ from those who are less educated and do not have a professional career. The former group is concerned about getting a right job that is relevant to their professional field, whilst the latter group is ready to do any type of work in order to tackle the financial crisis of the family. However, despite their educational and professional background, most Bangladeshi married women are highly inspired to take effective measures through which they will be able to overcome their labour market integration problems. The socio-cultural environment of Toronto is acting as a crucial factor in inspiring Bangladeshi married women to become economically independent and self-reliant. The broader perspectives of Canadian multicultural society provide a ground for these women to challenge their labour market barriers to gain economic independence. Bangladeshi married women perceive economic independence as a tool to overcome gender inequalities and gain respect both in the family and within the society. The gender friendly socio-cultural environment in Toronto, and relative situation of 'other' women with regard to accessing employment and income influence Bangladeshi married women to pursue economic independency and autonomy. As Kitson (2003: 7) states,

Women's relative access to material resources and implications for autonomy and economic self-sufficiency; women's understanding of feminine statuses in Canadian society; women's consciousness of rights and legal protection; the media and women's social networks are all sources of consciousness that can shape the form and content of learning. 
It is evident that a number of Bangladeshi married women provided the examples of other women (women of other ethnic groups) to explain their concern about getting a job and economic independence.

Mariam: If Indian and Pakistani women can find a job, why can't we? When I came here [in the neighbourhood], there were many Indian families here. Most of the families now have their own house ... No Indian women are sitting at home. All of them somehow managed to get a job ... Our situation is the worst among the South Asians.

Laila: Not only Indians, African women are progressing so fast. We spend most of our time doing household work. We are confused about going out and mixing with people, this is why we are much behind in the job searching process. The job market is very competitive and that is why we need to be more active to make our place there [in the job market].

Rosy: We are behind because we are less conscious of our self-worth. Most Bangladeshi women spend their lives serving their family members. They do not expect anything for themselves. They always sacrifice their happiness for the sake of their husbands and children. Look at the Canadian women... they are so conscious about their lives. If we do not take care of ourselves, we will suffer from depression and diseases ... I tell everyone that involvement with a work is very good for one's health.

Dorin encourages other participants to enhance their awareness about the labour market problems of Bangladeshi women as such:

Dorin: People do not know that we [Bangladeshi women] have lots of potential. We need to prove it by showing our ability by enhancing our own capacity. Before blaming employers, we need to make ourselves more efficient ... we need to prove that Bangladeshi women are not backward. They are not sitting at home anymore ... We should take our employment problems seriously. Otherwise, new Bangladeshi immigrants will suffer. Our next generation will suffer as well.

The opportunity for Bangladeshi married women to judge their lifestyle and material standard of living compared to other women of different ethnic groups enhances their 
her life within the four walls of her house, expects to utilize her abilities to become economically independent, because she is inspired by the fact that older people in Canada are not dependents, rather they are engaged in different activities and social events.

Zamila: Here there is no age limit to begin anything. People can start education at any age. Why should I sit at home? I want to do something ... I never worked before, but I know it gives one an enormous pleasure and makes one's life meaningful [worthwhile].

This study reveals that the changing economic circumstances and the exposure to a new socio-cultural context, where women's participation in public spheres is less restricted, therefore act as positive factors to inspire Bangladeshi married women to look for employment, as well as gain more visibility in public affairs after immigrating to Canada. Consequently, these women look for assistance through which they can express their interests and take actions to bring changes in their socio-economic situation. They become motivated to engage with the activities of $\mathrm{CBO}$ s in order to get support, especially to overcome their labour market barriers. Mostly these women seek assistance from those CBOs, which are located within or near the neighbourhood, because of the ease of accessibility. However, the extent to which they get assistance from these organizations influences the ultimate outcome of the mobilization of their agency. The roles of $\mathrm{CBOs}$ in Bangladeshi married women's labour market integration process are discussed in the following section.

\subsection{Accessing Organizations' Support and Gaining Achievements}

Researchers suggest that the involvement with grassroots organizations is essential to strengthen an individual's agency to take effective and collective actions to overcome 
their deprived situation and gain empowerment. Community-based/grassroots organizations have the capacity to initiate bottom-up approaches at the community level to understand the specific labour market challenges of particular groups of women, and to deliver necessary assistance based on their requirements. Another characteristic of these organizations is that they transform an individual's consensus to collective consensus through fostering minority immigrants' civic engagement and community interactions (Putnam 1995: 2). However, the mission of these Community Based Organizations (CBOs) are subject to bias, because these organizations are also a part of the socioeconomic structure in which each organization's own interests and constraints influence its capacity to deal with minority women's needs and requirements (Berger et al. 2005:14). Thus, overcoming labour market problems not only depends on women's individual involvement with community-based/grassroots organizations, but also on the availability of resources from these organizations, the viability of their collective initiatives, and the interests of the stakeholders of the organizations.

In this section, I discuss issues surrounding the roles of $\mathrm{CBO}$ based on the opinions of Bangladeshi married women, and three CBO workers who hold a reputable position in BCS, SAWRO and SAFSS. I illustrate what type of initiatives these CBOs take to promote women's empowerment, and which factors influence their activities. I also emphasize understanding the extent to which Bangladeshi married women benefit from the initiatives of CBOs with regard to overcoming their labour market problems. 
South Asian Family Support Services (SAFSS) is a non-profitable community based organization, which was established in 1990 in order to provide assistance to the victims of domestic violence (http://www.safss.com, 2009). The organization's activities expanded over time, and it gradually launched a number of programs free of cost for South Asian newcomers and refugees to assist their socio-economic integration in Toronto. SAFSS's activities include settlement and employment services, workshops and counselling on social problems (for example, violence against women and drug addiction among youth population), health education programs for seniors, and volunteer development programs. In order to support South Asian immigrants to integrate into the labour market, SAFSS provides assistance in their job searching and resume preparation. The organization also provides training in English language and computer programs. However, SAFSS does not provide any skill development training specifically for women. The activities of the Bangladeshi-Canadian Community Services (BCS) are quite similar to SAFSS, but its activities concentrate only on Bangladeshi immigrants. BCS was established in 1991 to assist the socio-economic integration of Bangladeshi immigrants and, since then, this organization has been providing referral and counselling services, and volunteering opportunities for Bangladeshi immigrants (http://www.bangladeshi.ca, 2009). Like SAFSS, BCS also does not have any programs specifically focused on Bangladeshi women's employment issues. The South Asian Women's Rights Organization (SAWRO) is a comparatively new organization, which was established in 2005 in order to assist South Asian women to overcome their poverty, 
unemployment and other socio-cultural issues (http://www.sawro.com, 2009). SAWRO's approaches are quite different from the other two organizations (SAFSS and BCS), as it is putting more emphasis on women's employment issues and work-place rights. The organization has also planned to create self-employment opportunities for women through micro-credit programs. However, presently, its activities are limited to providing training in home-based work (i.e., sewing, child-care) and the English language, and assisting South Asian women's socio-economic integration through referrals and counselling services. All of these three organizations organize various cultural and religious programs and workshops on different socio-economic and cultural issues for South Asian immigrants.

\subsubsection{The Controversies of Seeking and Getting Organizations' Support}

Most Bangladeshi married women are involved with community-based/grassroot organizations to find a feasible solution to their labour market problems. They expect to get necessary information about the job market, language and skill development training, and opportunities for volunteering from these organizations to be able to integrate into the labour market. They also expect to take effective initiatives to overcome issues of credential recognition, and gender and racial discrimination that constrain their labour market access through these organizations. However, most of these women are disappointed about the roles of CBOs. One of the major issues identified by these women is the gap in the flow of information about CBOs' activities within the neighbourhood. A number of women indicate that workers of the organizations do not interact with them personally, or disseminate information on their services adequately. Another issue is that 
most organizations have limited skill development programs for women, and do not have collaborative programs with other institutions. The latter could create opportunities for women to integrate into the labour market. The following conversations of Bangladeshi married women indicate their disappointment regarding the roles of CBOs.

Shilpi: We do not know what type of activities most of these organizations are doing. We do not have any source to get information. Workers of some organizations often come to the neighbourhood and talk about their programs. They talk about the importance of green city and health care. They try to raise awareness about social problems, but they do not talk about how we can gain employment, which is our main problem. They talk about domestic violence, but if we [women] do not have an income source, if we remain dependent on our husbands, how can we take active roles against domestic violence? Unfortunately, most organizations [CBOs] do not have any programs to solve our economic problems.

Sapna: Most organizations do not have any training opportunities except language training. In their website they mention that they provide volunteering opportunities, but if you go to their office, you will see that they do not have any vacancy for volunteers. They can not even provide a job for volunteers. What is the point of investing our time in volunteering when we know that we will not get a job after working for an organization?

Resma: We do not get a job because we are rejected from different companies even before the interview process ... Some organizations provide help to search for a job, prepare a resume, and take mock interviews to help job-seekers. These facilities are helpful to look for a job but, as I said, there is no job for us in the job market.

Anita: There is no guarantee that we will get a job after taking training or doing voluntary work in these organizations. I think these organizations do not have the capacity to make linkages with the employers to enhance our employment opportunities in the job market.

Dorin explained her opinion about the activities of organizations as such:

They [workers of organizations] only provided me some common suggestions, and [gave me] a bunch of papers containing some website links and a description of the organization's activities. They do not have the capacity to provide suggestions based on one's academic background and skills. They offer English language and computer training to everyone ... Mostly these organizations arrange cultural programs and workshops on different socio-economic issues. But, there is no effective program on 
women's labour market integration. For example, these organizations could develop partnership programs with different educational institutions and companies, and create the opportunity for women to take education and training in potential field, and get job placement in different companies. But, most organizations do not take this type of initiatives.

From the above conversations of Bangladeshi married women, it is evident that they are not satisfied with available supports that they get from CBOs. They mentioned that the initiatives of these organizations are not sufficient to help them to find a place in the job market. However, from the opinions of the workers of SAFSS, BCS and SAWRO, it is also evident that they have contradictory opinions about interests and nature of participation of Bangladeshi women in their organizations. Farida, who has been working in SAFSS for more than 10 years, described her experience of working with Bangladeshi married women as such:

Farida: When Bangladeshi families come to the organization for assistance, mostly male members show interest in employment and want to know about different information. Except those women who had a professional career in Bangladesh, no woman shows any interest in employment. Most women who have infants cannot think about starting a job because of their child rearing responsibilities. Sometimes their husbands do not want them to work. So, it takes long time for them to become conscious about their economic independency ... Most of the time we do not know their needs and demands. For example, we organize outreach programs in different neighbourhoods to learn about the problems of Bangladeshi immigrants. Generally, women do not participate in these programs or talk about their interests. There is no strong demand from their side for any specific service. Therefore, it is hard for us to convince our funding agencies to support skill development programs for these women.

Pervin, who works in BCS, also mentioned the lower rate of participation of Bangladeshi women in their programs and workshops. According to her, Bangladeshi married women cannot make time to look for information and participate in the workshops, because of 
their domestic responsibilities. She also mentioned that most women expect that CBO workers will provide them information by going door-to-door, which is not practical.

Pervin: They [Bangladeshi women] complain that we do not have programs for them. But, the fact is that they are not motivated to seek out information. Once, our organization wanted to arrange information sessions on employment opportunities and relevant issues for women in a few Bangladeshi neighbourhoods. We went door-to-door to convince them to participate in those information sessions. We requested them to come and talk about their problems, but they did not participate. Most of them could not make time to take part in these sessions.

Suphia, who is working in SAWRO, mentioned that her organization has adopted practical approaches to deal with employment issues of Bangladeshi women through providing them the opportunities to initiate different programs by themselves, based on their abilities and needs. She explained her experience of working with Bangladeshi women as such:

Suphia: It was hard for me to reach these women. Most women said that they do not expect any help from this type of organization because they are disappointed about the roles of other organizations. But, I went from door-to-door and convinced them to get involved with this organization. I told them that we will work together and create alternative employment opportunities ... We requested women to come forward and build their own programs ... Gradually, many women have [become] involved with this organization and they are actively working to build this organization. Many women are still not coming forward because they have lots of confusions about the interests of the organization.

From the opinions of CBO workers, it is evident that there is a lack of interest among Bangladeshi married women in seeking out information, participating in the organizations' workshops, and expressing their needs and recommendations. However, a number of women indicated that the information sessions are not helpful to overcome 
their labour market problems. They mentioned that the organizations should provide them hands-on work experience, skills development programs, and opportunities to make connections and linkages with the potential employment sector. Thus, it is evident that there are controversies between Bangladeshi married women and $\mathrm{CBO}$ workers about the roles of CBOs. On the one hand, $\mathrm{CBO}$ workers indicated that women are not interested in taking part in their activities, but, on the other hand, most women said that organizations do not provide them necessary supports for their labour market integration. It is also evident that the approaches of these organizations to assist Bangladeshi women vary in a number of ways. The aim of SAFSS and BCS is to increase awareness among women about their socio-economic rights and to provide them necessary information regarding employment, health care and their legal rights. SAWRO emphasizes providing them effective support, such as skill development training and access to microcredit, so that they can gain economic independence. It is important to note that all three organizations have a unique characteristic, that is, they all emphasize the importance of women's empowerment and identified 'empowering women' as one of their main objectives. This aspect led me to explore what these organizations mean by women's empowerment.

\subsubsection{The Constructs of Women's Empowerment}

Empowering women is the common rhetoric in the mandates of $\mathrm{CBOs}$. Many CBOs ranked empowerment of women as their number one objective. It is observed that the workers of SAFSS, BCS and SAWRO are very concerned about the socio-economic integration issues of women. They mentioned that Bangladeshi women need more help than men to integrate into a new socio-economic context after immigration, because of 
the absence of their family networks. Absence of family networks also increases their domestic responsibilities and makes them prone to domestic violence. Farida mentioned that domestic abuse is a major problem in the Bangladeshi community. It is evident that throughout the immigration process Bangladeshi married women do not play any active role and most of them are not informed about the rights that they have as permanent residents in Canada. As a result, they think that their husbands can send them back to Bangladesh if they complain about domestic abuse. This is one of the reasons why, presently, $\mathrm{CBO}$ s are paying more attention to introduce immigrant women with information about their rights and their economic independence. Farida explains the main concerns of SAFSS regarding women's empowerment:

Farida: Our main concern is to help the victims of domestic violence and create awareness among women about their citizenship and immigration rights. We also encourage women to look for employment and offer volunteering opportunities to gain Canadian work experience ... We provide child-care facilities in our office for those who come to take part in our language and computer training. Women's empowerment is the number one concern of our organization. We are looking forward to start more programs for them, especially on their mental and physical health.

Pervin explains BCS's roles in enhancing women's empowerment in the following ways:

Pervin: BCS tries to solve family disputes and provides counselling for women who need mental support. We offer volunteering opportunities for women so that they can utilize their volunteering experience while looking for a job. We know access to income is necessary for women to gain their equal rights. We try to reach those who never worked before in Bangladesh because they face more problems than those who already have work experience. We provide information, help women to fill up the forms and necessary documents, and we encourage them to participate in socio-cultural events to have exposure to outside environment.

Suphia mentions the initiatives of SAWRO to empower women in the following way: 
Suphia: SAWRO try to reach the most isolated women in the community. We want to provide an alternative option of earning for those women who are less educated and have less chance to integrate into the mainstream labour market. We assist them to upgrade their skills that they already have, such as sewing, catering, child-care. Through utilizing these skills they will be able to gain economic independence and freedom in making decisions in their lives.

From the opinions of CBO workers, it is evident that their organizations mainly focus on two aspects of women's lives to empower them. Firstly, they emphasize establishing women's rights and security in the domestic sphere, and, secondly, they emphasize women's access to employment based on the concept that women's economic independency strengthens their position in different spheres of their lives, including the domestic sphere. However, as stated earlier, these organizations offer limited opportunity for women to develop their skills through which they can strengthen their position in the job market. The only available skill development program for Bangladeshi married women within the neighbourhood is the home-based work program of SAWRO. The organization is providing training in sewing and child-care to create alternative employment opportunities for women in the self-employment sector.

SAWRO's home-based work programs have gained the attention of many Bangladeshi married women, especially those who are struggling with finding a job in the mainstream labour market due to domestic and reproductive responsibilities, and lack of communication and work skills. Many educated women also prefer home-based work because they lack other choices. For example, Laila mentioned that she wanted a quick solution of her financial struggles, and home-based work was the only available means to gain an alternative way of earning. These training programs also provide the opportunity 
to get formal certification to conduct home-based work for those who are already doing it informally within the neighbourhood. However, whether or not those women, who are taking training programs, will be able to start a home-based business and maintain a stable income source is uncertain. Mamata, who is taking training in sewing, explained her problems in starting a business in the following way:

I am learning to sew traditional dresses. There is a demand of traditional dresses in the community especially during festivals ... The problem is that I do not have money to buy materials. I need money to start making dresses to sell. I can apply for a loan to government and non-governmental organizations. But, I have to wait for a long time to get that loan ... I do not know how I will sell my products and how I will communicate with the buyers. So, everything is uncertain.

Various studies suggest that, generally, minority women encounter many difficulties to secure capital and manage a business. In most cases, their business is confined to the local market at the community level. Thus, they have less opportunity to expand their business, and maintain a stable income source (Rooney et al. 2003: 1). It is also argued that the gendered pattern of women's home-based work blurs the division between women's paid work and unpaid domestic activities, and reduces their chance to gain empowerment in different spheres of their lives (Day and Brodsky 1998: 31). Therefore, whether home-based work is feasible for these women, in terms of both gaining income and overcoming gender inequalities in different aspects of their lives, is a critical question.

It is also important to note that home-based work cannot satisfy the needs of all Bangladeshi married women. Those who have higher education and work experience are interested in getting a job in their professional field. However, as stated earlier, because 
of a number of issues, such as their credential recognition problems, work-place rights, issues of domestic and reproductive responsibilities, and cultural barriers, they cannot secure a desired job in the mainstream labour market. None of the CBOs have taken any measures to address the above stated core issues, which restrict Bangladeshi married women's access to labour market opportunities. The rhetoric of CBOs in terms of empowering women through fostering their economic independency will remain only rhetoric if these organizations do not address core labour market integration issues. However, it is necessary to consider that the capacity of $\mathrm{CBO}$ s to provide the required support to women depends on a number of factors, including funding sources, cooperation of community members and the organizations' own work ethic. These factors directly influence the efficacy of the organizations to promote women's empowerment and bring changes in their socio-economic situation.

\subsubsection{Constraints and Challenges of $\mathrm{CBO}$ s}

It is evident that the lack of funding opportunities is the most crucial factor that restricts the CBOs to expand their activities and develop appropriate programs necessary for women's economic integration. $\mathrm{CBO}$ workers mentioned that funding agencies show discriminatory attitudes in approving projects and providing funds to CBOs. Suphia explains that if an organization does not have a white Canadian in their governing body, then there is a less chance for that organization to get funding from both government and non-government funding agencies. Pervin discussed the problem of getting funds:

Pervin: We submitted three proposals on women's employment issues more than one year ago. But, we have not heard anything yet from the funding agencies. Many 
organizations have Canadian representatives, who make linkages with funding agencies easily but for us, it takes long time to convince them that our project is important as well for the community. Most of the time, they change the objectives of the proposal and include their own guidelines. For example, once we planned to supply paper bags containing information of job searching process to community stores so that women can get information while doing grocery shopping. But, our funding agency wanted us to supply plastic bags instead of paper bags, because paper bags are not durable. Yet, they did not offer us enough funding so that we can supply plastic bags. It was easier for us to supply paper bags because these are easy to produce and cheaper than plastic bags. In the end, the project was not implemented.

Farida mentioned that SAFSS gets funds from the federal government, and based on the stipulations of the federal government, SAFSS provides settlement services to immigrants who have been living in Canada for less than three years. Thus, their clients are mostly men, because, initially, men look for jobs and other social supports immediately after coming to Canada. It is less likely that women, especially married women, start looking for a job within the first three years. As a result, women's employment issues do not get priority in the action plans of the organization.

Farida: Often many Bangladeshi married women, who have been living in Toronto for more than three years, come here for information and language training, but we cannot provide them any support. I try to give them some suggestions, but do not file their cases. Their problems, thus, are not acknowledged in our documents. I am trying to extend our services for those who have been living here for more than three years, because, I observed that most immigrants, regardless of gender, struggle a long time to integrate into the labour market. But, the decision depends on the will of the funding agency.

It is evident that the lack of funding opportunities and the opinions and guidelines of funding agencies complicate the initiatives of CBOs. The dependency of the CBOs on the funding agencies, and their asymmetrical power relations, influence the extent to which CBOs can support Bangladeshi married women's needs and requirements. 
In addition to the lack of funding, socio-cultural barriers within the community also limit the roles of CBOs, especially, when these organizations address different issues of women. $\mathrm{CBO}$ workers mentioned that taking any initiative to reduce domestic violence or to reform the cultural ideologies that restrict Bangladeshi women's mobility outside the neighbourhood, and reduce their employment opportunities, is a risky task for any organization. Pervin indicated that on the one hand, most Bangladeshi women are inspired to overcome the cultural and ideological restrictions regarding their participation in the public sphere, but, on the other hand, there are strong objections from a section of Bangladeshi society against women's visibility in the public sphere including the labour market. According to Pervin, going against these objections may cause tensions and conflict of interests within the community. Thus, CBOs need to be careful in terms of taking any initiatives for Bangladeshi women. Suphia mentioned that, initially, SAWRO had a program on raising awareness against domestic violence, but it had to drop the program because women were not allowed by their husbands to participate in that program. Suphia raised issues of cultural sensitivity in their activities:

Suphia: We try to initiate programs, which will not create tension within the community. Generally, men think that community-based organizations encourage women to go against traditional ideologies, but I always try to involve men with our activities. I invite them to come to the organization and see what we are doing before allowing their wives to participate in our programs. When they see that our programs will help their wives to get a job, then they allow them to participate ... Our society is still male dominated and it will take time to change the situation.

The ideological conflicts among community members make the activities of CBOs more challenging and tedious. However, there are problems within the ideologies and work 
ethics of these CBOs that also reduce their capacity to deal with the labour market issues of Bangladeshi married women.

The study reveals that there is no attempt on behalf of most CBOs to build and enhance networks with different ethnic groups, as well as with other organizations through which they could attain a broader platform to deal with the core labour market issues of these women, such as credential recognition, and gender and racial discrimination in the employment sector. As indicated above, bridging social networks, that is establishing relations with different ethnic groups and institutions, is crucial because it increases the capacity of a particular group to gain support from others, and creates pressure on relevant authorities to achieve targeted goals (Parpart et al. 2002: 4; Putnam 1995: 66). Social networks also provide women with the opportunity to access necessary information, increase their mobility, help them to break their cultural barriers, and raise their awareness regarding their rights. However, the different political standing and the power struggles between $\mathrm{CBO}$ leaders discourage them to initiate collaborative programs and enhance inter-group interactions. There are fragmentations even within Bangladeshi community, which result in disintegration and rivalry among CBOs. Such a situation reduces the capacity of $\mathrm{CBOs}$ to enhance both intra- and inter-group bonding within the community. A number of Bangladeshi married women mentioned that the fragmentation of the CBOs makes it difficult for them to decide with which organization they will involve themselves.

Rosy described the impact of the fragmentation of $\mathrm{CBOs}$ on Bangladeshi women as such: 
Rosy: When women find out that the leaders of CBOs are not united, they become more frustrated. They do not see any hope to overcome their problems. There are four or five organizations within the community. Therefore, women are divided into four or five groups. These organizations are highly politicized. Political leaders are using these organizations to collect their votes. I think we need to concentrate in solving our own problems instead of getting involved with politics. It is important to strengthen our unity as a community. If we all work together, we will achieve more success in the cultural, social and economic sectors.

Resma explained the importance of integrity (close bonding) within the community as such:

Resma: When people [employers] see that our community is weak then they discriminate [against] us more, because, they know that there will be no strong resistance from the community. Having integrity within the community is crucial in this [multi-cultural] society. If you are alone, nobody will care for your problems and needs.

Most Bangladeshi married women mentioned that, instead of dividing the community, CBO leaders should unite the community through taking integrated programs to address employment and other socio-economic integration issues. CBO workers also expressed their concerns about the lack of collaboration with other organizations through which they could take effective initiatives to deal with the labour market issues of Bangladesh married women. For many women, who are struggling with labour market integration problems, CBOs are the most promising institutions through which they expect to find alternative opportunities to gain income sources and/or create pressure on authoritative bodies to uphold their rights. However, the lack of funding, the lack of collaboration among $\mathrm{CBOs}$, and ideological conflicts within the community regarding CBOs' roles, reduce CBOs' capacity to provide adequate support for these women to integrate into the labour market. Under such conditions, the credibility of CBOs in enhancing women's 
empowerment to overcome their labour market problems at the practical level is indecisive. The limited capacity of $\mathrm{CBOs}$ in providing the necessary support to Bangladeshi married women, thus, reduces the prospects of these women to gain a desired job through the mobilization of their agency.

\subsection{Conclusions: A Critical Insight}

From the narratives of Bangladeshi married women, it is evident that the experiences of Bangladeshi married women, with regard to gaining a job after coming to Toronto, is full of disappointment and uncertainty. Women who are comparatively well educated and have previous work experience in Bangladesh are struggling in getting a desired job because of the lack of recognition of their credentials and work experience. As a result, they are either unemployed or are working in the low-skilled job sector. Married Bangladeshi women, who are less educated and do not have previous work experience, are either looking for a job in the non-standard sector or trying to start home-based work in order to obtain an income source. However, their problems in language and communication, and a lack of required skill restrict their involvement in both the nonstandard and self-employment sectors. This study reveals that most Bangladeshi married women have narrow access to necessary training and job information, and limited mobility outside the neighbourhood, mainly because of the cultural norms that implies the separation of women from public (male dominating) spaces. Cultural norms also influence women to seek female-oriented jobs in order to avoid interaction with men, an issue that also reduces their employment opportunities. In addition to cultural norms, 
women's domestic and reproductive responsibilities hinder their chances of obtaining a job, as well as taking further training and education to enhance their skills. However, because of their family's financial crisis, most of these women are highly motivated to take the necessary steps to overcome their labour market problems. Those who are comparatively well educated and used to hold a professional entitlement in Bangladesh, are not only concerned about gaining an income source but also advancing their professional careers. The socio-cultural context of Canadian society, especially the relative situation of 'other' women with regard to accessing employment, enhances the awareness of Bangladeshi married women about their own employment rights. The agency and interests of Bangladeshi married women to search for paid-work, both in the mainstream labour market and self-employment sector, encourage them to become involved with CBOs.

Even though CBOs have succeeded in bringing the employment issues of these women in front of the public's eyes, and promoted grassroots movements, they have failed to provide adequate support to these women to develop adequate skills through which they can strengthen their position in the job market. The political ideologies of the organizations and their dependency on outside funding significantly affect the roles and objectives of these organizations. These organizations are fragmented within the community, rather that collaborating to strengthen their social networks and develop integrated programs with other organizations. Therefore, these organizations do not possess enough capacity to address the basic labour market issues of Bangladeshi married women, such as their credential recognition problems, work-place rights, issues of 
domestic and reproductive responsibilities, and cultural barriers in accessing labour market opportunities. Often, CBOs motivate these women to engage in home-based work, which has limited potential to provide them a stable income source. Therefore, the labour market struggles of these women are not lessening in the practical context. On the one hand, racial and gender discrimination in the employment sector make it difficult for them to get appropriate recognition of their academic and professional qualifications. On the other hand, domestic responsibilities, and the retention of Bangladeshi socio-cultural ideologies reduce their ability to embrace alternative options for upgrading their education and skills. Moreover, the different needs and expectations of these women, based on their level of education, age, work experience and family status, are not considered in any relevant policies and programs of both public and private institutions. Because of their family/dependant class status, Bangladeshi married women do not get priority in the economic integration initiatives of both public and private sector, as they are not considered to be income earners during the immigration process. Under such circumstances, there is little or no chance for these women to get a desired job in the mainstream labour market or to advance their careers. As a result, for many Bangladeshi married women, gaining employment based on their qualifications is utterly impossible. Because of their financial crisis, therefore, they have no choice but to accept whatever income opportunities they get. The purpose of the assessment of foreign credentials through the point system is confusing to many immigrants, as they think that the assessment of the point system includes their labour market potential. There is a lack in the flow of information about the labour market situation of Bangladeshi immigrants in Canada. However, it is not clear whether Bangladeshi families would stop migrating to 
Canada if they get information about labour market integration problems beforehand, because most Bangladeshi families come to Canada in order to provide better education and secured future to their children.

From the experience of the labour market integration process of Bangladeshi married women, it can be concluded that the practical situation of these women differs from the theoretical notion of women's empowerment, which suggests overcoming women's deprived situation through transforming structural barriers. At the practical level, Bangladeshi married women's inferior position in the patriarchal and racialized society forces them to adjust to the existing structural system rather than changing it. However, the deprived situation of these women in the labour market of Toronto does not mean that there is no way to bring about changes to their situation. Rather, the labour market barriers, and women's struggles to gain necessary support from $\mathrm{CBOs}$, indicate that the empowerment process needs to be looked at not only in terms of theoretical perspectives and assumptions, but also in terms of the practical social, economical, cultural and political challenges that determine Bangladeshi married women's location within the labour market. Understanding the risk to women inherent in such challenges is essential to stimulate debates on the broader perspectives of the core labour market integration issues of minority women, and to create pressure on both the public and private sector to ensure women's equal opportunity in the labour market, not only in policies but also in practice. 


\section{Chapter Six: Summary of the Research and Conclusions}

\subsection{Introduction:}

The journey of my research began by highlighting the overall labour market integration problems of visible minority women in Canada. Based on relevant literature, it is identified that the labour market constraints of minority women are the consequence of four major aspects. Firstly, the immigration policy of Canada excludes women, specially dependent and family class women, from the economic domain through constructing (defining) them as dependants of male partners and/or husbands. Secondly, the prominence of gendered and racialized norms within different spheres of society, including the employment sector, restricts minority women's entry into the labour market, as well as reduces their opportunity to develop required skills. Thirdly, the generalized representation of the labour market integration problems of minority women in socioeconomic integration policies, and the lack of study of employment issues of different ethnic minority women, forestall the inclusion of their specific labour market issues in mainstream policies. And fourthly, the socio-cultural norms of different ethnic groups often enforce women's subordination in the society, and impose domestic and reproductive responsibilities primarily on them, which in turn, hinder their access to labour market opportunities. The above stated aspects create a huge challenge for minority women with regard to obtaining employment and economic independence or in other words, obtaining 'empowerment'. The labour market scenario of minority women, therefore, indicates that voices of different ethnic minority women need to be integrated 
in the analysis of labour market integration processes in order to understand how these women deal with specific labour market issues in their day-to-day lives. Based on this realization, I attempted to bring in the voices of Bangladeshi married women to the academic arena in order to provide an insight into their labour market integration experiences. This study of Bangladeshi married women in Toronto has elaborated on some of the issues addressed in the literature on women's empowerment with regard to accessing employment opportunities. In this concluding chapter, I provide a brief summary of the study. The chapter is organized into three sections. In the first section, I briefly outline the queries of my research, the theoretical basis, and the methods of the research. In this section, I also illustrate the key finding of the research based on the opinions of the research participants. In the second section, I discuss the limitations that are associated with the research followed by the third section, in which I draw the conclusion of the research.

\subsection{A Synopsis of the Study}

How are Bangladeshi married women trying to make a place for themselves in the Canadian labour market? And to what extent have they succeeded in overcoming the labour market barriers? These are the main queries that led me to explore the labour market integration experience of Bangladeshi married women in Toronto. It is evident that the majority of Bangladeshi married women migrate to Canada along with their husbands, and as family and dependant class immigrants. One of the characteristics of these women is that most of them are either unemployed, or employed in the low-skilled 
and low-paid jobs even though having comparatively higher levels of educational qualifications than that of average Canadian women. The aim of my research endeavour was not only to explore the labor market problems of Bangladeshi married women but also to portray their efforts and enthusiasms to overcome labour market problems. For this purpose, I analyzed the labour market integration process of these women in light of theoretical perspectives of women's empowerment, that explicitly talk about women's capacity to overcome socio-cultural constraints to bring changes in their disadvantaged situation. The theoretical basis of my study is, therefore, framed through adopting the perspectives of women's empowerment.

The issues of women's empowerment came to the forefront of feminist literature since the beginning of $1970 \mathrm{~s}$ in order to create awareness among women about gender inequalities in different socio-economic spheres. Women's empowerment means getting power (ability to control lives and make decisions) in order to overcome the sociocultural barriers that create gender inequalities and powerlessness of women. Women's engagement in the economic sector is considered as a basic foundation of their economic empowerment (Nachtwey 2001: 2). Particularly, Liberal feminists emphasize women's participation in formal labour market in order to gain not only economic empowerment but also greater visibility in the public and political arena. Marxist feminists, on the other hand, emphasize the gendered pattern of labour recruitment, and the exploitation of female labour in the production sector. They argue that the process of capitalism exploits women in the labour market by maintaining gender hierarchies in the recruitment process, and utilizing women as a source of cheap labour. Therefore, the disempowerment of 
women in the economic sphere fails to establish their empowerment in other spheres of their lives. In this regard, poststructural feminists suggest that women's empowerment in every sphere of their lives, including the employment sector, needs to be analyzed through considering class, race, ethnicity, and cultural and historical differences among women in order to understand how women's marginalization takes place in different ways at the practical level. Through this notion, poststructural feminists emphasize not only gender inequalities but also various forms of inequalities (for example, inequalities based on race, class and ethnicity of women) that exist in the society. Poststructuralist feminists also emphasize the capacity of women to overcome labour market constraints through focusing on their community activism and grassroots movements. The above stated perspectives of Liberal, Marxist and poststructuralist feminists have enriched the theoretical grounding of my study. However, my study was mainly inspired by the notion of poststructuralist feminists for two reasons. Firstly, poststructuralist feminist theorising allowed me to scrutinize the socio-economic and cultural context in which gendered and racialized patterns of labour market integration takes place. Secondly, it provided me the ground to analyze how labour market experiences differ among Bangladeshi married women based on their different positionalities in society.

Understanding the process of empowerment of Bangladeshi married women in relation to their labour market integration was the main objective of the study. In this regard, the study raised two questions: how can Bangladeshi married women's empowerment be analyzed? And, based on what parameters can their empowerment in accessing job opportunities in Toronto be understood? In order to address these questions, I adopted the 
notion of Kabeer (2003: 169-175), who notes that women's empowerment process needs to be understood through considering three basic components, including women's agency, access to resources, and achievements. Kabeer defines 'agency' as the actions (decision making, bargaining, protest and negotiation), of women, as well as the meanings and purposes of those actions that women initiate to overcome their deprived situations. Kabeer describes the roles of grassroot organizations as 'resources' that mobilize women's agency to take active roles. In relation to empowerment, Kabeer defines 'achievements' as the consequences and/or outcomes of the actions of women. To be empowered, it is necessary for women to challenge and reform the existing institutional structures that create gender discrimination. In summary, Kabeer suggests that in order to gain empowerment, women should have access to resources (grassroot organizations), and have the agency (capacity and aspiration) to utilize those resources in order to reform the structural barriers that constrain their empowerment. In light of Kabeer's notion, I analyzed the labour market problems (structural barriers) of Bangladeshi married women, their motivation to overcome those problems (agency), the nature of their involvement with community-based organizations (resources), and the changes that they achieve in terms of accessing labour market opportunities (achievements). My study, thus, applies theoretical perspectives of women's empowerment to analyze the labour market integration of Bangladeshi married women in Toronto.

The methodological framework of the study was structured on the basis of poststructuralist feminist concepts that acknowledge the multiplicity of women's experience, and their relative positionalities in the society. The notion of 
poststructuralism, therefore, rejects the universality of women's standpoint, as well as the claim of producing absolute truth about their experience (Haraway 1991: 195). Poststructuralist feminism puts emphasis on adopting qualitative methods (for example, focus group discussions, interviews, participant observation, ethnographic study) to collect information, as these methods, especially open ended questions and discussions, provide the room to discover a person's experience and how he/she understands his/her experience. The concept of poststructuralist feminism also suggests the critical disposition of the positionalities of both the researcher and the participants within the research to make it transparent and subject to judgement. Through drawing on the concepts of poststructuralism, I analyzed the labour market integration process of Bangladeshi married women by bringing in their differential experiences and opinions. I also reflected upon my own interests in relation to this study, and outlined how the interrelationships between me and the research participants shaped the process of data collection. I conducted focus group discussions with four groups of Bangladeshi married women (in total with 19 women) to explore their opinions regarding their labour market integration experience. Focus groups were preferred to collect data from these women in order to understand how their opinions were constructed through the conversation and exchange of ideas among them. In order to understand the roles of $\mathrm{CBO}$ in assisting Bangladeshi married women to access employment opportunities, I conducted participant observation in a CBO (SAWRO), and interviewed three CBO workers. I analyzed the collected data in light of the four aspects of empowerment, including Bangladeshi married women's labour market integration problems, the nature of their agency, access 
to the resources through $\mathrm{CBOs,}$ and achievements in accessing labour market opportunities.

While discussing the labour market integration experience, most Bangladeshi married women reported their struggles and disappointments not only in finding a job but also in getting equal treatment at their work places in Toronto. It is evident that the expectations of these women with regard to accessing employment vary based on their levels of education, previous work experience, English language proficiency, age, and characteristics of the family (i.e., the employment status of husbands, and presence of infants in the family). Comparatively less well educated women, who do not have previous work experience, mainly seek out employment due to their family's financial crisis, and try to access either low-skilled jobs or start home-based work to gain a source of income. Along with the financial crisis, interests in advancing a professional career inspire comparatively well educated women to look for a job after coming to Toronto. However, the findings of the study suggest that most of these educated women who have post graduate degrees, are struggling not only to find a job in their own field but also to find even a survival job in the low-paid and non-standard sector. The lack of recognition of their foreign credentials and work experience in the employment sector is the main reason for the failure of these women to access job opportunities. As a result, most of these educated women do not have any other choice, but to seek employment in the lowpaid and non-standard job sector. This situation indicates that educational qualifications do not make any significant difference in the labour market situation of Bangladeshi married women. Whether they have higher education and work experience or not, all of 
these women have to start from the beginning in terms of accessing any type of job in Toronto. For many women who are lucky enough to get a job through overcoming a number of barriers, the experience at the work place is not a pleasant one. Many women are taken advantage by employers who are aware of their vulnerable situation. Moreover, they work under the constant threats of getting fired from their jobs, and face few opportunities to upgrade their position at the work place.

As the study indicates, the lack of English language proficiency and/or the lack of Canadian accent also create a huge challenge for Bangladeshi married women. Most of these women do not get opportunities to learn the English language because, as dependent and family class immigrants, they do not go through any English language test during the immigration process. Moreover, because of their domestic responsibilities and limited mobility outside the neighbourhood, it takes a long time for these women to participate in ESL or other English language courses after coming to Canada. It is evident that at the household level, Bangladeshi married women are primarily responsible for domestic and reproductive activities that reduce their opportunity to upgrade language and other skills, as well as negatively influence their job choices. For example, those who have infants and/or whose husbands also work, mostly prefer home-based work so that they can look after the children and perform domestic work. It is evident that sociocultural ideologies construct women as the sole responsible person to carry the burden of domestic and reproductive responsibilities. Besides enforcing gendered roles at the household level, socio-cultural ideologies also influence the nature of women's labour market participation. For example, 'purdah', which is a prominent cultural norm in the 
studied neighbourhood, has a huge impact on the job preferences of most Bangladeshi married women. 'Purdah' suggests the separation of women from the male sphere. This notion, thus, restricts women's mobility outside the house and/or neighbourhood, as well as access to job market. Many Bangladeshi married women prefer to work in either the female dominated sector or try to engage in home-based work in order to avoid interactions with males. The socio-cultural ideologies in the neighbourhood construct certain aspects, such as working with males, wearing Western outfits, and staying outside home till late at night, as negative characteristics of Bangladeshi women. Even though a few educated women have overcome these socio-cultural barriers with regard to searching for employment in the mainstream labour market, it is observed that most women have confined their job search in the female dominated sector considering the dominant socio-cultural ideologies and community expectations. Given the context of various constraints in entering into the mainstream labour market, many women prefer to do home-based work, such as home-based child-care, catering and sewing to get an alternative source of income. However, because of the lack of formal training and access to capital, most of them have failed to get a stable source of income through home-based work.

In summary, the findings of the study indicate that Bangladeshi married women are subject to gender and racial discrimination that both overtly and covertly influence their labour market participation in Toronto. The study then addressed why and how Bangladeshi married women are trying to overcome these barriers to access employment opportunities. It is evident that husband's unemployment or underemployment status, and 
financial crisis of the family are the most important reasons that motivate these women to deal with the labour market challenges. The findings of the study also suggest that, along with a financial crisis, interests in career advancement also inspire educated women to look for a job. Moreover, the relative situation of 'other' women in relation to employment status and standard of living provides the opportunity for these women to judge their situation, and raise questions regarding their deprivations in different spheres of their lives, including the employment sector. This aspect also creates awareness among them, and inspires them to take active roles to change their labour market situations. Consequently, most of these women involve themselves with CBOs, in order to get support to deal with their labour market integration problems.

With the purpose of understanding what types of assistance they get from these organizations, the study explores the roles of these organizations and the perspectives of CBO workers. This approach has been fruitful in exploring the nature of grassroots movements of these women, and their achievements in bringing changes in their labour market situations through the support of CBOs. The study reveals that even though $\mathrm{CBO}$ are concerned about the labour market problems of Bangladeshi women, and put emphasis on their empowerment, their roles are mostly limited to arranging workshops on employment issues, and providing training in English language and home-based work (for example, child-care and sewing). Although training programs on home-based work have provided an alternative means for a number of women to access income, it is important to note that home-based work is not the solution of the core labour market integration problems of these women. Moreover, there is no certainty that those women 
who are taking training, will be able to gain a stable income source through home-based work. Based on the findings of the study, it is evident that CBOs have failed to bring any fundamental change in the labour situation of these women due to three reasons. Firstly, CBOs are trying to create alternative employment opportunities for these women (for example, home-based work) rather creating pressure on government to take necessary initiatives to recognize their credentials and work experience. Secondly, CBOs are involved with national politics that, on the one hand, is dividing the community, and on the other hand, creating rivalry among the $\mathrm{CBO}$ workers. As a result, there is no integration among $\mathrm{CBO}$ with regard to taking concrete steps to deal with the labour market integration problems of these women. Thirdly, most CBOs avoid addressing the issues relevant to socio-cultural ideologies (for example, gendered roles in the household and separation of women from public sphere) that undermine the core concepts of women's empowerment. The study also explored that the dependency of CBOs on different funding agencies that influence the priorities of their activities and the scales of their initiatives. Moreover, $\mathrm{CBO}$ s of ethnic minority women are also subjected to discrimination in terms of getting funds from mainstream funding agencies. Because of the above stated constraints of $\mathrm{CBOs,} \mathrm{Bangladeshi} \mathrm{married} \mathrm{women's} \mathrm{grassroot}$ movements to overcome the labour market barriers through the support of CBOs are not getting significant momentum. At the practical context, the inferior position of these women in the social structure, the lack of necessary support from $\mathrm{CBOs}$, and financial crisis of their family, all these factors enforce them to accept whatever income opportunities they get. Thus, most of these women have not succeeded in bringing 
changes in their labour market situation which is the ultimate goal of the empowerment process.

\subsection{Limitations of the Study}

Before drawing conclusions, I want to illustrate the limitations that are associated with the study. The study is the reflection of my ability to analyze the labour market experience of Bangladeshi married women, and issues of their empowerment process. I cannot assert that my interpretation of the data absolutely captured the labour market issues of these women. I am also aware that the participants may not have fully shared their experience with me because of a number of reasons, such as their unfamiliarity with me, the presence of other women in focus groups, and their suspicion about the intent of the research. The study only focused on the labour market issues of Bangladeshi married women, thus, it did not cover the problems of overall Bangladeshi immigrant women in Toronto. Most importantly, the study did not take into account the problems of single women and single mothers, who might have different types of difficulties in the labour market. The location and characteristics of the study area also influenced the outcomes of the study. The study area is mainly inhabited by lower middle to poor class Bangladeshi immigrants and, generally, labour market integration problems among Bangladeshi immigrants are prominent in this area. Therefore, it is essential for future studies to examine labour market problems of different groups of Bangladeshi women to gain a better understanding of their labour market situation and issues of empowerment. It is also necessary for future studies to explore the labour market situation of women from 
other ethnic groups to draw comparative analysis of the labour market issues of minority women.

\subsection{Conclusions}

In conclusion, I want to convey that though the study is not free from limitations, it has brought the voices of Bangladeshi married women into the picture, voices that have never been heard before in the academic arena. Through exploring the labour market problems of Bangladeshi married women, the study points out how social, cultural and political factors influence the labour market situation of these women. The study critically analyzes the notion of women's empowerment, and sheds light on how empowerment takes shape through the influence of various socio-cultural factors and macro level policies. Through revealing the labour market integration problems of Bangladeshi married women, the study questions the expediency of immigration policy that, on the one hand, puts greater emphasis on immigrants' potential to contribute in the country's economic sector, but, on the other hand, constructs women (family and dependent class immigrants) as dependants and economically unproductive immigrants. The study has also opened the door for scholars to expand further debates on labour market integration of minority women, which is currently a major issue in Canada. For example, it is crucial to explore whether Bangladeshi women who came to Canada as principal applicants have different labour market experiences than family and dependent class women. Such an attempt definitely will provide new insights into the impact of immigration policies on visible minority women's labour market participation in Canada. The study also provides 
the basis to further explore the differential needs and capacities of women, and the resistance that they face within existing socio-cultural structures with regard to gaining empowerment in a practical context. The overall roles of different CBOs and the way these organizations conduct their activities within the existing socio-economic and institutional structure is another area that needs more in-depth study. In relation to this, it is crucial for future study to analyze the extent to which women's strategic gender interests are promoted by CBOs and/or other grassroots organizations in order to have a deeper understanding of how visible minority women's empowerment is supported and/or constrained by existing institutional structures. Through pointing out these critical aspects, the study, thus, suggests the necessity of further research on visible minority women's employment and empowerment issues in Canada. I consider this study as the beginning of my journey to explore the multi-dimensional context of women's empowerment and their labour market integration issues. The study has provided me with the ground to continue my inquiries on the labour market integration issues of minority women and the practical context of their empowerment in Canada. 


\section{Appendix - 1}

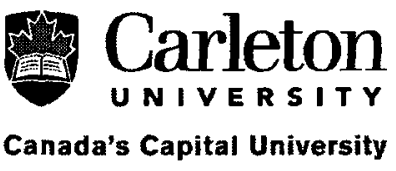

Date:

\section{LETTER OF INFORMATION AND CONSENT FORM}

(Prepared for the participants of focus group discussions)

\section{Dear Madam}

I am Marshia Akbar, a Master of Arts student in the Department of Geography and Environmental Studies at Carleton University. I am conducting research in order to understand the experience of Bangladeshi immigrant married women regarding their search for employment after coming to Canada. For this purpose, I will conduct focus group discussions with Bangladeshi married women, who are either family or dependant class immigrants, and have been living in Toronto for more than one year. During focus discussions, the opportunities and problems of getting a job in Toronto will be discussed with four groups of women. You are invited to share your experience, and any problem that you are facing while searching for employment. Your participation in focus group discussions will be greatly appreciated.

There is no financial compensation for your participation, and your participation will be completely voluntary. A sample questionnaire is attached with this letter so that you have a clear understanding about the discussion topic, and can decide whether you will participate in the research. The focus group discussions will take place in the Teesdale 
Place Community Center, and it will take around two hours. The time of the focus group discussions will be set through discussions with the participants. The focus group discussions will be recorded with the use of a $\mathrm{CD}$ recorder. The discussions might remind you of unpleasant memories and struggles that you experienced in searching for employment. But you are not required to answer those questions that make you feel uncomfortable. You can withdraw at any time during focus group discussions if you feel uncomfortable. If you decide to withdraw, you may decide at that time whether I will be able to use the information you have provided or you may request to destroy the information.

During focus group discussions, the participants will not be anonymous as their information will be shared with the other participants of focus group discussion. But, the identity of the participants will not be revealed in the analysis and presentation of the research findings. You will be given a pseudonym to protect your identity. Throughout the research, the note books, and CDs containing information, will be kept in a secure place and no one will have the access to the information except me, and my supervisor Dr. Fran Klodawsky. The data will be kept until the completion of the thesis paper, and after that, all data and records will be destroyed. The findings of the study will be presented in the thesis paper, journal articles, and seminar presentations. The participants will be able to know the result of the research through communicating with me. The proposed research was reviewed and approved by the Carleton University Ethics Committee. If you have any concerns or questions about the research please contact: 
Professor Antonio Gualtieri, Chair

Carleton University Research Ethics Committee

Office of Research Services

Carleton University

1125 Colonel By Drive

Ottawa, Ontario K1S 5B6

Tel: 613-520-2517

E-mail: ethics@carleton.ca

\begin{tabular}{|l|l|}
\hline Contact information of the & Contact information of the thesis \\
\hline Researcher: & Supervisor: \\
Marshia Akbar & \\
Master of Arts Student & Dr. Fran Klodawsky \\
Department of Geography and & Associate Professor \\
Environmental Studies & Department of Geography and \\
Loeb Building, Carleton University & Environmental Studies \\
1125 Colonel By Drive & Loeb Building, Carleton University \\
Ottawa, Ontario K1S 5B6 & 1125 Colonel By Drive \\
E-mail: makbar@connect.carleton.ca & Ottawa, Ontario K1S 5B6 \\
& Tel: 613 520-2600 ext. 8689 \\
& E-mail: fran klodawsky@carleton.ca \\
\hline
\end{tabular}

\section{Consent of the Participant:}

I, have read the above statement and understand that I am participating in a research project, and I voluntarily agree to participate. 


\section{Appendix - 2}

\section{Carleton}

U N I VER S I T Y

Canada's Capital University

Date:

\section{LETTER OF INFORMATION AND CONSENT FORM}

(Prepared for the participants of interviews)

\section{Dear Sir/Madam}

I am Marshia Akbar, a Master of Arts student in the Department of Geography and Environmental Studies at Carleton University. I am conducting research titled 'Reconstructing the Empowerment Process: Perspectives of Bangladeshi Immigrant Married Women in Toronto, Canada in Relation to their Labour Market Integration Process' for the partial fulfillment of the degree of Master of Arts. In this regard, I will conduct interviews of at least three persons, who are working in a community based organization, and dealing with the labour market integration issues of Bangladeshi women. As you are working in a community based organization, you are invited to participate in the interviews. Your participation will be greatly appreciated.

The purpose of the interviews is to understand the policies, and strategies of the organizations regarding the labour market integration issues of Bangladeshi immigrant married women. There is no financial or any other compensation for your participation and your participation will be completely voluntary. A sample questionnaire is attached with this letter so that you have a clear understanding about the research topic and can 
decide whether you will participate in the research. The interview will take 45 to 60 minutes, and will be conducted after office hours or weekend days. The time and location of the interview will be decided through consultation with you. The interviews will be recorded with the use of a CD recorder. You are not required to answer those questions, which make them feel uncomfortable, and you can withdraw at any time during the interview. If you decide to withdraw, you may decide at that time whether I will be able to use the information you have provided or may request to destroy the information.

Throughout the research, the opinion of the participants will be kept confidential, and the note books and CDs containing information will be kept in a secured place. No one will have the access to the information except me and my supervisor Dr. Fran Klodawsky. The name and identity of the participants will not be revealed in the analysis and presentation of the research findings. You will be given a pseudonym to protect your identity. The data will be kept till the completion of the thesis paper, and after that, all data and records will be destroyed. The findings of the study will be presented in the thesis paper, journal articles, and seminar presentations. The participants will be able to know the result of the research through communicating with me. The proposed research was reviewed and approved by the Carleton University Ethics Committee. If you have any concerns or questions about the research please contact:

Professor Antonio Gualtieri, Chair

Carleton University Research Ethics Committee

Office of Research Services

Carleton University

1125 Colonel By Drive

Ottawa, Ontario K1S 5B6

Tel: 613-520-2517

E-mail: ethics@carleton.ca 


\begin{tabular}{|l|l|l|}
\hline Contact information of the & Contact information of the thesis \\
\hline Researcher: & Supervisor: \\
Marshia Akbar & Dr. Fran Klodawsky \\
Master of Arts Student & Associate Professor \\
Department of Geography and & Department of Geography and \\
Environmental Studies & Environmental Studies \\
Loeb Building, Carleton University & Loeb Building, Carleton University \\
1125 Colonel By Drive & 1125 Colonel By Drive \\
Ottawa, Ontario K1S 5B6 & Ottawa, Ontario K1S 5B6 \\
E-mail: makbar@connect.carleton.ca & Tel: 613 520-2600 ext. 8689 \\
& E-mail: fran klodawsky@carleton.ca \\
\hline
\end{tabular}

Consent of the Participant: I, have read the above statement, and understand that I am participating in a research project, and I voluntarily agree to participate. 


\section{Appendix - 3}

\section{Questionnaire for Face-to-Face Interviews with the Workers of Community Based Organizations}

\section{Date:}

Title of the Study: Reconstructing the Empowerment Process: Perspectives of Bangladeshi Immigrant Married Women in Toronto, Canada in Relation to their Labour Market Integration Process.

\section{Personal Information:}

Name of the Respondent

Age:

Gender:

Occupation:

Affiliation:

Educational qualification:

\section{Experiences with Immigrant Bangladeshi Women:}

1. How many Bangladeshi women are involved with this organization? Are they motivated to look for employment? What are the reasons of their motivation to work here in Canada? What problems do they face in finding a job here? 
2. Are immigrant Bangladeshi women having similar types of problems? If not, why are different women facing different types of problems? What initiatives are you taking to deal with those problems?

3. Is this organization providing any kind of training programs for women to increase their skills? What kind of training programs does this organization offer?

4. Do Bangladeshi women take part in these training programs? Are they able to find a job after taking training from here? If not, why can't they find job after training?

\section{Perception of Empowerment:}

5. Do you think that the initiatives of this organization empower Bangladeshi women to gain access to the labour market? If yes, how are these initiatives empowering them to find a job?

6. Do you think that the labour market integration policies of government are gender sensitive? If not, what factors need to be incorporated in government policies?

7. Do you involve women in the decision making processes of your organization? If yes, how do you incorporate their opinion into the decisions and policies of your organization?

\section{Programs of the Organization}

8. Are there any particular program/projects going on now for increasing the employment opportunities for immigrant Bangladeshi women who are spouses? 
9. Do you have collaborative programs with other organizations for integrating women in the labour market? What types of collaborative programs do you have and with which organizations?

10. Do you think that the policies of this organization are sufficient to deal with the labour market integration process of immigrant Bangladeshi women? Would you please explain your opinion?

11. Who is funding for this organization? Do the funding institutions have any guidelines for you to follow? Is the funding enough for operating the desired programs of the organization?

12. Do you want more funding from Government (municipal, provincial and federal)? Have you taken any initiative to express your problems and demands to the government in terms of funding? What initiatives did you take?

13. Would you please tell me the future plan of this organization for helping immigrant Bangladeshi women regarding their search for employment?

Thanks for your co-operation 


\section{References}

Absar, S. S. (2001) 'Problems Surroundings Wages: the Ready Made Garment Sector of Bangladesh', Labour and Management in Development Journal, Vol. 2, pp.2-17.

Abu-Lughod, L. (1993) 'Introduction', Writing Women's Worlds, Bedouin Stories, Berkeley: University of California Press, pp. 1-42.

Agarwal-Narale, T. (2005) 'Mental Health of South Asian Women: Dialogue with Recent Immigrants on post-migration help seeking and coping strategies', An unpublished Master of Science thesis, Department of Psychiatry, McGill University.

Anderson, K.J. (1993) 'Constructing geographies: "Race", place and the making of Sydney's Aboriginal Redfern', P. Jackson and J. Penrose (eds.) In Constructions of race, place and nation, London: UCL Press, pp. 81-99.

Anucha, U., Dlamini, N. S., Yan, M. C. and Smylie, L. (2006) 'Social Capital and the Welfare of Immigrant Women: A Multi-Level Study of four Ethnic Communities of Windsor', A project report, Ottawa: Status of Women Canada, Available at http://dsppsd.pwgsc.gc.ca/collection 2007/swc-cfc/SW21-152-2006E.pdf, Accessed on $3^{\text {rd }}$ July, 2008.

BCS-Bangladeshi-Canadian Community Services, Available at http://www.bangladeshi.ca, Accessed on $3^{\text {rd }}$ July, 2008.

Barbour, R. S. and Kitzinger, J. (1999) 'Introduction: The challenge and promise of focus groups', R. S. Barbour and J. Kitzinger (eds.) Developing focus Group Research: politics, theory and practice, Thousand Oaks, California: Sage Publications.

Belleau, M. (2003) 'Mail-order brides and Canadian immigration policy', Canadian Woman Studies, Vol. 22, No. 3/4, p. 94.

Berger, I. Foster, M. and Meinhard, A. (2006) 'Ethnicity, Social Cohesion and Social Integration in Toronto, Canada', Center for Voluntary Sector Studies', Working Paper Series, No. 32, Toronto: Ryerson University.

Bernstein, S., Lippel, K. and Lamarche, L. (2001) 'Women and Homework: The Canadian Legislative Framenwork', A project report, Catalogue No. SW21-55/2000E, Ottawa: Status of Women Canada, Available at http://dsppsd.pwgsc.gc.ca/Collection/SW21-55-2000E.pdf, Accessed on 16 ${ }^{\text {th }}$ January, 2009.

Bhattacharyya, S. (1985) 'On the issues of underenumeration of Women's work in the Indian Data Collection System', D. Jain and N. Banergee (eds.) Tyranny of the household: Investigative essays on Women's work, New Delhi: Vikas Publishing house, pp. 195-214. 
Blunt, A. (2003) 'Home and Identity, Life stories in text and in person', A. Blunt, P. Gruffudd, J. May, M. Ogborn and D. Pinder (eds.) Cultural Geography in Practice, London: Arnold, pp. 71-90.

Bondi, L. (1993) 'Locating identity politics', M. Keith and S. Pile (eds.) Place and the politics of identity, London: Routledge, pp. 84-101.

Boserup, E. (1970) Women's Role in Economic Development, London: Allen and Unwin

Brigham, S. and Walsh, S. (2008) 'Representations of "Immigrant Women" Teachers in Nova Scotia', Our diverse cities, Spring, No. 5, pp. 155-159.

Busch, N. B. and Valentine, D. (2000) 'Empowerment Practice: A Focus on Battered Women', Journal of Women and Social Work, Vol. 15, No. 2, pp. 82-93.

Butler, J. (1992) 'Contingent Foundations: Feminism and the Questions of "Postmodernism"', J. Butler and J. W. Scott (eds.) Feminists Theorize the Political, New: York: Routledge.

Carr, E. S. (2003) 'Rethinking Empowerment Theory Using a Feminist Lens: The Importance of Process', Affilia-journal of Women and Social Work, Vol. 18, No. 1, pp. 820.

Chowdhry, G. (1994) 'Women and the international Political Economy', P. R. Beckman and F. D'Amico (eds.) Women, Gender and World Politics: Perspectives, Policies, and Prospects, Westport, CT: Bergin and Garvey.

Chui, T. (2003) Longitudinal Survey of Immigrants to Canada: Process, Progress and Prospects, Statistics Canada, Available at http://www.statcan.ca/english/freepub/89-611XIE/index.htm, Accessed on $10^{\text {th }}$ January, 2009.

Citizenship and Immigration Canada (2009) 'Immigrating to Canada', Available at http://www.cic.gc.ca/english/immigrate/index.asp, Accessed on 15 ${ }^{\text {th }}$ May, 2009.

Citizenship and Immigration Canada (2005) Recent Immigrants in Metropolitan Areas, Toronto, Prepared by Strategic Research and Statistics in collaboration with Informetrica Limited, Canada, Available at http://www.cic.gc.ca/english/pdf/research-stats/2001toronto.pdf, Accessed on $15^{\text {th }}$ January, 2009.

Colucci, E. (2007) 'Focus Groups Can Be Fun: The Use of Activity-Oriented Questions in Focus Group Discussions', Qualitative Health Research, Vol. 17, No. 10, pp. 14221433.

Cote, A., Kerisit, M. and Cote, M. (2001) 'Sponsorship ... for Better or for Worse: The Impact of Sponsorship on the Equality Rights of Immigrant Women' A project report, 
Ottawa: Status of Women Canada, Available at http://www.swccfc.gc.ca/publish/research/010504-0662296427-e.html, Accessed on 30 ${ }^{\text {th }}$ January, 2009.

Cotterill, P. (1992) 'Interviewing Women. Issues of Friendship, Vulnerability and Power', Women's Studies International Forum, Vol. 15, No. 5/6, pp. 593-606.

Cottrell, B (2008) 'Providing Services to Immigrant Women in Atlantic Canada', Our diverse cities, No. 5, Spring volume, pp. 133-137.

CPF-Canadian Parents for French (2008) 'Survey of Supervisors of Bilingual Employees', Ottawa: IPSOS Reid Public Affairs, Available at http://www.cpf.ca/eng/pdf/resources/reports/fsl/2008/IpsosReid FSL2008 E.pdf, Accessed on $3^{\text {rd }}$ September, 2009.

Day, S. and Brodsky, G. (1998) 'Women and Equality Deficit: The impact of Restructuring Canada's Social Programs', A project report, Ottawa: Status of Women Canada, Available at http://dsp-psd.pwgsc.gc.ca/Collection/SW21-32-1998E-1.pdf, Accessed on $25^{\text {th }}$ January, 2009.

Dobrowolsky, A. and Tastsoglou, E. (2008) 'Women, Gender and Networks', Our diverse cities, Spring, No. 5, pp. 80-83.

Dobrowolsky, A. and Tastsoglou, E (2006) 'Crossing Boundaries and Making Connections' in A. Dobrowolsky and E. Tastsoglou (eds.) Women, Migration and Citizenship, Making Local, National and Transnational Connections, England: Ashgate Publishing Limited

Doherty, G., Friendly, M. and Oloman, M. (1998) 'Women's Support, Women's Work: Child Care in an Era of Deficit Reduction, Devolution, Downsizing and Deregulation', A project report, Catalogue No. SW21-28/1998, Ottawa: the Status of Women Canada, Available at http://dsp-psd.pwgsc.gc.ca/Collection/SW21-28-1998E.pdf, Accessed on $25^{\text {th }}$ January, 2009.

Donaldson, I. (2007) 'Enhancing Policy Capacity on the Issues of Foreign Credential Recognition', Canadian Issues, Spring, CBCA Reference, pp. 55-58.

Dugan, K. and Roger, J. (2006) 'Voice and Agency in Social Movement Outcomes', Qual Social, Vol. 29, pp. 467-484.

Dutta, M. (2006) 'Men Not Allowed: The Social Construction and Rewards of the Work of Domestic Maids of Kolkata', An unpublished Masters Thesis, Department of Geography and Environmental Studies, Carleton University, Canada.

Elam, D. and Wiegman, R. (eds.) (1995) Feminism Beside Itself, New York and London: Routledge. 
Galabuzi, G. (2005) 'Factors Affecting the Social Economic Status of Canadian Immigrants in the New Millennium', Canadian Issues, Spring 2005, CBCA Reference, pp. 53-57.

Ghosh, S. (2007) "We are not all the same": the Differentia Migration, Settlement Patterns and Housing Trajectories of Indian Bengalis and Bangladeshis in Toronto', A paper published by the Canada Mortgage and housing Corporation, pp. 1-4.

Grant, P. R. (2007) 'The Inclusion of Skilled Migrants into the Canadian Labour MarketResearch Relevant to the Development of More Person-centered Policies', Canadian Issues, Spring, 2007, pp. 137-142.

Gulson, K. N. (2008) 'Urban Accommodations: policy, education and a politics of place', Journal of Education and Policy, Vol. 23, No. 2, pp. 153-163.

Gunew, S. (ed.) (1990) Feminist Knowledge Critiques and Construct, New York and London: Routledge.

Haraway, D. J. (1991) Simians, cyborgs and women: the reinvention of nature, London: Free Association Books.

Hathiyani, A. (2007) 'Professional Immigrants on a Road to Driving Taxis in Toronto', Our diverse cities, Fall, No. 4, pp. 128-133.

Hickey, M. and Lawson, V. (2005) 'Beyond Science Human Geography, Interpretation and Critique', N. Castree, A Rogers and D. Sherman (eds.) Questioning Geography: fundamental debates, Blackwell Publications, pp. 96-111.

Hoggart, K., Lees, L. and Davies, A. (2002) Researching Human Geography. London: Arnold.

Hossain, M. A. and Tisdell, C. A. (2005) 'Closing the gender gap in Bangladesh: inequality in education, employment and earmings', International Journal of Social Economics, Vol. 32, No. 5, pp. 439-453.

Hou, F and Picot, G. (2004) 'Visible Minority Neighbourhoods in Toronto, Montreal and Vancouver', Canadian Social Trends, Statistics Canada, Catalogue No. 11-008, pp. 8-13.

Hunjan, S. (1997) 'South Asian Women In Cnada: Experiences of Intimate Partner Violence', An unpublished PhD Thesis, Department of Psychology, University of Windsor, Canada.

Ikura, J. (2007) 'Foreign Credential Recognition and Human Resources and Social Development Canada', Canadian Issues, Spring, 2007, pp. 17-20. 
Jeanotte, M. S. (2008) 'Case Study of Social Integration of Canada - Foreign Credential Recognition', A paper presented at a conference on Expert Group Meeting: Promoting Social integration, Helsinki, Finland, July 8-10, 2008.

Johnston, R. J., Gregory, D., Pratt, G. and Watts, M. (eds.) (2000) The Dictionary of Human Geography, USA: Blackwell Publishing Ltd.

Kabeer, N. (2003) Gender Mainstreaming in Poverty Eradication and the Millennium Development Goals, London: Marlborough House.

Kabeer, N. and Mahmud, S. (1992) 'Rags, Riches and Women Workers: Export Oriented Garment Manufacturing in Bangladesh', Chains Final, pp. 133-163, Available at http://www.wiego.org/publications/Chains\%20of\%20Fortune\%20Chapters/Kabeer\%20an d\%20Mahmud\%20Export\%20Oriented\%20Garment\%20Manu\%20in\%20Bangladesh.pd f, Accessed on $11^{\text {th }}$ June, 2007.

Kershaw, P. W. (1997) 'Work-Family Balance: Rethinking the Rights and Responsibilities of Canadian Social Citizenship', An unpublished $\mathrm{PhD}$ thesis, Faculty of Graduate Studies, McGill University.

Kibria, N. (1998) 'Becoming a Garment Worker: The Mobilization of Women in the Garments Factories of Bangladesh', Occasional Paper 9, United Nations Research Institute of Social Development.

Kitson, E. (2003) 'Rethinking Gender Relations: The Micro Politics within the Ghanaian Immigrant Households in Metropolitan Toronto', An unpublished $\mathrm{PhD}$ thesis, Department of Sociology, York University, Toronto.

Kline, M. (1991) 'Women's Oppression and Racism: Critique of the "Feminist Standpoint"', in J. Vorst, L. Allbutt and K. McCallum (eds.) Race, Class, Gender: Bonds and Barriers, Toronto: Garamond Press.

Kobayashi, A. (2002), 'Negotiating the personal and the political in critical quanlitative research', M. Limb and C. Dwyer (eds.) Qualitative Methodologies for Geographers, London: Arnold, pp. 55-70.

Kobayashi, A. (1994) 'Coloring the field: gender, 'race', and the politics of fieldwork', Professional Geographer, Vol. 46, pp. 73-80.

Lahey, K. (2005) 'Women and Employment: Removing Fiscal Barriers to Women's Labour Force Participation', A project report, Catalogue No. SW21-122/2005, Ottawa: Status of Women Canada, Available at http://dsp-psd.pwgsc.gc.ca/Collection/SW21-1222005E.pdf, Accessed on $16^{\text {th }}$ January, 2009. 
Ley, D. and Mountz, A. (2001) 'Interpretation, representation, posionality: issues in field research in human geography', M. Limb and C. Dwyer (eds.) Qualitative Methodologies for Geographers, London: Arnold, pp. 234-247.

Lin, L. (2005) 'A Network Theory of Social Capital', to appear in Dario, C. and Guglielmo, W. (eds.) Handbook on Social Capital, Oxford University Press.

Lindsay, C. (2001) 'Profiles of Ethnic Communities in Canada: The South Asian Community in Canada", Analytical Paper, Statistics Canada, Catalogue No. 89-621-XIENo. 6.

Liu, E. (2007) 'A Descriptive Study of employers' Attitudes and practices in Hiring Newcomer Job Seekers', Policy Matters, No. 31, CERIS- The Ontario Metropolis Center, pp. 1-17.

Lochhead C (2005) 'Civic Participation, Social Capital and the Labour Market Integration of New Comers', Canadian Issues, Summer, pp. 35-38.

Lochhead, C (2003) 'The Transition Penalty: Unemployment among Recent Immigrants to Canada', CLBC Commentary, Toronto: Canadian Labour and Business Center.

MacPhail, F. and Bowles, P. (2007) 'Employer-Supported Volunteer Activity: How do Women Employees and Women's Organizations Fare?', A project report, Catalogue No. SW21-155/2007, Ottawa: Status of Women Canada, Available at http://dsppsd.pwgsc.gc.ca/collection_2007/swc-cfc/SW21-155-2007E.pdf, Accessed on 1st November, 2008.

Madge, C. (1993) 'Boundary disputes: comments on Sidaway', Area, Vo. 25, pp. 294-99.

Mahmud, S. (1997) 'Women's Work in Urban Bangladesh: Is there an Economic Ratinale?', Development and Change, Vol. 28, Blackwell Publishers Ltd. pp. 235-260.

Marchand, M. H. and Runyan, A. S. 2000, 'Feminist Sightings of Global Restructuring: Conceptualizations and Reconceptualizations' Marianne H. M. and Anne S. R. (eds.) Gender and Global Restructuring. Sightings, sites and resistances, New York: Routledge, pp. 1-21.

McLaren, A. T. and Dyck, I. (2004) 'Mothering, human capital, and the "ideal immigrant"', Women's Studies International Forum, Vol. 27, pp. 41-53

Mensah, J. and Firang, D (2007) 'The Heterogeneity of Blacks in Ontario and the Racial Discrimination Boomerang', Our diverse cities, Fall, No. 4, pp. 20-25.

Mills, M. B. (2003) 'Gender and Inequality in the Global Labour Force', Annual Review of Anthropology, Vol. 32, pp. 41-62. 
Mitra, D. (2007) 'Globalization, Women's Labour Force Status and Empowerment: A Cross-National Study, An unpublished PhD thesis, University of Connecticut.

Mohammad, R. (2001) 'Insiders' and /or 'outsiders': positionality, theory and praxis', M. limb and C. Dwyer (eds.) Qualitative Methodologies for Geographers, London: Arnold, pp. 101-117.

Mohanty, C. T. (1991) 'Introduction-Cartographies of Struggle: Third world Women and Politics of Feminism', in C. T. Mohanty, A. Russo and L. Torres (eds.) Third World Women and the Politics of Feminism, Bloomington: Indiana University Press, pp. 1-47.

Molynuex, M. (2001) Women's Movements in International Perspective: Latin America and Beyond, New York: Palgrave Macmillan.

Montell, F. (1999) 'Focus group interviews: a new feminist method', NSWA Journal, Vol. 11 , No. 1, pp. 44-71.

Morgan, D. L. (1998) The focus group kit: The focus group guidebook, Thousand Oaks, California: Sage Publications.

Morgan, D. L. (1988) Focus groups as qualitative research, Newbury Park, California: Sage Publications.

Mullen, K. (2005) 'How does Access to Public Transit Affect the Quality of Life of Seniors Over 75 in Ottawa? A Qualitative Analysis', An unpublished Master pf Arts thesis, Department of Geography and Environmental studies, Carleton University, Ottawa.

Nachtwey, J. L. (2001) 'Women, Employment and Possibilities of Empowerment: A Comparative Analysis of Morocco, Algeria and Tunisia', An unpublished PhD thesis, Department of Political Science, The University of Wisconsin-Milwaukee.

Ng, R. (1991) 'Sexism, Racism, and Canadian Nationalism', J. Vorst, L. Allbutt and K. McCallum (eds.) Race, Class, Gender: Bonds and Barriers, Toronto: Garamond Press.

O' Brien, S. and O' Fathaigh, M. (2004) 'Bringing in Bourdieu's Theory of Social Capital: Renewing Learning Partnership Approaches to Social Inclusion', A paper presented at the ESAI Annual Conference, NUI Maynooth, April 1-3, 2004.

OCISO - Ottawa Community Immigrant Services Organization (2005) 'Barriers to Immigtants in the Canadian Labour Market', A presentation to the Standing committee on Citizenship and Immigration, March 22 ${ }^{\text {nd }}$, 2005, Available at http://www.ociso.org/presentations.htm, Acessed on $15^{\text {th }}$ January, 2009.

O'Mahony, J. M. (2005) 'Exploring Immigrant Women's Mental Health Care Experiences: From a health Care Provider's Perspective', An unpublished Master of Nursing Thesis, Calgary University, Alberta, Canada. 
Ooka, E. and Wellman, B. (2003) 'Does Social capital Pay Off more within or between Ethnic Groups?, Analysing Job Searchers in Five Toronto Ethnic Groups', Eric, F. (ed.) Inside the Mosaic, Toronto: University of Toronto Press.

Ostergaard, L. (1992) Gender and Development, A practical Guide, Routledge: London.

Owen, T. (2007) 'International Credential Evaluation and the Labour Market integration of Immigrants’, Canadian Issues, Spring, pp. 39-42.

Owen, T. (2003) 'The Labour Market Experience of Immigrants', World Education Services, Available at http://lifelong.oise.utoronto.ca/papers/pOwenPaper.pdf, Accessed on $14^{\text {th }}$ November, 2008.

Papademetriou, D. G. (2007) 'Selecting Economic Stream Immigrants through points systems', Migration Information Source, Migration Policy Institute, pp. 1-3.

Parpart, J. L., Rai, S. M. and Staudt, K. (eds) (2002) Rethinking Empowerment, Gender and Development in a Global/Local World, London: Routledge.

Perkins, D. D. and Zimmerman, M. A. (1995) 'Empowerment theory, research, and application', American Journal of Community Psychology, Vol. 23, No. 5, pp. 569-580.

Pinder, S. (2002) 'Welfare, Workfare, Single Mothers and their Re-entry into the Workforce: Canada and The United States', An unpublished $\mathrm{PhD}$ thesis, Faculty of Political and Social Science, New School University, USA.

Poelzer, I. A. (1991) 'Métis Women and the Economy of Northern Saskatchewan', J. Vorst, L. Allbutt and K. McCallum (eds.) Race, Class, Gender: Bonds and Barriers, Toronto: Garamond Press.

Pratt, G. (2004) 'Feminist geographies: Spatialising feminist politics', P. Cloke, P. Crang and M. Goodwin, (eds.) Envisioning Human Geography, Sage Publication, pp. 128-145.

Preston, V. and Murnaghan, A. M. (2005) 'Immigrants and Racialization in CanadaGeographies of Exclusion', Canadian Issues, Spring, CBCA reference, PP. 67- 71.

Putnam, R.D. (1995) 'Bowling Alone: America's Declining Social Capital', Journal of Democracy, Vol. 6, No. 1, pp. 65-78.

Pyle, J. L. and Ward, K. B. (2003) 'Recasting our Understanding of Gender and Work during Global Restructuring', International Sociology, SAGE publications, Available at http://iss.sagepub.com/cgi/content/abstract/18/3/461), Accessed on $30^{\text {th }}$ October, 2007.

Raghuram, P. and Kofman, E. (2004) 'Out of Asia: Skilling, Reskilling and Deskilling of Female Migrants', Women's Studies International Forum, Vol. 27, No. 2, pp. 95-100. 
Raghuram, P. and Madge, C. (2006) 'Towards a method for postcolonial development Geography? Possibilities and challenges', Singapore Journal of Tropical Geography, Vol. 27, pp. 270-288.

Raju, S. (1993) 'Introduction', in S. Raju and D. Bagchi (eds.) Women and Work in South Asia: Regional Pattern and Perspectives, New York and London: Routledge, pp. 1-38.

Rankin, K. N. (2002) 'Social Capital, Microfinance, and the Politics of Development', Feminist Economics, Vol. 8, No. 1, pp. 1-24.

Ray, R. and Korteweg, A. C. (1999) Women's Movements in the Third World: Identity, Mobilization and Autonomy, Annual Review of Sociology, Available at http://www.questia.com/googleScholar.qst?docId $=5001895309$, Accessed on $17^{\text {th }}$ February, 2009.

Rooney, J, Lero, D, Korabic, K. and Whitehead, D. L. (2003) 'Self-Employment for Women: Policy Options that Promote Equality and Economic Opportunities', A project report, Catalogue No. SW21-108/2003, Ottawa: Status of Women Canada, Available at http://www.uoguelph.ca/cfww/research/documents/selfemployedexecsum.pdf, Accessed on $7^{\text {th }}$ November, 2008.

Rose, D. (2001) 'Revisiting Feminist Research Methodologies: A Working Paper', Ottawa: Status of Women Canada, Available at http://dsppsd.pwgsc.gc.ca/Collection/SW21-142-2001E.pdf, Accessed on $12^{\text {th }}$ February, 2009.

Rose, G. (1997) 'Situating knowledges: positionality, reflexivities and other tactics', Progress in Human Geography, Vol. 21, No. 3, Sage Publications, pp. 305-320.

Sadan, E. (1997) Empowerment and Community Planning, [in Hebrew] Translated in English by Richard Flantz, Tel Aviv: Hakibbutz Hameuchad Publishers

SAFSS -South Asian Family Support Services, Available at http://www.safss.com, Accessed on $13^{\text {th }}$ May, 2008.

Saloojee, A. (2003) 'Social Inclusion and Democratic Citizenship', Canadian Diversity, Spring, Vol. 2:1, pp. 38-41.

Salway, S., Jesmin, S. and Rahman, S. (2005) 'Women's Employment of Urban Bangladesh: A Challenge to Gender Identity', Development and Change, Vol. 36, No. 2, pp. 317-349.

Sassen, S. (1996) 'Toward a Feminist Analytics of the Global Economy', Indiana Journal of Global Legal Studies, Vol. 4, No. 2, pp. 7-42.

SAWRO -South Asian Women's Rights Organization, Available at http://www.sawro.com, Accessed on $12^{\text {th }}$ May, 2008. 
Schellenberg, G. and Hou, F. (2005) 'The Economic Well being of Recent Migrants to Canada', Canadian Issues, Spring 2005, pp. 49-52.

Scott, J. (1992) 'Experience' J. Butler and J. W. Scott (eds.) Feminists Theorize the Political, New York: Routledge, pp. 22-40.

Siemiatycki, M. (2005) 'Introduction', Canadian Issues, Spring, pp. 3-5.

Sinclair, M. T. (1991) 'Women, Work and Skill: Economic Theories and Feminist Perspectives', N. Redclift and M. T. Sinclair (eds.) Working Women: International Perspectives on Labour and Gender Ideology, London: Routledge, pp. 1-24.

Smith, K. E. (2007) 'Domestic violence in Sponsored Relationships and its Links to Homelessness: Implications for Service Delivery for Immigrant and Refugee Women', Our diverse cities, Fall, No. 4, pp. 169-176.

Staples, L. H. (1990) 'Powerful ideas about empowerment', Administration in Social Work, Vol. 14, pp. 29-42.

Statistics Canada (1996) 'Women in the Economy', Ottawa.

Statistics Canada (2005) 'Knowledge of Official Languages among New Immigrants: How Important Is It in the Labour Market', Catalogue No. 89-624-XIE.

Stephenson, M. and Emery, R. (2003) 'Living Beyond the Edge: The Impact of Trends in Non-Standard Work on Single-Lone-Parent Mothers', A project report, Catalogue No. SW21-107/2003E-IN, Ottawa: Status of Women Canada.

Stromquist, N. P. (2002) Education as a Means for Empowering Women, in J. L. Parpart, S. M. Rai and K. Staudt (eds) Rethinking Empowerment, Gender and Development in a Global/Local World, Routledge: London.

Takhar, S. (2003) 'South Asian Women and the Question of Political Organization', in N. Puwar and P. Raghuram (eds.) South Asian Women in the Diaspora, New York: Berg Publishers.

Tastsoglou, E., Ray, B. and Preston, V. (2005) Gender and Migration Intersections-In a Canadian Context, Canadian Issues, Spring 2005, pp.

Tolley, E. (2003) ‘The Skilled Worker Class', Metropolis Policy Brief, No. 1, January.

Topen, A. (2008) 'How integrated are Women from Sub-Saharan Africa in the Canadian Labour force? A Halifax Case Study', Our diverse cities, Spring, No. 5, pp. 138-142.

Tossutti, L. (2003) 'A Tradition of Social Capital in Minority Communities', Canadian Diversity, Spring, Vol. 2:1, pp. 32-37. 
Townson, M. (2003) 'Women in Non-Standard Jobs: The Public Policy Challenge', A project report, Catalogue No. SW21-105/2003E-IN, Ottawa: Status of Women Canada, Available at http://dsp-psd.pwgsc.gc.ca/Collection/SW21-105-2003E.pdf, Accessed on $16^{\text {th }}$ January, 2009.

Walby, S. (1990) Theorizing Patriarchy, Oxford: Basil Blackwell.

Wallace, M. and Frisken, F. (2004) 'Meeting the Challenges of Immigrant Settlement: Is Your Municipality Ready?', Our diverse cities, Spring, No. 1, pp. 148-152.

Winchester, H. P. M. (2000) 'Qualitative research and its place in human geography', I. Hay (ed.) Qualitative research Methods in Human Geography, South Melbourne, Victoria: Oxford University Press.

Yax-Fraser, M. J. (2008) "“Canada does not Want me, Canada Wants my Children": Cross Cultural Mothering in Halifax', Our diverse cities, Spring, No. 5, pp. 143-148.

Youdell, D. (2006) Impossible bodies, impossible selves: exclusions and students subjectivities, Dordrecht: Springer.

Zeytinoglu, I. U. (2000) 'Social Justice for Workers in Non-Standard Employment Forms and Contracts', R. P. Chaykowski (ed.) Globalization and the Canadian Economy: The Implications for Labour Markets, Society and the State, Kingston, Ontario: Queen's University Press.

Zimmerman, M. (1995) 'Psychological empowerment: Issues and illustrations', American Journal of Community and Psychology, Vol. 23, pp. 581-598. 